\title{
Beitrag zur Kenntnis der Scaphidiidae (Coleoptera) von Neuguinea
}

von

\author{
Ivan LÖBL
}

Mit 82 Abbildungen

Die ersten Scaphidiiden von Neuguinea, zwei Arten der Gattung Scaphidium Oliv., sind schon von GeSTRo (1879) beschrieben worden. Seitdem aber haben nur zwei Autoren in je einer Arbeit zur Kenntnis der papuanischen Scaphidiidae-Fauna beigetragen. CsIKI (1909) benannte zwei Arten, für die er neue Gattungen, Bironium und Scaphobaeocera, gründete. Acht weitere Arten beschrieb erst viel später PIC (1956). Insgesamt sind also von Neuguinea 12 Arten bekannt geworden, die nach der Literatur folgenden Gattungen angehören: Scaphidium Oliv. (2), Amalocera Er. (1), Scaphisoma Leach (3), Scaphobaeocera Csiki (1), Toxidium LeC. (2), Bironium Csiki (1) und Heteroscapha Achard (2).

Für die vorliegende Studie untersuchte ich das Originalmaterial dieser Arten und noch unbestimmtes Material aus den Ausbeuten von L. Biró, M. E. Bacchus, J. Balogh und J. J. Szent-Ivány, O. Beccari, L. E. Cheesman, L. Loria sowie einige weitere Exemplare aus verschiedenen Museen.

Die Typen-Revision zeigte, dass fünf Arten unter unrichtigen Gattungsnamen geführt wurden, ein Name synonym ist und alle Taxa, ausser den Scaphidium-Arten, zu vage charakterisiert worden sind, um sie zu identifizieren. Deshalb werden die ,,bekannten" Scaphisomini und Toxidiini neu beschrieben und die Beschreibungen der artenarmen Heteroscaphini (nur zwei Arten der Gattung Bironium in Neuguinea) ergänzt. Ausserdem werden 28 neue Arten und eine neue Gattung beschrieben.

Das besprochene Material stammt aus den Sammlungen des British Museum (Natural History), London (P. M. Hammond), Muséum d'Histoire naturelle, Genf, Muséum National d'Histoire naturelle, Paris (Frau A. Bons, Dr. A. Villiers), Museo Civico di Storia naturale, Genova (Prof. E. Tortonese), Museum für Naturkunde, Berlin (Dr. F. Hieke) und Természettudományi Múzeum, Budapest (Dr. Z. Kaszab). Für die Leihgabe des Materials sei an dieser Stelle herzlichts gedankt.

Bemerkung. Bei den Arten der Gattung Scaphidium ist die Gesamtlänge angegeben; sonst ist die Länge der übrigen Arten von der Mitte des Halsschildvorderrandes zum inneren apikalen Winkel der Flügeldecken gemessen. Die Fühler wurden bei der gleichen Vergrösserung $(\times 200)$ gemessen und die angeführten relativen $\mathrm{Ma} \beta \mathrm{e}$ sind daher bei verschiedenen Arten vergleichbar. Die Sternite sind vom 1. freiliegenden Segment gezählt. 


\section{Scaphidium Oliv.}

Erstaunlicherweise sind alle vier nun bekannten papuanischen Arten dieser Gattung metallisch gefärbt.

1 Entweder Halsschild oder Flügeldecken zweifarbig. Beine sehr dunkel, Schienen mit deutlichen Längsfurchen . . . . . . . . . . . . . . . . . . .

- Kopf und Halsschild einfarbig, sehr dunkel, eher grünlich metallisch glänzend. Flügeldecken und Metasternum ebenfalls einfarbig, aber bläulich glänzend. Mesosternum, Epimeren und Episterna schwarz, wie die Abdominalsegmente und Hüften mit einer punktierten Mikroskulptur versehen. Epipleuren der Flügeldecken rötlich. Beine, Abdomen und Fühlerglieder I-V rötlichbraun, Fühlerkeule schwarz, Glied XI am Ende heller. Schienen I an der Aussenseite, II und III an der Innenseite mit je einer sehr seichten Längsfurche

metallescens Gestro

2 Halsschild auf einer breiten Zone vor der Querpunktreihe mehr oder weniger rötlich oder orange. Flügeldecken einfarbig. Beine länger

- Halsschild einfarbig metallisch grün glänzend. Flügeldecken im basalen Drittel orange, sonst ähnlich wie der Halsschild. Fühlerglied XI nur an der Basis schwarz. Beine kürzer . . . . . . . . . . . . . . . cheesmanae sp. n.

3 Kopf schwarz oder fast schwarz und bläulich glänzend. Halsschild, ausser dem rötlich gefärbten Teil des Diskus und den umgeschlagenen Seiten, sowie Flügeldecken deutlich violett. Fühlerglied XI am Ende gelblich. Rand des Halsschildlappens in der Mitte gerade abgestutzt. Pygidium ähnlich wie die Sternite rötlichbraun

cyanipenne Gestro

- Kopf, Halsschild, ausser dem rötlich gefärbtem Teil des Diskus und den umgeschlagenen Seiten, und Flügeldecken metallisch blau glänzend. Fühlerglied XI einfarbig schwarz. Rand des Halsschildlappens etwas konkav in der Mitte. Pygidium dunkler als die Sternite oder Propygidium und mehr oder weniger deutlich metallisch glänzend

papuanum $\mathrm{sp} . \mathrm{n}$.

\section{Scaphidium metallescens Gestro}

Scaphidium metallescens Gestro, 1879: 560; Holotypus of: Fly River (Museum Genova).

Das einzige Typus-Exemplar ist bezettelt ,,Nuova Guinea Fly River L. M. D’Albertis 1876-77“/,,Typus“ (rot)/,,metallescens Gestro“ und „Scaphidium metallescens typus ! Gestro" (handschriftlich).

\section{Scaphidium cyanipenne Gestro}

Scaphidium cyanipenne Gestro, 1879: 559: Holotypus ô: Fly River (Museum Genova).

Der Holotypus hat die gleichen Fundortzettelchen wie der Typus von metallescens und ist auch sonst analog bezettelt. Von ,Fly River“ lagen mir noch weitere 3 Exemplare vor, alle von D'Albertis gesammelt.

ACHARD (1920) meldete cyanipenne von ,,baie de Geelwink“. Es war mir nicht möglich, diese Angabe nachzuprüfen. 


\section{Scaphidium cheesmanae sp. $\mathrm{n}$.}

Abgesehen von der Färbung der Art metallescens äusserlich sehr ähnlich. Mit metallescens, cyanipenne und papuanum verwandt und eine eigene Arten-Gruppe bildend.

Kopf, Halsschild, Flügeldecken an der Basis, vor der basalen Querpunktreihe, und auf den distalen zwei Drittel, Unterseite, ausser der des Abdomens, sehr dunkel metallisch grün glänzend. Flügeldecken nach der Querpunktreihe im basalen Drittel zwischen den Seiten- und Nahtstreifen orange und durchscheinend, dahinter beleuchtet und unter Vergrösserung etwas rötlich. Scutellum dunkel rötlich braun. Sternite I---IV rötlich dunkelbraun, apikale Abdominalsegmente inklusive des Propygidiums und Pygidiums orange. Fühlerglieder I-III orange, IV-VI rötlichbraun, V und VI am Ende noch verdunkelt, VII-X schwarz, XI schwarz an der Basis, in der apikalen Hälfte gelb. Schenkel und Schienen sehr dunkel, etwas rötlich und leicht metallisch glänzend. Tarsen dunkelbraun. Stirn an der schmalsten Stelle zwischen den Augen $0,20 \mathrm{~mm}$ breit. Scheitel im mittleren Teil kräftiger und viel dichter punktiert als die Sitrn oder als bei metallescens. Fühler ähnlich wie bei metallescens, relative Länge/Breite der Glieder wie: I 53/19 : II 29/16 : III 28/12 : IV 40/13 : V 35/15 : VI 25/18 : VII 33/29 : VIII 28/33 : IX 33/44 : X 30/50 : XI 47/46. Halsschild auf dem Diskus fein und dicht, etwas gröber als bei metallescens punktiert; Seitenkielchen kräftiger, Vorderrandstreifen tiefer als bei metallescens; subbasale Querpunktreihe in der Mitte breiter unterbrochen, die inneren Punkte dieser Reihe etwas spärlicher, die äusseren Punkte dichter aneinander liegend und kräftiger als bei metallescens. Scutellum gewölbt. Punktierung auf dem orangen basalen Drittel der Flügeldecken viel feiner, sonst die Flügeldecken wie bei metallescens. Mediankielchen des Mesosternums kräftig, vollständig. Metasternum

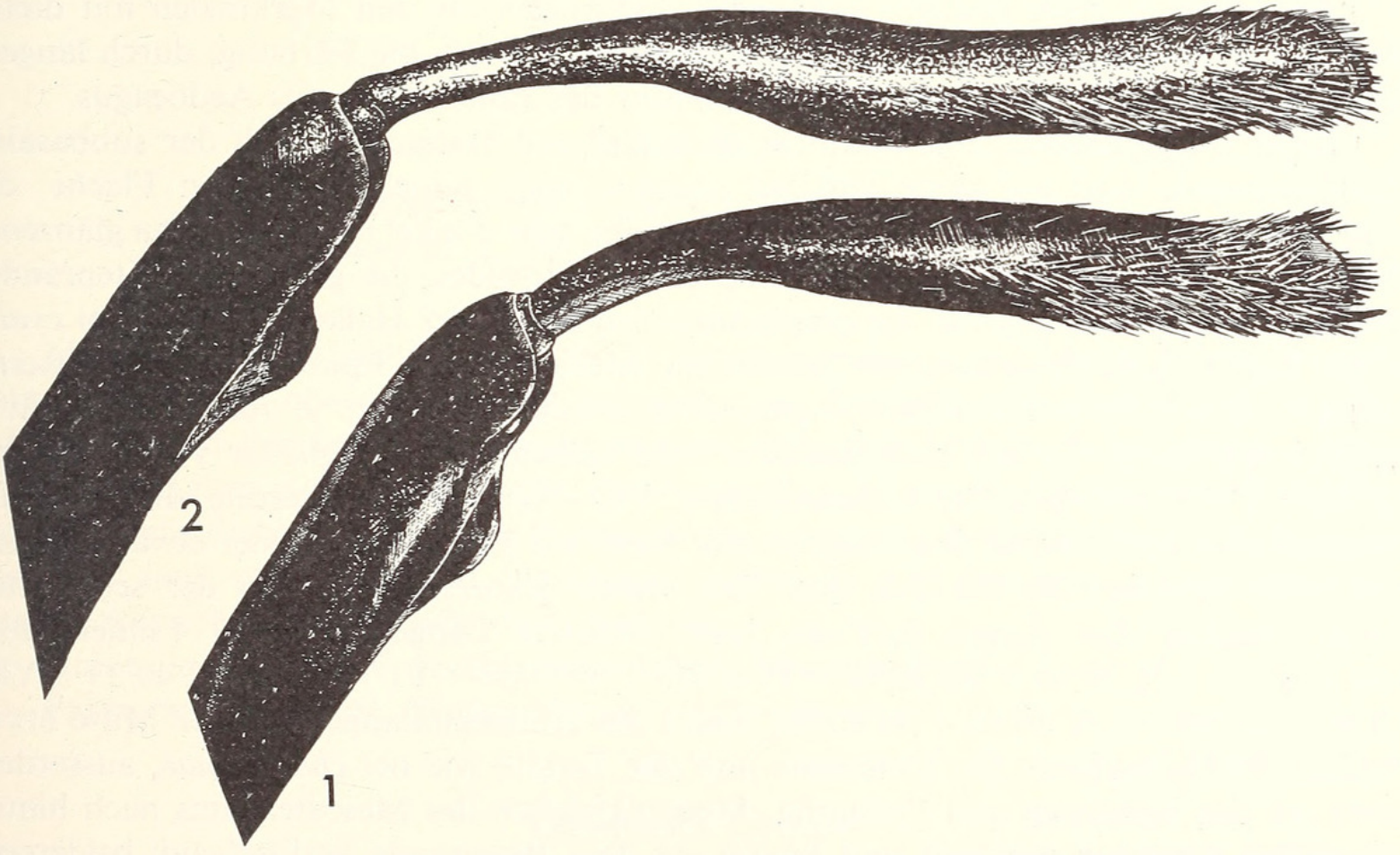

Авв. 1 und 2.

Vorderschienen und Schenkel von Scaphidium.

1. cheesmanae sp. n., Holotypus; 2. papuanum sp. n., Paratypus von Wareo; del S. Vit. 
mit einem ziemlich tiefen, vollständigen Medianstreifen, sein mediodistaler Eindruck gross, mässig tief, relativ gut abgegrenzt, nach vorne verjüngt, wie die Sternite und die sichtbaren Tergite mit einer punktierten Mikroskulptur versehen. Apikalränder der Sternite I-IV mit hellem mikroskulptiertem Saum. Alle Schienen mit deutlichen Längsfurchen.

Maße in mm: Länge 5; Halsschild 1,7 lang, an der Basis 2,5 breit; Scutellum 0,15 lang, 0,19 breit; Flügeldecken an der Naht 2,2 lang, an den Seiten fast 2,7 lang, zusammen 2,7 breit. Schienen I 1,2, II 1,4, III 1,6 lang.

Männchen. Vorderschienen (Abb. 1) auf der Innenseite dichter behaart als auf der Aussenseite und ohne Längsfurchen, auf der Aussenseite deutlich gefurcht. Schienen II etwas, III deutlicher gebogen, mit Längsfurchen auf der Innenseite. Vorderschenkel mit einem subapikalen Höckerchen auf der Unterseite (Abb. 1). Medioapikale 0,20-0,25 mm des Metasternums dicht und mässig grob punktiert, die Punktradien sind meistens ein wenig kleiner als die Punktzwischenräume; dort sehr lang, abstehend behaart. Aedoeagus (Abb. 3) 1,28 mm lang, mit sehr dicht und sehr fein bedornten Membranen des Innensackes.

Holotypus đ̊: Cyclops Mts., Mt. Lima, 3500 ft. III. 1936 leg. L. E. Cheesman (British Museum, London).

Diese Art ist sehr gut gekennzeichnet durch die Färbung. Ausserdem weicht sie deutlich von der sonst sehr ähnlichen metallescens durch die Punktierung des Scheitels, durch die subbasale Punktreihe des Halsschildes, durch den Medianstreifen des Metasternums (bei metallescens ist er vorne und hinten sehr seicht, in der Mitte verlöscht) und durch die Mikroskulptur des Metasternaleindruckes ab.

\section{Scaphidium papuanum sp. n.}

Täuschend ähnlich der Art cyanipenne und in den meisten Merkmalen mit dieser identisch. Von cyanipenne deutlich unterschieden nur durch die Färbung, durch längere Beine und durch die sehr abweichende Armatur des Innensackes des Aedoeagus.

Kopf, Flügeldecken, Metasternum, Schenkel und Halsschild nach der subbasalen Querpunktreihe und auf einer variabel grossen, nach hinten verjüngten Fläche, die vom Vorderrand mindestens gegen die Mitte reicht, sehr dunkel metallisch blau glänzend. Eine breite Zone vor der Querpunktreihe des Halsschildes, die gegen die Seitenränder weit nach vorne reicht, sowie die umgeschlagenen Seiten des Halsschildes wie bei cyanipenne rötlich oder braunorange. Scutellum, Mesosternum, Epimeren und Episterna schwarz. Schienen etwas rötlich braunschwarz oder schwarz, je nach Beleuchtung bläulich glänzend. Tarsen braunschwarz oder schwarz. Fühlerglieder I-III orange, IV und V rötlichbraun, VI schwarzbraun, VII-XI schwarz. Sternite dunkelbraun. Propygidium heller braun. Pygidium an der Basis wie Propygidium oder etwas dunkler, sonst viel dunkler und bläulich oder fast violett glänzend. Stirn an der schmalsten Stelle zwischen den Augen $0,19 \mathrm{~mm}$ breit. Relative Länge/Breite der Fühlerglieder wie: I 57/18 : II 29/14 : III 30/12 : IV 43/13 : V 37/15 : VI 30/19 : VII 40/33 : VIII 32/36 : IX 39/45 : X 40/52 : XI 60/54. Rand des Halsschildlappens in der Mitte etwas konkav. Mikroskulptur der Unterseite und der Tergite wie bei cheesmanae, ausserdem noch auf den Epimeren und Episterna. Mediankielchen des Mesosternums nach hinten allmählich niedriger werdend und knapp vor dem Basalrande verlöschend, beiderseits von ihm eine feine Längsfurche. Punktierung des Metasternums deutlich dichter als bei cheesmanae, Metasternaler Medianstreifen vollständig und ziemlich fein, in der Mitte sehr seicht. 
Maße in mm: Länge 5,5; Halsschild 2,0 lang, an der Basis 2,6 breit; Scutellum 0,18 lang, 0,20 breit; Flügeldecken an der Naht 2,1 lang, an den Seiten 2,7 lang, zusammen 3,0 breit; Schienen I 1,7, II 2,2, III 2,0 lang.
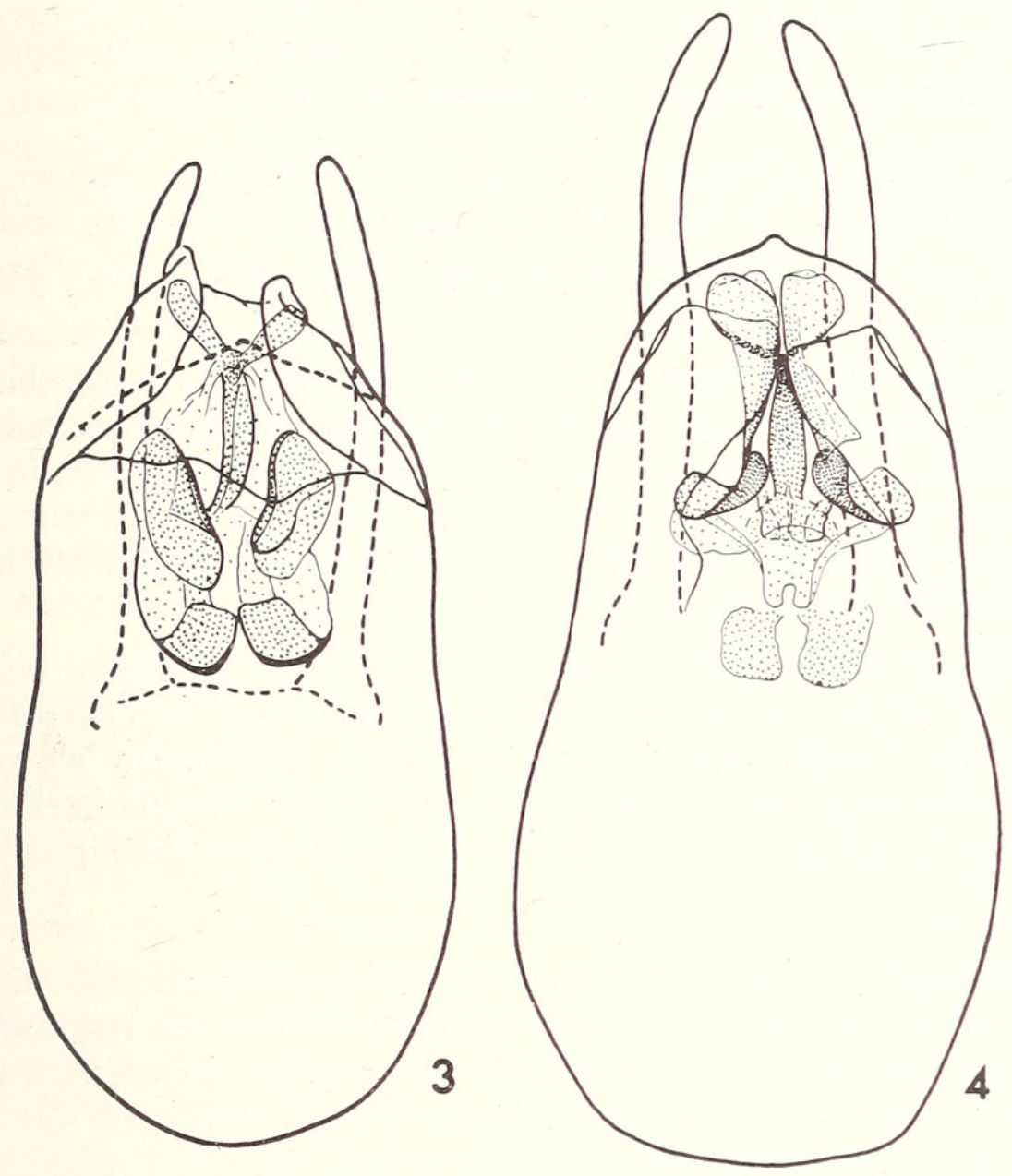

AвB. 3 und 4.

Aedoeagi von Scaphidium bei Dorsalansicht.

3. cheesmanae sp. n., Holotypus; 4. papuanum sp. n., Holotypus.

Männchen. Vorderschienen (Abb. 2) mit einer tiefen Längsfurche an der Aussenseite. Schienen II etwas, III leicht gebogen, mit Längsfurchen auf der Innenseite; Schienen II auf der Innenseite länger behaart. Schenkel I (Abb. 2) mit einem subapikalen Höckerchen auf der Unterseite. Medioapikale 0,20 mm des Metasternums ziemlich grob und sehr dicht punktiert, die Punkte liegen meistens knapp aneinander; Behaarung dort sehr lang und abstehend. Aedoeagus (Abb. 4) 1,47 mm lang, Membranen des Innensackes sehr fein und sehr dicht bedornt.

Holotypus ô: „D. N. Guinea Sattelberg“ (Museum Berlin).

Paratypus §̋: „D. N. Guinea Wareo“ (Museum Genf).

\section{Eubaeocera Cornell}

Von dieser Gattung liegen sieben Arten vor. Zwei davon, bironis (Pic) und insperata sp. n. stehen isoliert. Die übrigen gehören in die typisch orientalische Arten-Gruppe 3 (LöBL, 1971), die ich nun lenta-Gruppe nenne. 
1 Nahtstreifen der Flügeldecken stark verkürzt, verlöschen in der Nähe des Scutellums oder hinter dessen Niveau und biegen vorne nicht nach aussen; entlang dem Halsschildlappen sind sie höchstens durch je eine Punktreihe angedeutet

- Nahtstreifen der Flügeldecken biegen vorne entlang dem Halsschildlappen nach aussen und verlaufen mehr oder weniger weit lateralwärts

2 Nahtstreifen der Flügeldecken verlöschen noch hinter dem basalen Viertel der Flügeldeckenlänge, weiter nach vorne gegen das Niveau des Scutellums sind sie durch je eine Punktreihe angedeutet. Kleine, kaum $1 \mathrm{~mm}$ lange Art

biroi $\mathrm{sp} . \mathrm{n}$.

- Nahtstreifen der Flügeldecken verlöschen in der Nähe des Scutellums und können noch weiter entlang dem Halsschildlappen durch eine Punktreihe angedeutet sein. Etwas grössere, über $1 \mathrm{~mm}$ lange Art .

egena sp. $\mathrm{n}$

3 Nahtstreifen der Flügeldecken verlaufen entlang dem Basalrand etwa gegen die Mitte der Basalbreite der Flügeldecken .

- Nahtstreifen der Flügeldecken verlaufen entlang dem Basalrand bis gegen die Seiten, wo sie mit den Seitenstreifen verbunden sind; nach der Mitte der Basalbreite der Flügeldecken sind sie V-förmig eingebogen. Körper tief schwarz. Punktierung der Oberseite sehr fein, auf den Flügeldecken nur ein wenig deutlicher als auf dem Halsschild. Grössere, über 1,6 mm lange Art

bacchusi sp. n.

4 Körper mässig gewölbt. Flügeldecken irregulär, überwiegend grob punktiert, an der Basis, entlang den Nahtstreifen und in der Nähe des Apex sehr fein punktiert; Seitenstreifen im mittleren Teil tief punktiert. Mindestens 1,4 mm lange Arten

- Körper stark gewölbt. Flügeldecken praktisch gleichmässig punktiert; Seitenstreifen nicht oder kaum bemerkbar punktiert. Kleine, unter 1,2 mm lange Arten .

5 Seitenstreifen der Flügeldecken biegen vorne nach innen und verlaufen kurz entlang dem Basalrand, der Abstand zwischen ihnen und dem Ende der Nahtstreifen ist etwa $0,3 \mathrm{~mm}$ breit

- Seitenstreifen der Flügeldecken biegen vorne nach innen und verlaufen lang entlang dem Basalrand, der Abstand zwischen ihnen und dem Ende der Nahtstreifen ist etwa $0,1 \mathrm{~mm}$ breit insperata $\mathrm{sp} . \mathrm{n}$.

6 Punktierung der Flügeldecken ausgesprochen grob, tief, relativ spärlich, die 0,02 bis $0,03 \mathrm{~mm}$ grosse Punktradien sind meistens deutlich grösser als die Punktzwischenräume. Seiten der Flügeldecken ziemlich gleichmässig abgerundet. Körper sehr dunkel, fast schwarz, die Flügeldeckenbasis etwas rötlich

punctata sp. n.

- Punktierung der Flügeldecken fein, seicht und dicht, die etwa 0,01 mm grosse Punktradien sind deutlich kleiner als die Punktzwischenräume. Seiten der Flügeldecken ab der breitesten Stelle gegen das apikale Viertel geradlinig. Körper dunkel rötlichbraun, Flügeldecken heller als der Halsschild . .papua sp. n. 


\section{Eubaeocera egena sp. n.}

Diese Art gehört in die Gruppe lenta und ist der murphyi Löbl ziemlich ähnlich, von dieser besonders durch die kürzeren Nahtstreifen und durch viel breiteren Apizes der Flügeldecken abweichend.

Körper ziemlich stark gewölbt, einfarbig rötlichbraun. Endglied der Kiefertaster apikalwärts allmählich verjüngt, viel schlanker und etwa um 1/4 länger als das vorhergehende Glied. Fühler länger als bei murphyi, relative Länge der Glieder wie: III 12-13 : IV 11-12 : V 15-16 : VI 13-15 : VII 17-18 : VIII 15 : IX $19:$ X $18:$ XI 20-21; Glieder III und IV gleich schlank, deutlich schlanker als die zwei folgenden; VII etwa 3,5-4 mal länger als breit; VIII nur etwas breiter als VI, 4-4,5 mal länger als breit; XI etwa 3 mal länger als breit. Halsschild sehr fein, bei $\times 25$ Vergrösserung schlecht sichtbar punktiert; Seitenkielchen bei Dorsalansicht mindestens im mittleren Teil, manchmal von dort bis gegen die Basis deutlich; Mittelteil des Vorderrandes leicht konvex hervorragend, die Vorderrandstreifen dort feiner, aber gut bemerkbar. Distalteil des Scutellums freiliegend. Flügeldecken an den Seiten ziemlich gleichmässig abgerundet, apikalwärts leicht verjüngt, der abgerundete Apikalrand breit; Seitenkielchen bei Dorsalansicht im basalen Viertel sichtbar; Nahtrand nicht erhaben; Nahtgegend flach, in der Mitte etwa 0,03 mm breit, ihre Punktreihe etwas dichter und gröber als bei murphyi; Nahtstreifen ein wenig seichter als bei murphyi, biegen vorne nur etwas nach aussen, verlöschen seitlich des Scutellums oder noch hinter dem Niveau der Scutellumspitze; diskale Punktierung gleichmässig dicht und kräftig, ein wenig dichter und kaum seichter als bei murphyi, die Punktradien sind meistens ähnlich gross wie die Punktzwischenräume. Pygidium sehr fein punktiert. Mesosternum hinten und am Seitenrande dicht und mässig grob punktiert. Mes-Epimeren sehr schlank, mehr als 3 mal länger als der Abstand zwischen ihnen und den Hüften II. Mittelteil des Metasternums überwiegend glatt, nur etwas gewölbt, hinten verflacht und mit einer Querreihe grober Punkte; Apikalrand zwischen den Hüften gerade. Metasternalseite dicht und grob punktiert, die Punktradien sind meistens grösser als die Punktzwischenräume; auf den Flächen zwischen den Hüften II und III ist die Punktierung ein wenig feiner, aber oft noch dichter. Flächen hinter den Coxalkavitäten II sehr schmal. Met-Episterna nicht sichtbar. Sternit I fast so grob und etwas spärlicher punktiert als die Metasternalseiten, die sehr dichte Basalreihe grober Punkte in der Mitte nicht unterbrochen, reicht lateralwärts bis zum Seitenrand, ihre seitlichen Punkte sind länglich. Schienen gerade, die hinteren etwas länger als die zugehörigen Tarsen (Index 40:37-38).

Maße in mm: Länge 1,05-1,1; Basalbreite des Halsschildes 0,69-0,71; Flügeldecken an der Naht 0,67-0,71 lang, zusammen 0,75-0,77 breit; Schienen III 0,37 lang.

Männchen. Tarsenglieder I-III der Vorderbeine ein wenig erweitert. Aedoeagus (Abb. 5 und 6) 0,29-0,32 mm lang, mässig stark sklerotisiert; Membranen des Innensackes im distalen Teil sehr fein, bei $\times 300$ Vergrösserung noch schlecht sichtbar beschuppt

Holotypus ô: Astrolabe Bai, Friedrich-Wilhems-Hafen, leg. L. Biró (Museum Budapest).

Paratypen: wie Holotypus, 1 ô und 3 qqo; Astrolabe Bai, Stephansort, 4 ỗ ; Astrolabe Bai, Mt. Hansemann, 1 ^ै. Alles leg. L. Biró. (Museum Budapest, Genf und Paris).

\section{Eubaeocera biroi sp. n.}

Sehr ähnlich der Art egena, aber kleiner. Fühler kürzer als bei egena, relative Länge der Glieder wie: III 11-12 : IV $11-12$ : V 14-15 : VI 11-12 : VII 15-16 : VIII 
11-13 : IX 14-16 : X 15-17 : XI 17-19; Glieder III und IV gleich schlank, V und VI deutlich breiter; VII etwa 4 mal länger als breit; VIII breiter als VI, fast 4 mal länger als breit; XI etwa 2,5 mal länger als breit. Halsschild noch feiner, bei $\times 25$ Vergrösserung kaum wahrnehmbar punktiert, sonst wie bei egena. Seiten der Flügeldecken im mittleren Teil fast geradlinig, apikalwärts ein wenig stärker verjüngt, nicht aber so wie bei murphyi; Seitenkielchen bei Dorsalansicht mindestens im basalen Drittel sichtbar, öfter bis gegen die Mitte der Seitenlänge deutlich; Nahtstreifen sehr seicht, stark verkürzt, verlöschen noch hinter dem basalen Viertel der Nahtlänge und sind weiter nach vorne durch je eine Punktreihe angedeutet; diskale Punktierung etwas oder kaum dichter und feiner als bei egena. Mesosternum mit einigen grösseren Punkten am Hinterrande. Mes-Epimeren 3 mal länger als der Abstand zwischen ihnen und den Hüften II. Metasternalseiten ein wenig dichter punktiert als bei egena.

Maße in mm: Länge 0,90-0,97; Basalbreite des Halsschildes 0,59-0,64; Flügeldecken an der Naht 0,61-0,66 lang, zusammen 0,65-0,70 breit; Schienen III 0,290,30 lang.

Männchen. Tarsenglieder I-III der Vorderbeine ein wenig erweitert. Aedoeagus (Abb. 7 und 8) 0,22-0,25 mm lang, mässig stark sklerotisiert.

Holotypus đ̃: Astrolabe Bai, Friedrich-Wilhems-Hafen, leg. L. Biró (Museum Budapest).

Paratypen: wie Holotypus, 3 oิ ô und 3 우; Huon Golf, Sattelberg, 1 ô. Alles leg. L. Biró (Museum Budapest, Genf und Paris).

\section{Eubaeocera papua sp. n.}

Diese neue Art ist nahe verwandt mit egena und ist dieser auch äusserlich ähnlich, unterscheidet sich am deutlichsten durch die Ausbildung der kürzeren Fühler, durch die Punktierung und Form der Nahtstreifen der Flügeldecken und durch die Merkmale auf der Unterseite.

Körper nach hinten leichter verjüngt als bei egena, scheint länglicher und relativ subparallel. Halsschild deutlich, Flügeldecken ein wenig dunkler als bei egena. Relative Länge der Fühlerglieder wie: III 10 : IV 12 : V 15 : VI 13 : VII 15 : VIII 12-13 : IX 15 : X 15 : XI 18. Flügeldecken apikalwärts gegen das apikale Drittel nur sehr leicht und geradlinig verjüngt, die Seiten sind fast parallel, erst hinten abgerundet verjüngt; Nahtstreifen biegen vorne nach aussen, verlaufen schräg entlang dem Halsschildlappen gegen den Basalrand, verlöschen etwa in der Mitte der Basalbreite der Flügeldecken; Nahtgegend breiter als bei egena, in der Mitte fast $0,05 \mathrm{~mm}$ breit; diskale Punktierung etwa so dicht wie bei egena, aber viel feiner, die Punktzwischenräume sind meistens 3-5 mal grösser als die Punktradien. Mesosternum mit sehr kleinen Mediankielchen, dicht und fein punktiert. Mes-Epimeren etwa 2,5 mal länger als der Abstand zwischen ihnen und den Hüften II. Mittelteil des Metasternums gewölbt, ausser einer grösseren Fläche in der Mitte und der verflachten Fläche zwischen den Hüften III, sehr dicht und kräftig punktiert; Apikalrand zwischen den Hüften gerade. Punktierung der Metasternalseiten deutlich gröber als jene der Flügeldecken und ein wenig spärlicher als zwischen den Hüften II und III, die Punkte sind meistens kleiner als die Punktzwischenräume, gegen den Seitenrand werden sie länglich, länger und schmaler als die Abstände zwischen ihnen. Flächen hinter den Coxalkavitäten II gut 0,03 mm lang, am Rande sehr fein punktiert. Sternit I mit einer dichten Basalreihe bis zu 0,05 mm langer Längsrunzeln, die nach innen sukzessiv verkürzt sind und in längliche Punkte übergehen; in der Mitte ist diese Reihe unterbrochen; Sternitseiten in der Nähe der basalen Runzeln länglich, ziemlich fein und dicht punktiert, in der Nähe des Apikalrandes 

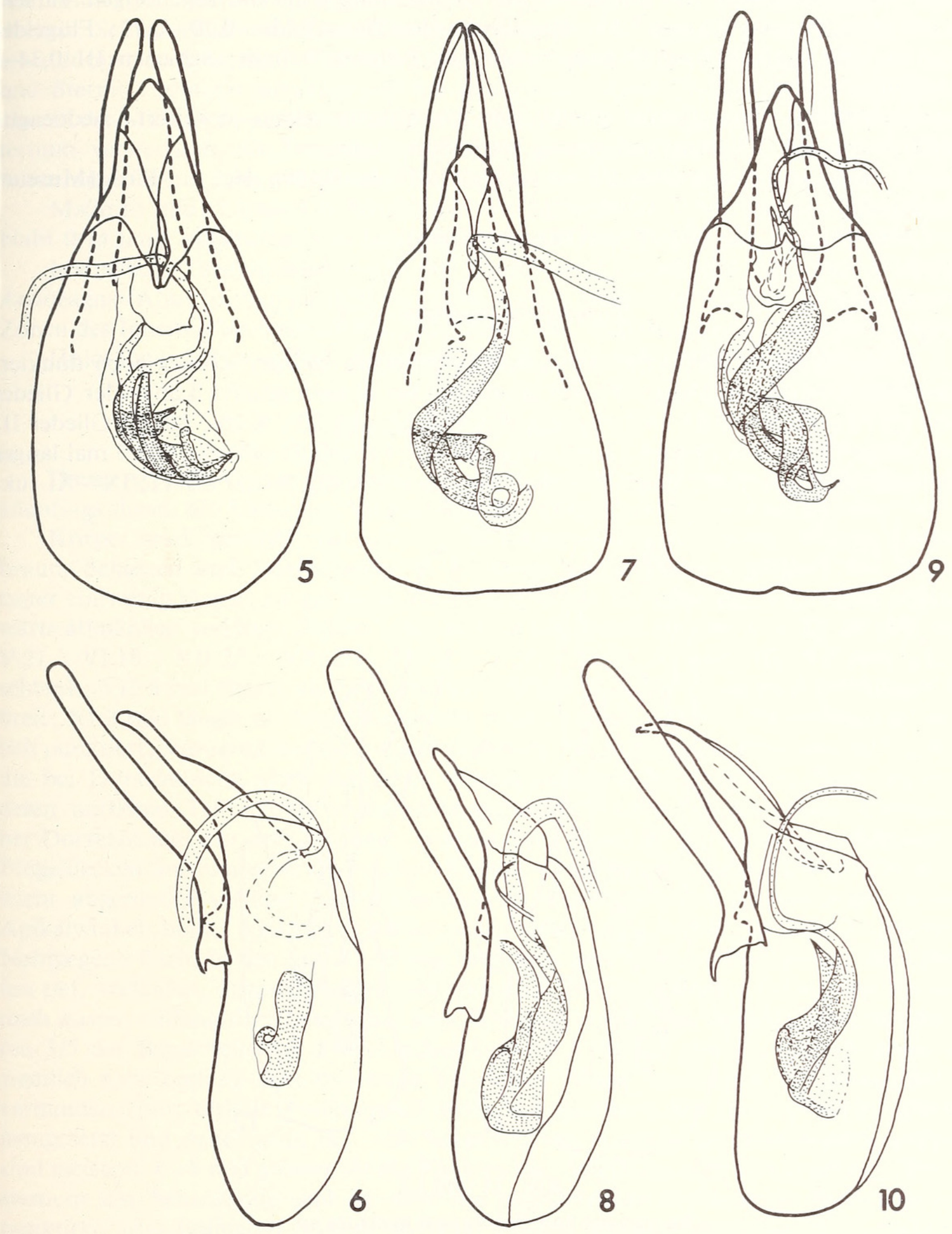

AвB. 5 bis 10 .

Aedoeagi von Eubaeocera bei Dorsal- und Lateralansicht.

5 und 6. egena sp. n., Paratypus von Stephansort; 7 und 8. biroi sp. n., Paratypus von FriedrichWilhems-Hafen; 9 und 10. рариа sp. n., Paratypus von Friedrich-Wilhems-Hafen. 
sehr fein punktiert; ganzer Medianteil des Segments spärlich und fein bis sehr fein punktiert. Schienen gerade, die hinteren etwa 1,1 mal länger als die zugehörigen Tarsen.

Maße im mm: Länge 1,15; Basalbreite des Halsschildes 0,70-0,72; Flügeldecken an der Naht 0,71-0,72 lang, zusammen 0,76-0,78 breit; Schienen III 0,340,36 lang.

Männchen. Tarsenglieder I-III der Vorderbeine etwas erweitert. Aedoeagus (Abb. 9 und 10) 0,31 mm lang, mässig stark sklerotisiert.

Holotypus $0^{\hat{~}}$ : Astrolabe Bai, Friedrich-Wilhems-Hafen, leg. L. Biró (Museum Budapest).

Paratypus $\widehat{\jmath}$ : wie Holotypus (Museum Genf).

\section{Eubaeocera punctata sp. n.}

Habituell sehr ähnlich der Art taylori Löbl, etwas kleiner, Körper noch dunkler, die Flügeldeckenbasis rötlich. Fühler länger als bei taylori, relative Länge der Glieder wie: III 12 : IV 14 : V 17 : VI 15 : VII 19 : VIII 17 : IX 20 : X 20 : XI 22; Glieder III und IV gleich schlank, V und VI ein wenig breiter; VII relativ schlank, fast 5 mal länger als breit; VIII fast 6 mal länger als breit und nur ein wenig breiter als VI; IX-XI suk-
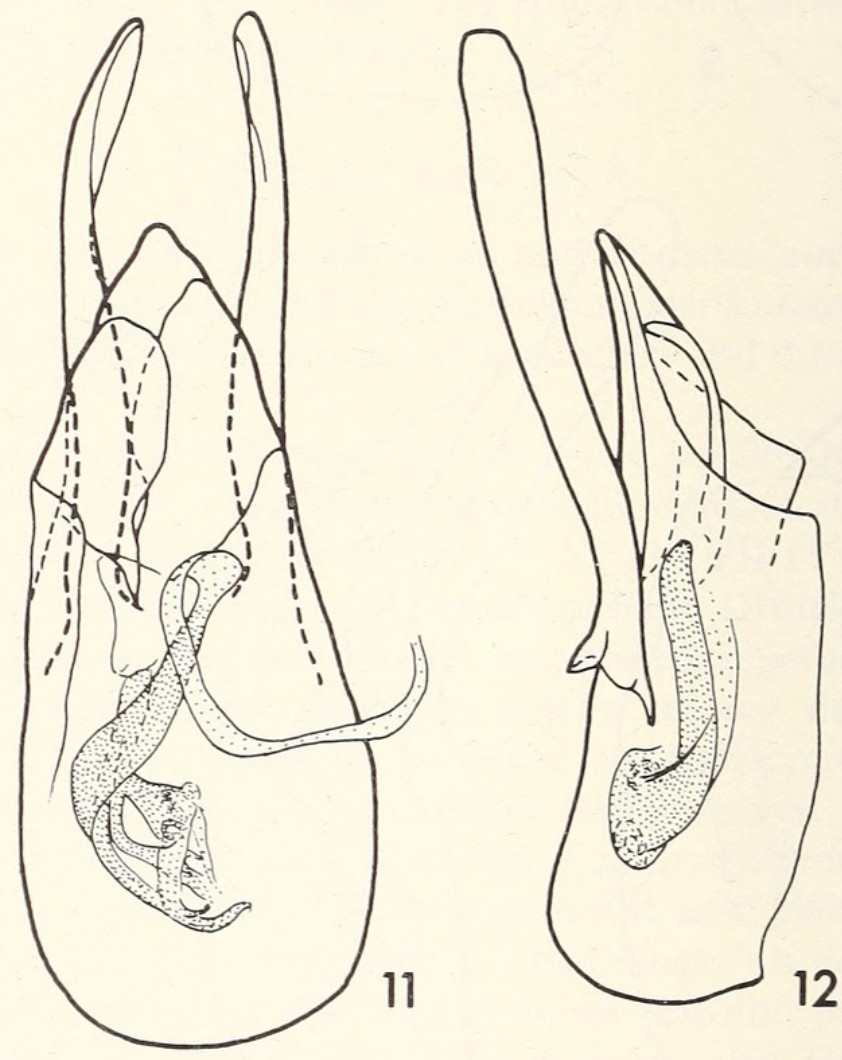

ABB. 11 und 12.

Aedoeagus von Eubaeocera punctata sp. n. bei Dorsal- und Lateralansicht, Holotypus.

zessiv breiter, XI etwa 3 mal länger als breit. Halsschild, abgesehen davon, dass die Seitenkielchen bei Dorsalansicht nicht sichtbar sind, wie bei taylori. Distalteil des Scutellums freiliegend. Flügeldecken sehr ähnlich wie bei taylori, auch was die überall grobe und dichte Punktierung betrifft; die 0,02-0,03 mm grossen Punktradien sind meistens deutlich grösser als die Punktzwischenräume; Nahtstreifen seichter als bei 
taylori, sind vorne weiter lateralwärts verlängert und verlaufen nicht so knapp entlang dem Basalrand, verlöschen kurz nach der inneren Hälfte der Basalbreite der Flügeldecken; Seitenkielchen bei Dorsalansicht vorne nur sehr kurz sichtbar. Mes-Epimeren etwa doppelt so lang wie der Abstand zwischen ihnen und den Hüften II. Metasternum und Sternit I ähnlich punktiert wie bei taylori, die basale Punktreihe des 1. Sternits aber in der Mitte nicht unterbrochen. Met-Episterna sehr schmal, nahtlos mit dem Metasternum verwachsen, ihr Innenrand durch die äusserste Punktreihe der Metasternalseiten angedeutet. Schienen gerade, die hinteren so lang wie die zugehörigen Tarsen.

Maße in mm: Länge 1,1; Basalbreite des Halsschildes 0,71; Flügeldecken an der Naht 0,74 lang, zusammen 0,76 breit; Schienen III 0,35 lang.

Männchen. Tarsenglieder I-III der Vorder- und Mittelbeine ein wenig erweitert. Aedoeagus (Abb. 11 und 12) 0,27 mm lang, mässig stark sklerotisiert; die beschuppten Zonen des Innensackes äusserst fein, auch bei $\times 600$ Vergrösserung kaum wahrnehmbar. Holotypus §̂: Huon Golf, Sattelberg, leg L. Biró (Museum Budapest).

\section{Eubaeocera bacchusi sp. n.}

Diese Art gehört wie die vier vorher beschriebenen in die lenta-Gruppe, weicht allerdings durch die Form der Nahtstreifen der Flügeldecken sehr auffällig ab.

Körper stark gewölbt, tief schwarz. Schenkel und Fühlerglieder V-XI dunkelbraun, Schienen und Fühlerglieder I-IV heller, rötlichbraun. Endglied der Kiefertaster ein wenig länger, an der Basis viel schlanker als das vorhergehende Glied, apikalwärts allmählich verjüngt. Fühler lang, relative Länge der Glieder wie: III 19 : IV 20 : V 21 : VI 18 : VII 25 : VIII 20 : IX 24 : X 22 : XI 27; Glieder III-VI etwa gleich schlank; VII 5 mal länger als breit und um 1/5 breiter als VIII, dieses 5 mal länger als breit; XI 3 mal länger als breit. Halsschild dicht und fein, bei $\times 25$ Vergrösserung deutlich punktiert; Vorderwinkel relativ weit unterhalb des Niveaus der Hinterwinkel liegend, die bei Dorsalansicht nicht sichtbaren Seitenkielchen daher nach dem stark abgerundeten mittleren Teil schräg ventralwärts gerichtet; Vorderrand geradlinig abgestutzt, bei Dorsalansicht nur sein mittlerer Teil sichtbar. Distalteil des Scutellums freiliegend. Flügeldecken am breitesten im basalen Viertel, von dort apikalwärts fast gleichmässig, leicht abgerundet verjüngt; Seitenkielchen bei Dorsalansicht nicht sichtbar; äussere Apikalwinkel breit, Apikalrand sonst leicht abgerundet; Nahtrand nicht erhaben; Nahtgegend flach, in der Mitte $0,05 \mathrm{~mm}$ breit, mit einer dichten Punktreihe; Nahtstreifen tief, verlaufen, abgesehen vom apikalen Teil, parallel mit der Naht, biegen vorne nach aussen entlang dem Basalrand, etwa 0,04 $\mathrm{mm}$ von diesem entfernt, nach den inneren 3/5 der Basalbreite der Flügeldecken sind sie V-förmig gekniet, danach gehen sie ziemlich nahe entlang dem Basalrand bis an die Seiten, wo sie mit den Seitenstreifen verbunden sind; diskale Punktierung dicht, aus kleinen, aber tiefen Punkten zusammengesetzt und daher auch bei $\times 10$ Vergrösserung deutlich, die Punktzwischenräume sind meistens 4-5 mal grösser als die Punktradien. Pygidium sehr fein punktiert. Mesosternum am Seitenrande und an dem nur angedeuteten Hinterrande dicht und fein punktiert. Mes-Epimeren doppelt so lang wie der Abstand zwischen ihnen und den Hüften II. Metasternum im mittleren Teil deutlich gewölbt, zwischen den Hüften III flach eingedrückt, sein Apikalrand dort gerade; die glatte Medianfläche in der Mitte $0,04 \mathrm{~mm}$, hinten $0,10 \mathrm{~mm}$ breit, Punktierung seitlich dieser Fläche dicht und tief, die Punktradien sind dort meistens etwa so gross, zum Teil grösser als die Punktzwischenräume; Seiten zum Teil etwas länglich, deutlich gröber, aber nicht so dicht punktiert wie gegen die Mitte. Flächen hinter den Coxalkavitäten II kaum 0,03 mm lang. MetEpisterna leicht gewölbt und glatt, nahtlos mit dem Metasternum verwachsen. Sternit I 

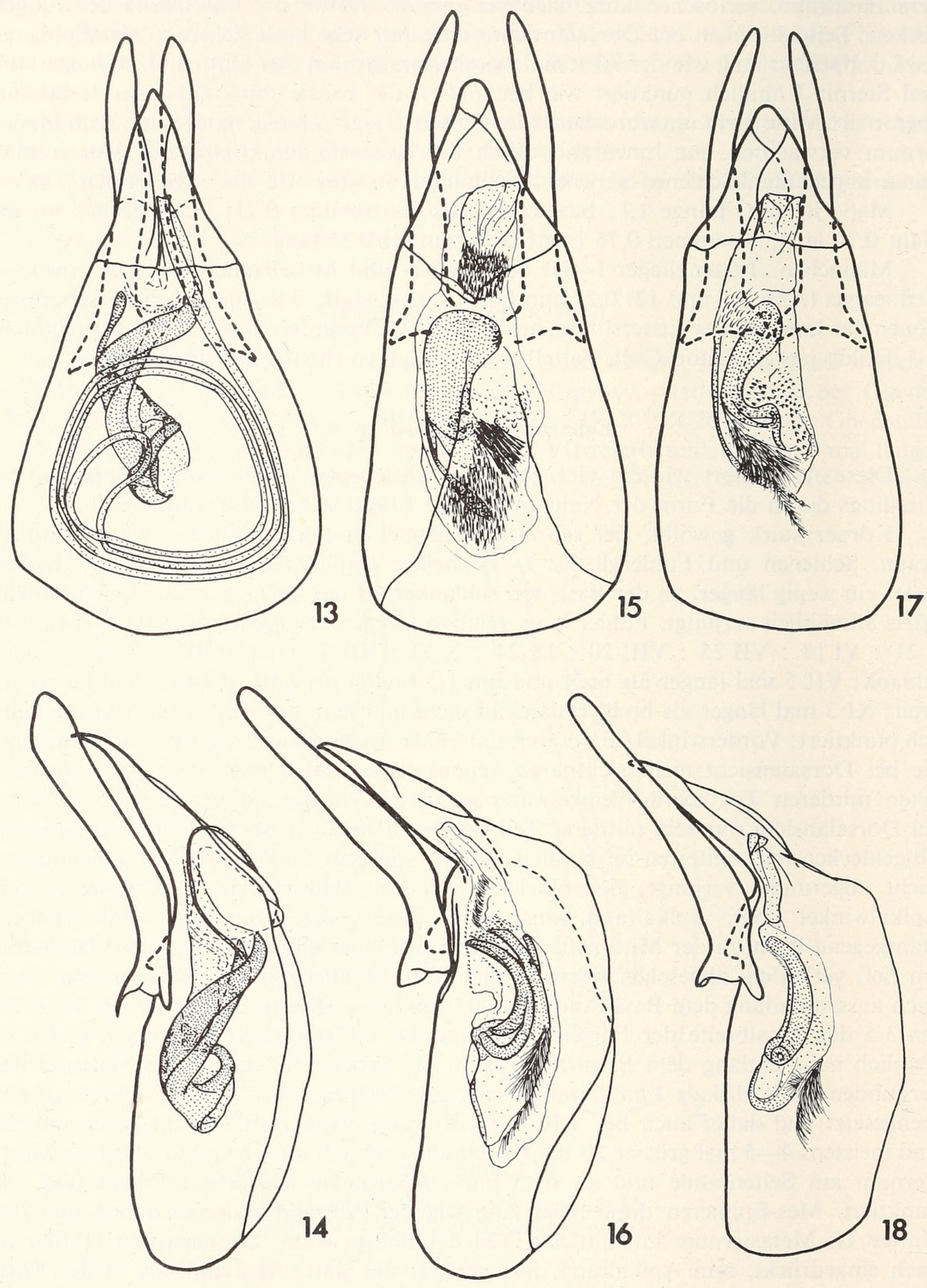

Авв. 13 bis 18 .

Aedoeagi von Eubaeocera bei Dorsal- und Lateralansicht.

13 und 14. bacchusi sp. n., Holotypus; 15 und 16. bironis (Pic) von Friedrich-Wilhems-Hafen; 17 und 18. insperata sp. n., Paratypus von Stephansort. 
dicht, ähnlich kräftig punktiert wie das Metasternum seitlich der glatten Medianfläche, die basale Punktreihe sehr dicht, in der Mitte kurz unterbrochen, lateralwärts gegen den Seitenrand reichend, aus leicht länglichen Punkten zusammengesetzt. Schienen gerade, die hinteren gut 1,1 mal länger als die zugehörigen Tarsen.

Maße in mm: Länge 1,65; Basalbreite des Halsschildes 1,0; Flügeldecken an der Naht 1,10 lang, zusammen 1,10 breit; Schienen III 0,55 lang.

Männchen. Tarsenglieder der Vorderbeine I und II leicht, III kaum erweitert. Aedoeagus (Abb. 13 und 14) 0,44 mm lang, ziemlich stark sklerotisiert.

Holotypus ô: Morobe Dist., Mt. Kainde, 8000 ft. (Stn. No. 20) 22.IX.1964 leg. M. E. Bacchus (British Museum, London).

Eubaeocera bironis (Pic), comb. nov.

Scaphosoma bironis PIC, 1956: 73; Lectotypus ô: Friedrich-Wilhems-Hafen (Museum Budapest).

Typen. In der Sammlung des Pariser Museums fanden sich unter unbestimmten papuanischen Scaphidiiden drei Exemplare, die die Pic'sche Determinationszettelchen „Scaphosoma bironis“ tragen. Sie entsprechen der Beschreibung und sind zweifellos Syntypen dieser Art (keines wurde als Typus bezeichnet). Ein Männchen bezettelt „N. Guinea Biro 1901“/,,Friedrich Wilh.-hafen“/,,Bironis Csiki i. 1.“ (handschriftlich von Csiki)/,,Scaphosoma bironis nov s" (handschriftlich von Pic) designiere ich als Lectotypus. Er ist jetzt im Museum Budapest aufbewart. Die zwei übrigen Exemplare, mit den gleichen Fundortangaben, bezeichne ich als Paralectotypen; sie sind im Museum Budapest ( + ) und Museum Paris (ふ̋).

Diese Art ist durch den nur mässig gewölbten Körper und durch die Form des Aedoeagus recht auffällig. Sie steht isoliert von allen bekannten Arten der Gattung und stellt mit der folgend beschriebenen Art insperata eine eingene Arten-Gruppe dar.

Körper mässig grwölbt, etwas rötlich, sehr dunkel braun bis braunschwarz. Endglied der Kiefertaster ein wenig länger, an der Basis viel schlanker als das 3. Glied, nach der Mitte stark verjüngt. Fühler lang, relative Länge der Glieder wie: III 14-15 : IV 14-16 : V 19-20 : VI 15-18: VII 20-21: VIII 15-16: IX 19-21:X 20-21 : XI 20-22; Glieder III und IV gleich schlank, V und VI deutlich breiter, VII gut 4 mal länger als breit, VIII etwa 4 mal länger als breit, kaum schlanker bis etwas breiter als VI, XI etwa doppelt so lang wie breit. Halsschild sehr fein, bei x50 Vergrösserung schlecht sichtbar punktiert; Vorderrand im mittleren Teil nur etwas konvex, der Vorderrandstreifen dort ein wenig feiner als an den Seiten, sehr deutlich; Seiten gleichmässig abgerundet; Seitenkielchen bei Dorsalansicht meistens in der ganzen basalen Hälfte sichtbar, manchmal auch davor, seltener nur in der Nähe der Basis bemerkbar. Spitze des Scutellums freiliegend. Flügeldecken am breitesten nach dem basalen Viertel; Seiten leicht abgerundet oder im mittleren Teil fast geradlinig, apikalwärts ziemlich stark verjüngt; Seitenkielchen bei Dorsalansicht nur vorne, ziemlich kurz sichtbar; Apikalrand breit, leicht abgerundet oder, seltener, gerade abgestutzt; Nahtgegend gewöhnlich mehr oder weniger deutlich gewölbt, manchmal ganz flach, in der Mitte fast $0,06 \mathrm{~mm}$ breit, mit einer feinen Punktreihe; Nahtstreifen tief, biegen vorne nach aussen entlang dem Basalrand der Flügeldecken, verlöschen gegen die Mitte deren Basalbreite; Seitenstreifen zwischen dem basalen Fünftel und dem apikalen Drittel spärlich und kräftig punktiert, sie biegen vorne nach innen und verlaufen kurz entlang dem Basalrand, enden etwa 0,3 mm entfernt vom Ende der Nahtstreifen; diskale Punktierung auf dem basalen Achtel bis Sechstel, auf dem apikalen Drittel und auf einem $0,10-0,15 \mathrm{~mm}$ breiten Streifen entlang der Nahtstreifen spärlich, seicht und sehr fein, 
auf der Fläche dazwischen irregulär grob und dicht, die Radien der grössten Punkte sind selten so gross wie die Punktzwischenräume, meistens sind sie deutlich kleiner. Punktierung des Pygidium hinten sehr fein, gegen die Basis dichter und kräftiger, viel gröber als jene des Halsschildes. Mesosternum mit sehr niedrigem Mediankielchen, hinten und am Seitenrande dicht und tief punktiert. Mes-Epimeren gross, 2,5-3 mal länger als der Abstand zwischen ihnen und den Hüften II. Metasternum im mittleren Teil deutlich gewölbt, diese Wölbung durch eine breit U-förmige dichte Reihe grober Punkte abgegrenzt; zwischen den Hüften III flach und am Rande konkav abgerundet; Flächen hinter den Coxalkavitäten II gross, bis etwa 0,05 mm lang, am Rande dicht und grob punktiert; sonst Punktierung des Metasternums überall spärlich und sehr fein, noch feiner als jene des Halsschildes. Met-Episterna stark gewölbt, parallelseitig, 0,08-0,09 $\mathrm{mm}$ breit, nur an den inneren Vorderwinkeln abgerundet, mit sehr tiefer, furchenartiger Innennaht. Met-Epimeren im Niveau der Met-Episterna gewölbt, danach flach. Sternit I mit einer dichten Basalreihe ziemlich breiter Längsfurchen, die durch schmale, aber kräftige Kielchen getrennt sind; diese Furchen sind am längsten (bis $0,10 \mathrm{~mm}$ ) im Niveau der Spitze der Met-Epimeren; Punktierung des Sternits sehr spärlich und etwa so fein wie auf dem Halsschild. Apikalrand des Sternits I-IV mit mikroskulptiertem Saum versehen. Vorderschienen deutlich, Mittelschienen etwas gebogen, Hinterschienen gerade oder fast gerade, etwa 1,2 mal länger als die zugehörigen Tarsen.

$\mathrm{Maße}$ in $\mathrm{mm}$ : Länge 1,45-1,65; Basalbreite des Halsschildes 0,87-1,0; Flügeldecken an der Naht 0,91-1,06 lang, zusammen 0,96-1,08 breit; Schienen III 0,460,49 lang.

Männchen. Tarsenglieder I-III der Vorder- und Mittelbeine deutlich erweitert. Aedoeagus (Abb. 15 und 16) 0,41-0,45 mm lang, ziemlich stark sklerotisiert.

Untersuchtes Material. Astrolabe Bai: Friedrich-Wilhems-Hafen, 10 Ex.; Stephansort, 5 Ex.; Erima 1 Ex.; Huon Golf: Sattelberg, 7 Ex. Alles leg. L. Biró.

\section{Eubaeocera insperata sp. $\mathrm{n}$.}

Diese Art steht sehr nahe der E. bironis, unterscheidet sich jedoch eindeutig durch die Form der Seitenstreifen der Flügeldecken und durch abweichenden Innensack des Aedoeagus.

Körper wie bei bironis mässig gewölbt, etwas rötlich sehr dunkel braun gefärbt. Kiefertaster wie bei bironis. Fühler kaum kürzer als bei bironis, die relative Länge der Glieder wie: III 12-13 : IV 14 : V 18 : VI 15-16 : VII 20 : VIII 15 : IX 19 : X $18-19$ : XI 20-22; Glieder III-VI fast gleich schlank, VII 4 mal länger als breit, VIII etwa 4 mal länger als breit, XI ein wenig mehr als doppelt so lang wie breit. Halsschild wie bei bironis. Scutellum, abgesehen von dessen Apikalrand, überdeckt. Flügeldecken apikalwärts stärker verjüngt als bei bironis; Apikalrand schmaler und gerade abgestutzt; Nahtgegend flach, in der Mitte nicht ganz 0,05 mm breit; Nahtstreifen tief, biegen vorne nach aussen entlang dem Basalrand und verlöschen kurz nach der Mitte der Basalbreite der Flügeldecken; Seitenstreifen spärlicher und feiner punktiert als bei bironis, biegen vorne nach innen und verlaufen relativ lang entlang dem Basalrand, enden etwa $0,1 \mathrm{~mm}$ weit entfernt vom Ende der Nahtstreifen; diskale Punktierung sehr fein und sehr spärlich auf einer schmalen Zone entlang dem Basalrand und den Nahtstreifen, sonst etwas dichter und kaum feiner als die grobe Punktierung bei bironis, apikalwärts feiner werdend, in der Nähe der Apizes aber noch kräftig. Mesosternum mit kräftigem Mediankielchen, am Seiten- und Hinterrande dicht und tief punktiert. Mes Epimeren doppelt so lang wie der Abstand zwischen ihnen und den Hüften II. Mittelteil des Metasternums sehr leicht gewölbt; mit je einer dichten Gruppe grober Punkte zwischen den 
Hüften II und III, die durch eine Querreihe grober Punkte verbunden sind, sonst Metasternum wie bei bironis sehr fein punktiert; Apikalrand zwischen den Hüften gerade. Flächen hinter den Coxalkavitäten II etwas schmaler als bei bironis, am Rande dichter, etwas länglich und grob punktiert. Met-Episterna stark gewölbt, in der Mitte am breitesten, dort etwas schmaler als bei bironis, der sehr tiefe, furchenartige Innenrand leicht konvex abgerundet. Sternite wie bei bironis, die Längsfurchen am Basalrande des Ster-

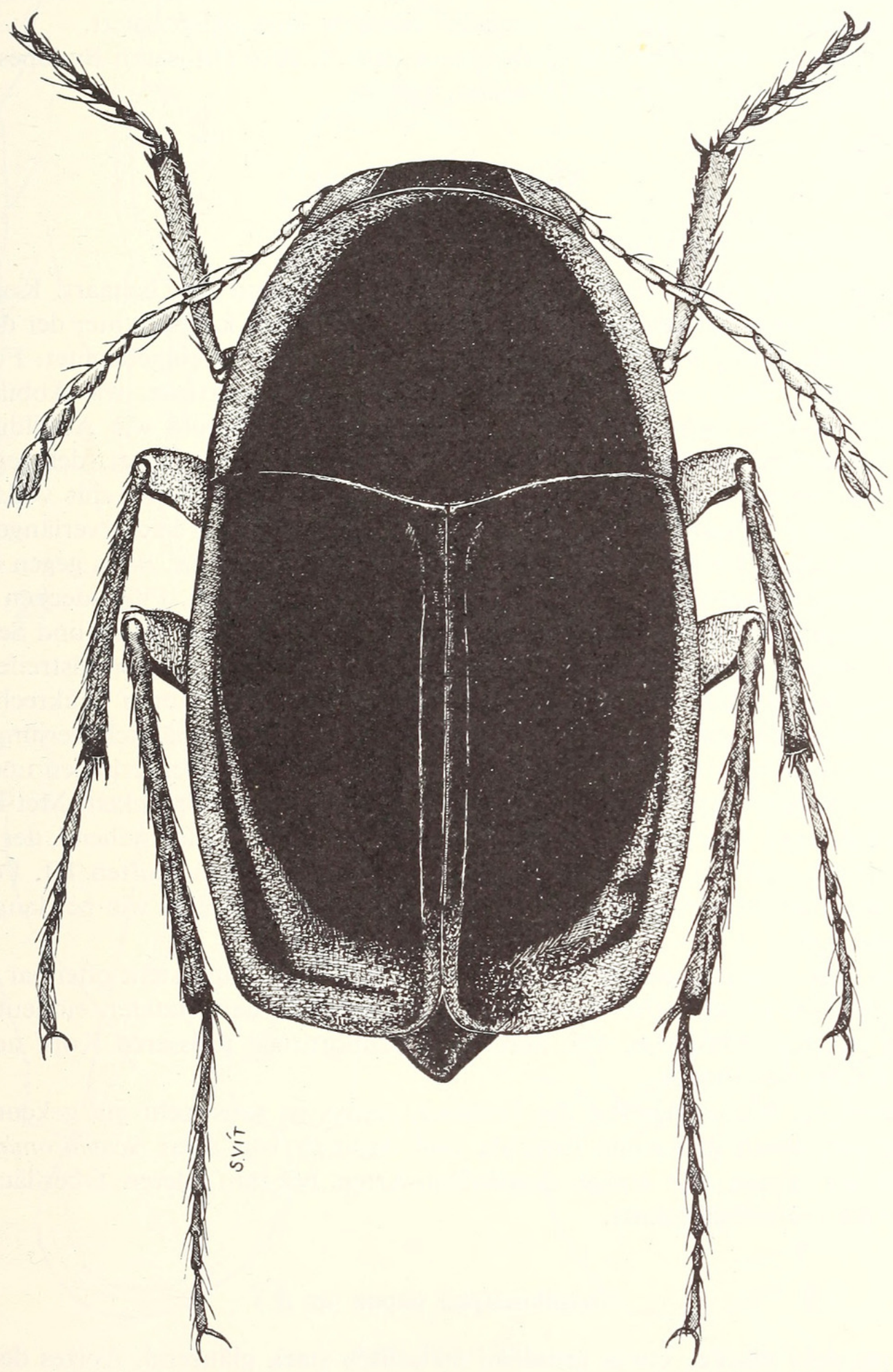

Авв. 19.

Metalloscapha gen. n. papua sp. n.; del. S. Vít. 
nits 1 aber schmaler und daher dichter und höchstens $0,08 \mathrm{~mm}$ lang. Vorderschienen etwas gebogen, Mittel- und Hinterschienen gerade, Hinterschienen 1,3 mal länger als die zugehörigen Tarsen.

Maße in mm: Länge 1,4-1,45; Basalbreite des Halsschildes 0,85-0,86; Flügeldecken an der Naht 0,90-0,91 lang, zusammen 0,93-0,94 breit; Schienen III 0,44 0,46 lang.

Männchen. Tarsenglieder I-III der Vorder- und Mittelbeine deutlich erweitert. Aedoeagus (Abb. 17 und 18) 0,42 mm lang, ziemlich stark sklerotisiert.

Holotypus ỗ: Astrolabe Bai, Stephansort, leg. L. Biró (Museum Budapest).

Paratypus $\widehat{o}^{\mathfrak{t}}$ : wie Holotypus (Museum Genf).

Metalloscapha gen. n.

Typus-Art: Metalloscapha papua sp. n.

Körper mässig gross, sehr glänzend, äusserst kurz und fein behaart. Kopf gross; Stirn breit und flach; Clypeus gewölbt; Fühlerinsertion liegt knapp hinter der deutlichen frontoclypealen Naht; Augen seitlich der Fühlerinsetion tief eingebuchtet. Fühler wie bei der Gattung Eubaeocera, mit langem 3. Glied und Kiefertaster wie Abbildung 20, die Lacinia schlank und einfach. Labialpalpen und Mandibula wie Abbildungen 21 und 22. Halsschild gewölbt, nach vorne relativ sehr leicht verjüngt, der regelmässig abgerundete Vorderrand viel breiter als die Hälfte der Basalbreite; mit vollständigen Vorderrand- und Seitenstreifen; Seitenkante fein; Hinterwinkel leicht verlängert, abgerundet, überdecken die äusseren Vorderwinkel der Met-Episterna; Basis gegen die Mitte nur etwas nach hinten verlängert, Basallappen kaum entwickelt. Flügeldecken gewölbt, in der Mitte am breitesten, hinten fast so breit wie an der Basis; Naht- und Seitenstreifen nicht entlang dem Basal- und Apikalrand verlaufend; Epipleuralstreifen enden vorne kurz hinter dem Basalrande der Flügeldecken; Epipleuren senkrecht, vorne ein wenig schmaler als die Pseudoepipleuren, apikalwärts allmählich verjüngt, enden im Niveau des Sternits II. Vordere Seitenränder des Mesosternums erhaben und kantig. Meso-metasternale Naht nicht sichtbar. Mes-Epimeren gut entwickelt. Met-Episterna und Met-Epimeren sehr gross. Hüften II mässig weit voneinander stehend, der Abstand zwischen ihnen nur ein wenig kleiner als jener zwischen den Hüften III. Postcoxale Flächen des Sternits I deutlich. Beine lang und schlank, ähnlich wie bei langbeinigen Scaphisoma-Arten.

Diese neue Gattung gehört in die Tribus Scaphisomini und steht offenbar der Gattung Scaphisoma Leach nahe. Sie untescheidet sich von der letzteren eindeutig durch die Form des Körpers (Abb. 19), durch den proportional grösseren Kopf und durch die Ausbildung der Fühler.

Bemerkung. Die einzige Art der Gattung, papua, ist sonst sehr gut gekennzeichnet durch die metallisch glänzende Cuticula und dadurch von allen Scaphisomini abweichend. Bisher waren nur einige Scaphidium-Arten bekannt, deren Oberfläche mehr oder weniger metallisch glänzt.

\section{Metalloscapha papua sp. n.}

Körper sehr dunkel, etwas grünlich, metallisch stark glänzend. Apizes der Flügeldecken und des Abdomens gewöhnlich dunkelbraun. Beine rötlich dunkelbraun. Scapus und Pedicellus ziemlich hell rötlichbraun, folgende Fühlerglieder dunkler, meistens dunkler als die Beine. Ober- und Unterseite sehr fein, bei $\times 50$ Vergrösserung schlecht 


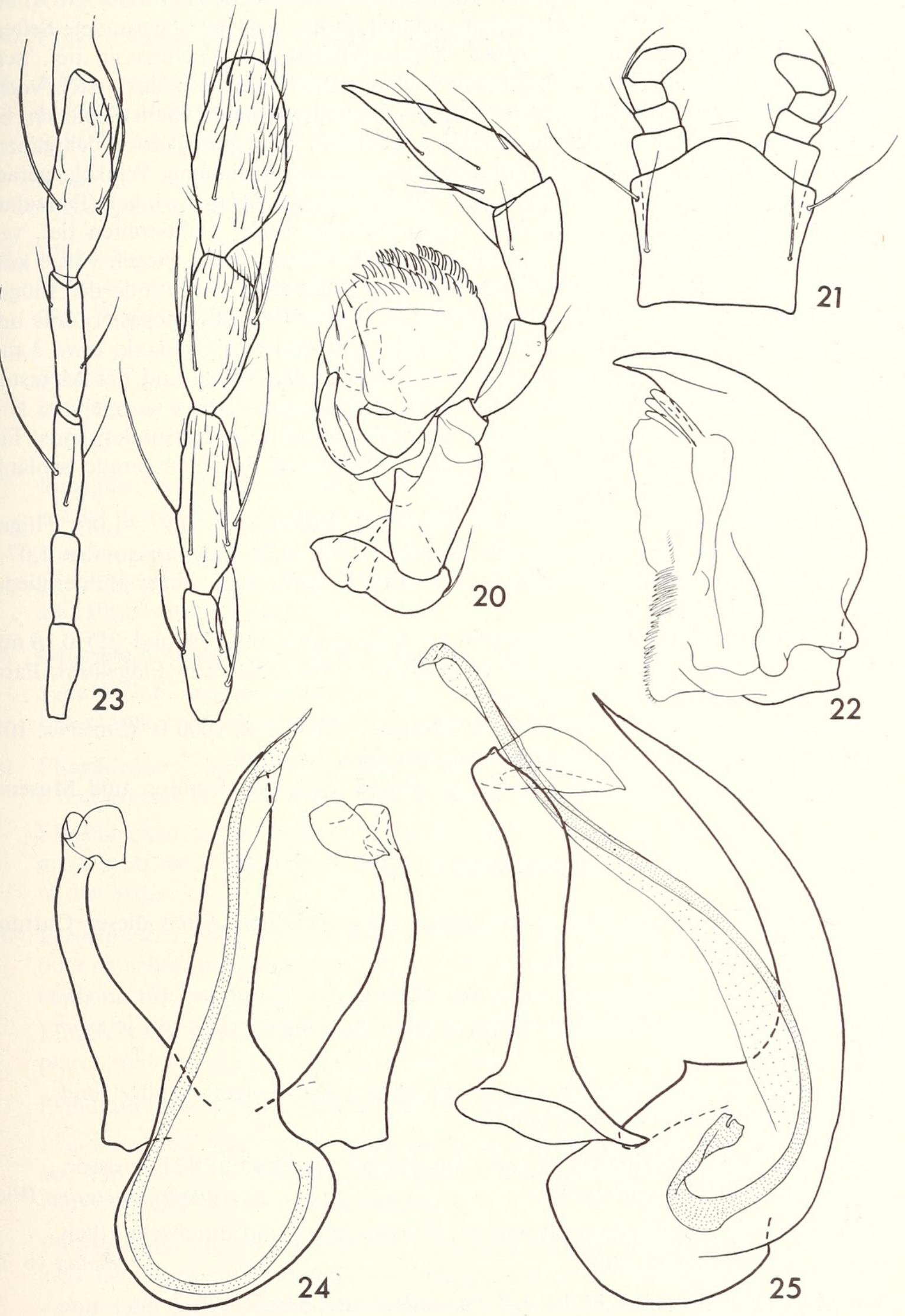

Авв. 20 bis 25 .

Metalloscapha gen. n. papua sp. n.

20. Kiefer mit Taster; 21. Labium mit Taster; 22. Mandibula; 23. Fühlerglieder III-XI; 24 und 25. Aedoeagus bei Dorsal- und Lateralansicht, Paratypus von Mt. Abilala. 
sichtbar punktiert. Ohne Mikroskulptur, abgesehen von der der Beine. Fühler wie Abbildung 23. Halsschild nach vorne allmählich verjüngt, Seiten konvex abgerundet; Seitenkielchen bei Dorsalansicht nicht sichtbar; Vorderrandstreifen gleichmässig tief. Scutellum verdeckt. Flügeldecken im mittleren Teil am breitesten, von dort nach vorne mässig, gegen den Apex deutlicher verjüngt; Seiten abgerundet; Seitenkielchen bei Dorsalansicht gewöhnlich nur vorne sichtbar, bei einem Exemplar jedoch der ganzen Länge nach deutlich; Apikalrand, ausgenommen die abgerundeten Winkel, gerade abgestutzt; apikaler Innenwinkel liegt etwa im Niveau der Aussenwinkel (Dorsalansicht); Nahtgegend gewölbt, in der Mitte etwa $0,06 \mathrm{~mm}$ breit; Nahtstreifen tief, verlaufen hinten divergierend, sonst überwiegend parallel mit der Naht, biegen vorne kurz nach aussen und verlöschen plötzlich ziemlich weit hinter dem Basalrande der Flügeldecken. Flügel nur rudimentär ausgebildet. Mediodistaler Teil des Mesosternums und das Metasternum zwischen den Hüften II gewölbt. Mes-Epimeren schlank, etwa 3 mal länger als der Abstand zwischen ihnen und den Hüften II. Apikalrand des Metasternums zwischen den Hüften konkav. Met-Episterna sehr gross, etwa doppelt so lang wie breit, nach vorne verjüngt, ihre Innennaht tief, vorne breit abgerundet, sonst fast geradlinig. Met-Epimeren noch breiter als die Met-Episterna. Schienen gerade, schlank, die hinteren länger als die zugehörigen Tarsen.

Maße in mm: Länge 1,65-1,8; Basalbreite des Halsschildes 0,97-1,06; Flügeldecken an der Naht 1,02-1,11 lang, an der Seiten 1,13-1,21 lang, zusammen 1,071,14 breit; Schienen I $0,44-0,47$, II $0,51-0,60$, III $0,70-0,80$ lang; Fühlerglieder III-XI 0,79-0,84 lang.

Männchen. Tarsenglieder nicht erweitert. Aedoeagus (Abb. 24 und 25) 0,36 mm lang, stark sklerotisiert; Innensack sehr lang, einfach, mit schlankem Flagellum; Parameren mit sehr dünnen apikalen Lappen.

Holotypus ㅊ: Morobe Dist., Finisterre Mts., Mt. Abilala, c. 9000 ft. (Stn. No. 103) 19._-22.XI.1964, leg. M. E. Bacchus (British Museum, London).

Paratypen: 1 ô und 5 oq wie Holotypus (British Museum, London und Museum Genf).

\section{Scaphisoma Leach}

Die Mehrzahl von den 20 nun bekannten neuguineischen Arten dieser Gattung scheint isoliert $\mathrm{zu}$ stehen.

1 Nahtstreifen der Flügeldecken verlaufen entlang dem Basalrand bis an die Seiten und sind mit den Seitenstreifen verbunden. Flügeldecken mit je zwei hellen Flecken

- Nahtstreifen der Flügeldecken sind vorne mehr oder weniger verkürzt und nicht mit den Seitenstreifen verbunden

2 Aedoeagus wie Abbildungen 58 und 59. Körper durchschnittlich grösser, 1,85-1,95 mm lang, und dunkler . quadripunctatum (Pic)

- Aedoeagus wie Abbildungen 60 und 61. Körper heller und durchschnittlich kleiner, 1,55-1,75 mm lang

audax sp. n.

3 Seitenkielchen des Halsschildes bei Dorsalansicht nicht sichtbar oder nur gegen die Mitte kurz und schlecht bemerkbar

- Seitenkielchen des Halsschildes bei Dorsalansicht mindestens im basalen Drittel oder in der vorderen Hälfte sichtbar, oft der ganzen Länge nach deutlich . 
4 Flügeldecken deutlich zweifarbig . . . . . . . . . . . . . . . . . . . 5

Flügeldecken einfarbig, höchstens am Apex leicht heller . . . . . . . . . 7

5 Körper rötlichbraun, Flügeldecken mit je einem grossen hellen humeralen Fleck und einem hellen apikalen Band. Vorderrandstreifen des Halsschildes vollständig. Kleine Art, weniger als 1,2 mm lang . . . . . . . . dissimile sp. $\mathrm{n}$.

Kopf und Halsschild schwarz. Vorderrandstreifen nur an den Seiten entwickelt. Grössere Arten, über 1,5 mm lang .

6 Flügeldecken mit je einem breiten, scharf abgegrenzten gelben apikalen Band, sonst sehr dunkel; Seitenkielchen bei Dorsalansicht der ganzen Länge nach deutlich. Metasternum mit einer medianen Furche. Länge 1,55-1,9 mm

sulcatum $\mathrm{sp} . \mathrm{n}$.

Flügeldecken mit je einem schmalen hellen posthumeralen Querband und mit je zwei kleinen subapikalen Flecken; Seitenkielchen bei Dorsalansicht nur im basalen Viertel sichtbar. Länge 2,2 $\mathrm{mm}$

blandum sp. n.

7 Flügeldecken ebenso dunkel wie Halsschild, am Seitenrande deutlich abgerundet und apikalwärts mässig oder leicht verjüngt

- Kopf und Halsschild schwarz. Flügeldecken ziemlich dunkel rötlichbraun, an den Seiten sehr leicht abgerundet, mit fast geradlinigem Seitenrand, apikalwärts auffällig stark verjüngt . . . . . . . . . . . budemuense sp. n.

8 Grössere, mindestens 1,9 mm lange, stark gewölbte Arten . . . . . . . . . 9

- Sehr kleine, mässig gewölbte Art, unter $1 \mathrm{~mm}$ lang. Seitenkielchen der Flügeldecken bei Dorsalansicht der ganzen Länge nach deutlich. .papuanum sp. n.

9 Flügeldecken spärlicher punktiert, die Punktzwischenräume meistens 6 9 mal grösser als die Punktradien. Sternit V bei Männchen einfach . .triste sp. n.

- Flügeldecken dichter punktiert, die Punktzwischenräume meistens 2-3 mal grösser als die Punktradien. Sternit V bei Männchen mit einem Höckerchen in der Mitte

.loriai sp. n.

10 Flügeldecken ohne Flecken oder Querbändern, schwarz oder dunkelbraun oder rötlichbraun, ähnlich gefärbt wie der Halsschild, nur am Apex manchmal heller

- Flügeldecken mit Flecken oder Querbändern, bei nicht ausgefärbten Exemplaren manchmal einfarbig, dann sehr hell

11 Pygidium und Sternite deutlich querrunzelig mikroskulptiert

- Pygidium und Sternite mit einer kaum wahrnehmbaren punktierten Mikroskulptur versehen. Flügeldecken spärlich und sehr fein punktiert, wie der Halsschild schwarz oder braunschwarz. bacchusi sp. n.

12 Flügeldecken ein wenig kräftiger punktiert als der Halsschild, die Punktzwischenräume sind meistens 4-7 mal grösser als die Punktradien. Apikales Zehntel der Flügeldecken heller. Sternit V bei Männchen einfach .inornatum sp. n.

- Flügeldecken viel kräftiger punktiert als der Halsschild, die Punktzwischenräume sind meistens so gross bis doppelt so gross wie die Punktradien. Apex der Flügeldecken nicht oder kaum heller als der Diskus. Sternit V bei Männchen in der Mitte verlängert und mit drei winzigen Zähnchen beccarii sp. n. 
13 Kleine, etwa $1-1,3 \mathrm{~mm}$ lange und mehr oder weniger hell gefärbte Arten

Grössere, mindestens 1,5 mm lange Arten

14 Körper auffällig schlank. Halsschild nach vorne fast geradlinig und sehr leicht verjüngt. Flügeldecken an der Basis verdunkelt und mit je einem dunkeln apikalen Fleck. Sternit V bei Männchen einfach

festivum sp. $\mathrm{n}$.

- Körper normal breit. Halsschild nach vorne deutlich abgerundet verjüngt. Falls Farbung ähnlich wie bei festivum, Sternit V bei Männchen verziert

15 Pygidium und Sternite querrunzelig mikroskulptiert .

Pygidium und Sternite mit punktierter Mikroskulptur

16 Flügeldecken mit je einem grossen hellen Fleck, der fast die ganzen basalen 2/5 der Oberfläche einnimmt. Sternit V bei Männchen einfach . . . baloghi sp. n.

- Flügeldecken normalweise an der Basis verdunkelt und mit je einem dunklen apikalen Fleck, bei nicht ausgefärbten Exemplaren einfarbig oder fast einfarbig. Sternit V bei Männchen in der Mitte verlängert und mit drei winzigen Zähnchen

tridentatum sp. n.

17 Flügeldecken an der breitesten Stelle zusammen $0,84-0,90 \mathrm{~mm}$ breit. Parameren des Aedoeagus sehr breit, mit Einbuchtungen und Lamellen an der Innenseite

fasciatum Pic

- Flügeldecken an der breitesten Stelle zusammen 0,77-0,82 mm breit. Parameren des Aedoeagus schlank und einfach . . . . . . . . pseudofasciatum sp. $\mathrm{n}$.

18 Pygidium und Sternite mit punktierter Mikroskulptur. Flügeldecken sehr dunkel, mit je einem hellen Fleck vor dem Apex

- Pygidium und Sternite querrunzelig mikroskulptiert. Flügeldecken hell, an der Basis, an der Nahtgegend, vor dem Apex und in der Mittel verdunkelt

ornatipenne sp. n.

19 Punktierung der Flügeldecken überwiegend grob und dicht, viel kräftiger als jene des Halsschildes. Apikalfleck der Flügeldecken quer und gross

.unifasciatum Pic

- Punktierung der Flügeldecken fein und spärlich, nur ein wenig kräftiger als jene des Halsschildes. Apikalfleck der Flügeldecken irregulär rundlich und kleiner

unimaculatum $\mathrm{sp} . \mathrm{n}$.

\section{Scaphisoma fasciatum Pic}

Scaphosoma fasciatum PIC, 1956: 72; Holotypus 9 : Astrolabe Bai, Stephansort (Museum Budapest).

Scaphosoma fasciatum var. biroi PIC, 1956: 73; Holotypus ơ: Huon Golf, Sattelberg (Museum Budapest). - syn. nov.

Körper mässig stark gewölbt, mehr oder weniger hell rötlichbraun bis gelbbraun. Flügeldecken mindestens zum Teil durchscheinend, mit je einem breiteren mittleren und einem schmaleren apikalen dunkleren Querband. Oft sind diese Bänder fast so hell wie die übrige Diskalfläche, oder sie fehlen völlig oder nur das mittlere Band ist mehr oder weniger bemerkbar. Fühler ab dem Glied VII abgeplattet; relative Länge der Glieder wie: III 3-4: IV 11-14: V 17-18: VI 17: VII 21-22: VIII 15-16: IX 21-22: 


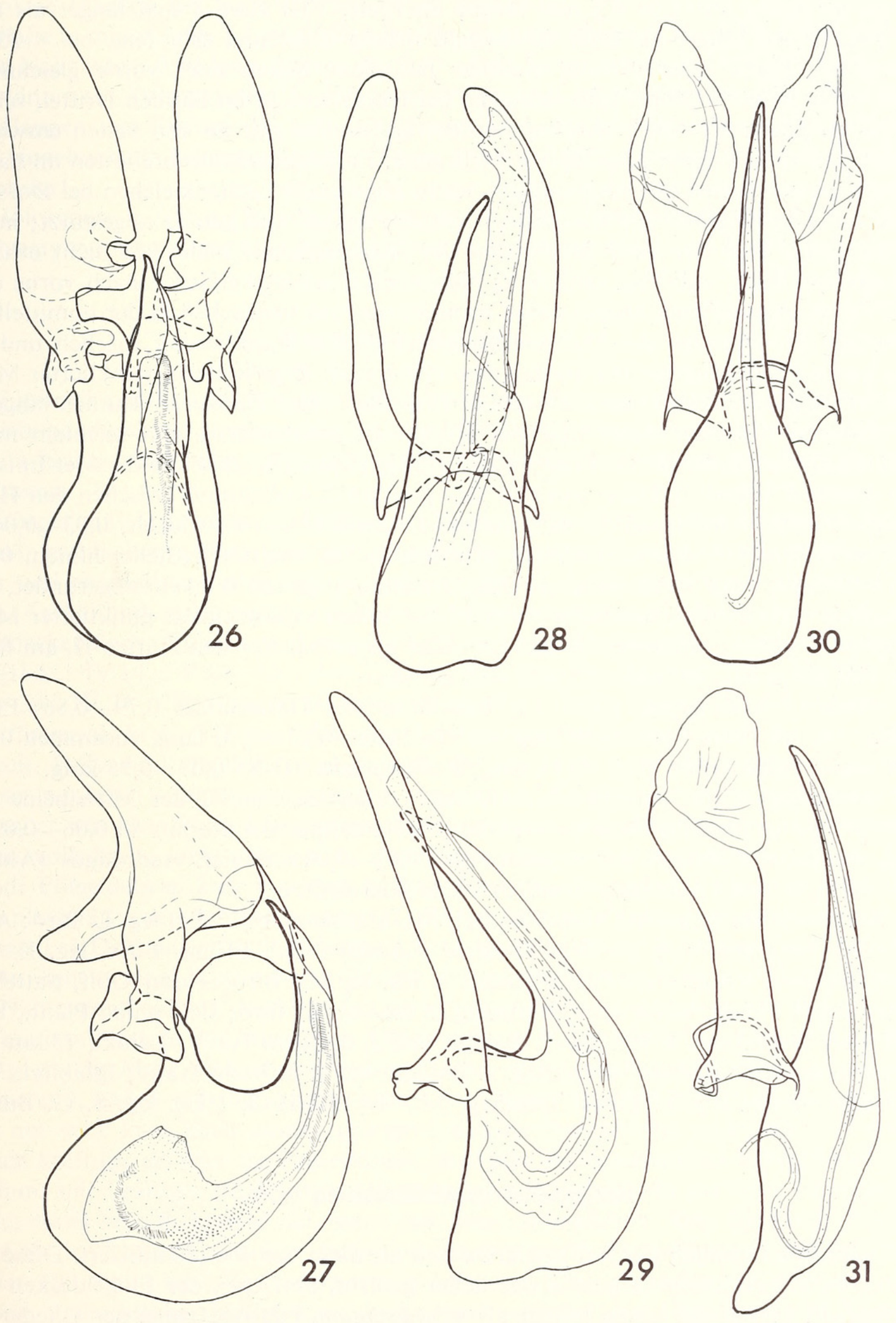

Авв. 26 bis 31 .

Aedoeagi von Scaphisoma bei Dorsal- und Lateralansicht.

26 und 27. fasciatum Pic, Paratypus von Sattelberg; 28 und 29. pseudofasciatum sp. n., Holotypus; 30 und 31. dissimile sp. n., Paratypus von Stephansort. 
X 20-21: XI 21-23: Glieder V und VI gleich breit, ein wenig breiter als IV, etwa 6 mal länger als breit; VII 3,5-4,5 mal länger als breit; VIII etwa 4 mal länger als breit; XI etwa 3 mal länger als breit. Halsschild mässig dicht und sehr fein, bei $\times 25$ Vergrösserung kaum oder schlecht sichtbar punktiert; Seiten nach vorne gleichmässig stark abgerundet verjüngt; Seitenkielchen bei Dorsalansicht im basalen Drittel, seltener weiter bis gegen die Mitte sichtbar; Vorderrandstreifen nur an den Seiten entwickelt. Scutellum verdeckt oder seine Spitze freiliegend. Flügeldecken am breitesten im basalen Viertel, an den Seiten fast gleichmässig, leicht abgerundet; Seitenkielchen bei Dorsalansicht vorne kräftig, fast bis zum Apex sichtbar; Apikalrand gerade abgestutzt; innerer Apikalwinkel liegt vor oder im Niveau der Aussenwinkel; Nahtrand nicht erhaben; Nahtgegend flach, sehr fein punktiert; Nahtstreifen seicht, verlaufen nach vorne etwas oder kaum divergierend, biegen vorne nach aussen und verlöschen in der unmittelbaren Nähe des Seitenrandes des Halsschildlappens; diskale Punktierung spärlich und sehr fein, kaum bis deutlich gröber als auf dem Halsschild. Pygidium mit punktierter Mikroskulptur, meistens feiner punktiert als der Halsschild. Mes-Epimeren deutlich länger als der Abstand zwischen ihnen und den Hüften II. Metasternum mit seichtem mediodistalem Eindruck, dieser dicht und relativ kräftig punktiert, sonst wie die Met-Episterna und Sternit I überall spärlich und sehr fein punktiert; Apikalrand zwischen den Hüften gerade. Flächen hinter den Coxalkavitäten II ziemlich gut entwickelt, $0,03-0,04 \mathrm{~mm}$ lang. Met-Episterna flach oder leicht gewölbt, an der breitesten Stelle, hinten, 0,08$0,11 \mathrm{~mm}$ breit, nach vorne leicht verjüngt, Innenrand an den Winkeln abgerundet, sonst geradlinig oder etwas abgerundet. Sternit I mit kaum wahrnehmbar punktierter Mikroskulptur $(\times 100)$; postcoxale Flächen schmaler als jene hinter den Hüften II, am Rande sehr fein punktiert. Schienen schlank und gerade.

Maße in mm: Länge 1,15-1,3; Basalbreite des Halsschildes 0,79-0,86; Flügeldecken an der Naht 0,69-0,76 lang, an den Seiten 0,83-0,90 lang, zusammen 0,840,90 breit; Schienen III 0,42-0,47 lang; Fühlerglieder III-XI 0,67-0,75 lang.

Männchen. Tarsenglieder I bis III der Vorderbeine und I der Mittelbeine stark erweitert, II der Mittelbeine etwas erweitert. Apikallappen des Sternits VI 0,06-0,09 mm lang, die Einbuchtungen des Apikalrandes 0,03-0,04 mm tief. Aedoeagus (Abb. 26 und 27) $0,52-0,62 \mathrm{~mm}$ lang, ziemlich stark sklerotisiert.

Untersuchtes Material: Astrolabe Bai, Mt. Hansemann, 23 Ex. leg. L. Biró; Astrolabe Bai, Stephansort, 2 Ex. leg. L. Biró; Astrolabe Bai, Erima, 1 Ex. leg. L. Biró; Astrolabe Bai, Friedrich-Wilhems-Hafen, 3 Ex. leg. L. Biró; Huon Golf, Sattelberg, 25 Ex. leg. L. Biró; Huon Golf, Simbang, 2 Ex. leg. L. Biró; Leuvomba Plant., 8 mil. S of Lae, 11.IV.1965, 2 Ex. leg. J. Balogh und J. J. Szent-Ivány; Laloki, 15 km N of Port Moresby, 30.III.1965, 1 Ex. leg. J. Balogh und J. J. Szent-Ivány; Ighibirei, VIIVIII 1890, 2 Ex. leg. L. Loria; Quelilag, 13.-16.VIII.1912, 1 Ex. leg. S. G. Bürgers.

\section{Scaphisoma pseudofasciatum $\mathrm{sp} . \mathrm{n}$.}

Täuschend ähnlich der Art fasciatum und als diese von Pic identifiziert. Diese neue Art ist durchschnittlich kleiner, etwas heller gefärbt, am Apex der Flügeldecken nicht verdunkelt. Fühler ein wenig kürzer als bei fasciatum, relative Länge der Glieder wie: III 3-4: IV 12-13: V 14-15: VI 15-16: VII 18-19: VIII 13-14: IX 19: X 19: XI 20-22; Glieder V und VI gleich breit oder VI etwas breiter, etwa 5 mal länger als breit; VII etwa 3 mal länger als breit; VIII 3,5 länger als breit und etwa um 1/4 breiter als VI; XI etwa 3 mal länger als breit. Flügeldecken apikalwärts stärker verjüngt und mit noch seichteren Nahtstreifen, die weit nach vorne parallel mit der Naht verlaufen. 
Innenrand der Met-Episterna in der vorderen Hälfte geradlinig, hinten etwas abgerundet. Postcoxale Flächen des Sternits I ein wenig grösser.

Maße in mm: Länge 1,1-1,2; Basalbreite des Halsschildes 0,72-0,76; Flügeldecken an der Naht 0,65-0,69 lang, zusammen 0,77-0,82 breit; Schienen III 0,34-0,37 lang.

Männchen. Tarsenglieder I-III der Vorder- und Mittelbeine deutlich erweitert. Apikallappen des Sternits VI kaum 0,05 mm lang, Apikalrand seitlich des Lappens kaum eingebuchtet. Aedoeagus (Abb. 28 und 29) 0,29-0,33 mm lang, ziemlich schwach sklerotisiert.

Holotypus đ̃: Huon Golf, Sattelberg, leg. L. Biró (Museum Budapest).

Paratypen: wie Holotypus 13 ธิธิ (Museum Budapest, Genf und Paris).

\section{Scaphisoma dissimile sp. $\mathrm{n}$.}

Habituell ziemlich ähnlich den Arten fasciatum und pseudofasciatum, jedoch durch die Färbung, durch die abgerundeten Apizes der Flügeldecken und durch die furchenartig vertiefte Nahtgegend neben dem erhabenen Nahtrand der Flügeldecken sehr deutlich verschieden.

Körper mässig gewölbt, rötlichbraun. Flügeldecken mit je einem variabel grossen, irregulär rundlichen gelben oder gelbbraunen humeralen Fleck und mit einem gleich hellen und ebenfalls variabel breiten apikalen Band; dieses endet kurz vor dem dunkleren Apikalrand, nach vorne reicht es höchstens knapp vor das Apikaldrittel der Flügeldeckenlänge. Fühler ab dem Glied VI abgeplattet; relative Länge der Glieder wie: III 5 : IV 14 : V 14-15 : VI 15-17 : VII 19-20 : VIII 16-18 : IX 20-21 : X 19-20 : XI 21-22; Glied V deutlich breiter als IV und schlanker als VI, dieses etwa 4 mal länger als breit; VII und VIII etwa 3 mal länger als breit; XI etwa 3,5 mal länger als breit. Halsschild ziemlich spärlich und sehr fein, bei $\times 25$ Vergrösserung schlecht sichtbar punktiert; Seiten gleichmässig abgerundet; Seitenkielchen bei Dorsalansicht nicht oder vor der Mitte kaum bemerkbar; Vorderrand leicht konvex; Vorderrandstreifen vollständig, aber sehr seicht. Scutellum ganz verdeckt oder seine Spitze freiliegend. Flügeldecken kurz vor dem Mediandrittel der Seitenlänge am breitesten, von dort apikalwärts ziemlich stark verjüngt; Seiten fast gleichmässig abgerundet; Seitenkielchen bei Dorsalansicht der ganzen Länge nach sichtbar; Apikalrand abgerundet; apikaler Innenwinkel liegt etwa im Niveau der Aussenwinkel; Nahtrand deutlich erhaben; Nahtgegend entlang der Naht furchenartig vertieft, knapp entlang der Nahtstreifen sehr fein punktiert, in der Mitte etwa $0,05 \mathrm{~mm}$ breit; Nahtstreifen tief, verlaufen ab dem Apex gegen die Mitte leicht divergierend, von der Mitte parallel miteinander oder kaum divergierend, enden plötzlich knapp hinter dem Rand des Halsschildlappens, vor dem Ende nur sehr kurz nach aussen gebogen; diskale Punktierung dicht bis sehr dicht, deutlich kräftiger als jene des Halsschildes, aber sehr seicht und daher schlecht sichtbar. Pygidium mit kräftiger punktierter Mikroskulptur versehen, die normale Punktierung auf der Basis sehr dicht und tief, sonst sehr fein und spärlich. Mes-Epimeren deutlich länger als der Abstand zwischen ihnen und den Hüften II. Metasternum überall ähnlich wie der Halsschild sehr fein punktiert, im mittleren Teil sehr leicht gewölbt, mit sehr seichten mediodistalen Eindrücken; Apikalrand zwischen den Hüften gerade. Flächen hinter den Coxalkavitäten II schmal, mit einer feinen Punktreihe am Rande, die seitlich entlang dem Metasternalrand fast bis zum Halsschildrand reicht. Met-Episterna flach, relativ gross, an der breitesten Stelle $0,07-0,08 \mathrm{~mm}$ breit, nach vorne leicht verjüngt; Innenrand vorne und hinten konvex, sonst geradlinig oder etwas abgerundet. Sternit I ebenso fein punktiert wie der Halsschild, bei $\times 100$ Vergrösserung kaum bemerkbar 
mikroskulptiert; postcoxale Flächen in der äusseren Hälfte sehr schmal, in der inneren Hälfte erweitert, konvex, bis $0,03 \mathrm{~mm}$ lang. Schienen schlank, gerade.

Maße in mm: Länge 1,05-1,15; Basalbreite des Halsschildes 0,68-0,77; Flügedecken an der Naht 0,63-0,70 lang, an den Seiten 0,71-0,77 lang, zusammen 0,760,86 breit; Schienen III 0,40-0,42 lang; Fühlerglieder III-XI 0,66-0,70 lang.

Männchen. Tarsenglieder I-III der Vorderbeine leicht erweitert. Apikalrand des Sternits VI in der Mitte ein wenig vorgezogen. Aedoeagus (Abb. 30 und 31) 0,47$0,52 \mathrm{~mm}$ lang leicht, die apikale Lamelle der Parameren und der Innensack sehr leicht sklerotisiert.

Holotypus ô: Astrolabe Bai, Stephansort, leg. L. Biró (Museum Budapest).

Paratypen: wie Holotypus 2 ธิ oิ (Museum Budapest und Genf).

\section{Scaphisoma papuanum sp. $\mathrm{n}$.}

Äusserlich am ähnlichsten der Art nanulum Löbl, aber noch kleiner, weniger gewölbt und durch den nach vorne weniger stark verjüngten Halsschild, durch die bei Dorsalansicht der ganzen Länge nach sichtbaren Seitenkielchen der Flügeldecken und durch die Ausbildung der Fühler auffällig abweichend.

Körper mässig gewölbt, einfarbig. etwas rötlich dunkelbraun. Fühler ab dem Glied VII abgeplattet; relative Länge der Glieder wie: III 4 : IV 9 : V 13 : VI 12 : VII 15 : VIII 11 : IX 15 : X 15 : XI 17; Glieder IV-VI fast gleich schlank, VIII 3 mal länger als breit, VIII gut 3 mal länger als breit, etwa um 1/3 breiter als VI, XI fast 3,5 mal länger als breit. Halsschild ziemlich spärlich und fein, bei $\times 12$ Vergrösserung schon sichtbar punktiert; Seiten abgerundet, relativ stark nach vorne verjüngt; Seitenkielchen bei Dorsalansicht nicht sichtbar; Vorderrand gleichmässig konvex; Vorderrandstreifen sehr kurz, nur in der unmittelbaren Nähe der Winkel ausgebildet. Spitze des Scutellums freiliegend. Flügeldecken am breistesten kurz nach dem basalen Viertel der Seitenlänge, von dort apikalwärts leicht abgerundet und mässig verjüngt; Seitenkielchenbei Dorsalansicht der ganzen Länge nach deutlich; Apikalrand breit, leicht abgerundet; apikaler Innenwinkel liegt im Niveau der Aussenwinkel; Nahtrand nicht erhaben; Nahtgegend flach, sehr fein punktiert, in der Mitte etwa 0,03 mm breit; Nahtstreifen seicht, ein wenig gröber punktiert als der Diskus, verlaufen nach vorne parallel miteinander und vorne dem Halsschildlappen und kurz dem Basalrand der Flügeldecken entlang, verlöschen etwas nach dem inneren Drittel der Basalbreite der Flügeldecken; diskale Punktierung spärlich, nur ein wenig kräftiger als jene des Halsschildes, die Punktzwischenräume sind meistens 4-7 mal grösser als die Punktradien. Pygidium ohne Mikroskulptur, dicht, in der Nähe des Apex sehr fein, sonst etwa so kräftig wie die Flügeldecken punktiert. Mes-Epimeren etwa 3 mal länger als der Abstand zwischen ihnen und den Hüften II. Metasternum spärlich, auf dem leicht gewölbten mittleren Teil fein, sonst sehr fein punktiert; mediodistale Eindrücke deutlich, länglich, parallel miteinander; Apikalrand zwischen den Hüften kaum konkav. Flächen hinter den Coxalkavitäten II fast 0,03 mm lang, mit einer feinen Punktreihe am Rande, die seitlich gegen die Mes-Epimeren reicht. Met-Episterna flach, an der breitesten Stelle, hinten, 0,06 mm breit, von dort nach vorne allmählich verjüngt; Innenrand vorne und hinten abgerundet, sonst geradlinig. Sternit I ohne Mikroskulptur, mässig dicht, ein wenig deutlicher als die Metasternalseiten punktiert; postcoxale Flächen relativ gross, fast $0,05 \mathrm{~mm}$ lang, gegen die Mitte der medianen Segmentlänge reichend. Schienen schlank, gerade.

Maße in mm: Länge 0,85; Basalbreite des Halsschildes 0,57; Flügeldecken an der Naht 0,51 lang, an den Seiten 0,56 lang, zusammen 0,66 breit; Schienen III 0,28 lang; Fühlerglieder III-XI 0,49 lang. 
Männchen. Tarsenglieder I-III der Vorderbeine und I der Mittelbeine deutlich erweitert. Apex des Sternits VI mit winzigem dreieckigem Medianlappen, ohne Einbuchtungen. Aedoeagus (Abb. 32 und 33) 0,24 mm lang, ziemlich leicht sklerotisiert. Holotypus ô: Sattelberg (Museum Genf).

\section{Scaphisoma sulcatum sp. $\mathrm{n}$.}

Diese isoliert stehende Art ist offenbar recht variabel. Sie ist gut gekennzeichnet duch die Färbung, durch die Medianfurche des Metasternums und durch die Form des Aedoeagus.

Körper mässig stark gewölbt, schwarz, Flügeldecken im apikalen Viertel gelb, sonst wie Halsschild oder etwas heller. Fühler ab dem Glied VII abgeplattet; relative Länge der Glieder wie: III 5-7 : IV 15-19 : V 18-20 : VI 20-24 : VII 25-28 : VIII 21-23 : IX 26-30 : X 26-29 : XI 32-36; Glied IV schlank, V deutlich breiter, 4,5-5 mal länger als breit; VI breiter als V, 4 bis fast 5 mal länger als breit; VII 3,54 mal länger als breit; VIII so breit oder etwas breiter als VI, etwa 4 mal länger als breit; XI 3,5 mal länger als breit. Halsschild dicht und sehr fein punktiert, die Punkte sind scharf abgegrenzt und daher schon bei $\times 12$ Vergrösserung bemerkbar; Seitenrand und Vorderrand gleichmässig abgerundet; Seitenkielchen bei Dorsalansicht nicht sichtbar oder nur in der Mitte kurz und schlecht bemerkbar; Vorderrandstreifen nur an den Seiten entwickelt. Spitze des Scutellums freiliegend. Flügeldecken am breitesten nach dem basalen Viertel, Seiten gleichmässig abgerundet; Seitenkielchen ziemlich kräftig, bei Dorsalansicht der ganzen Länge nach gut sichtbar; Apikalrand leicht abgerundet oder fast gerade abgestutzt; apikaler Innenwinkel liegt im Niveau der Aussenwinkel; Nahtrand nicht erhaben; Nahtgegend flach, dicht und irregulär punktiert, in der Mitte etwa 0,06 $\mathrm{mm}$ breit; Nahtstreifen ziemlich tief, im apikalen Drittel divergierend, ab dem mittleren Drittel parallel miteinander verlaufend, biegen vorne nur kurz nach aussen, verlöschen noch hinter oder etwas seitlich des Halsschildlappens; diskale Punktierung sehr dicht, deutlich kräftiger als jene des Halsschildes, aus sehr kleinen, aber relativ tiefen Punkten zusammengesetzt; die Punktzwischenräume sind meistens etwa doppelt so gross wie die Punktradien. Propygidium und Pygidium mit punktierter Mikroskulptur, ähnlich oder ein wenig feiner punktiert als der Halsschild. Mes-Epimeren ein wenig kürzer oder ähnlich lang wie der Abstand zwischen ihnen und den Hüften II. Metasternalseiten spärlich und sehr fein punktiert. Mittelteil des Metasternums leicht gewölbt, hinten verflacht, dichter punktiert, mit einer medianen, nach hinten erweiterten Furche; mediodistale Eindrücke sehr seicht oder deutlich und ziemlich breit; Apikalrand zwischen den Hüften gerade. Flächen hinter den Coxalkavitäten II etwa 0,05 mm lang, am Rande dicht und ziemlich tief punktiert. Met-Episterna flach und gross, an der breitesten Stelle, hinten, 0,16-0,19 $\mathrm{mm}$ breit, fast so breit wie die Met-Epimeren, nach vorne allmählich leicht verjüngt; Innenrand an den Winkeln abgerundet, sonst geradlinig. Sternite mit einer punktierten Mikroskulptur versehen. Punktierung des Sternits I sehr fein, auf dem mittleren Teil dichter als auf den Seiten; postcoxale Flächen schmal, 0,04-0,05 mm lang, nach aussen subparallel, nur sehr leicht verjüngt. Schienen gerade, schlank.

Maße in mm: Länge 1,55-1,9; Basalbreite des Halsschildes 1,0-1,12; Flügeldekken an der Naht 0,89-1,12 lang, an den Seiten 1,02 - 1,22 lang, zusammen 1,10-1,27 breit; Schienen III 0,52-0,64 lang; Fühlerglieder III-XI 0,84-1,0 lang.

Männchen. Tarsenglieder I-III der Vorderbeine stark, der Mittelbeine etwas erweitert. Apex des Sternits VI leicht dreieckig verlängert. Aedoeagus (Abb. 34 und 35) $0,41-0,42 \mathrm{~mm}$ lang, ziemlich schwach sklerotisiert. 

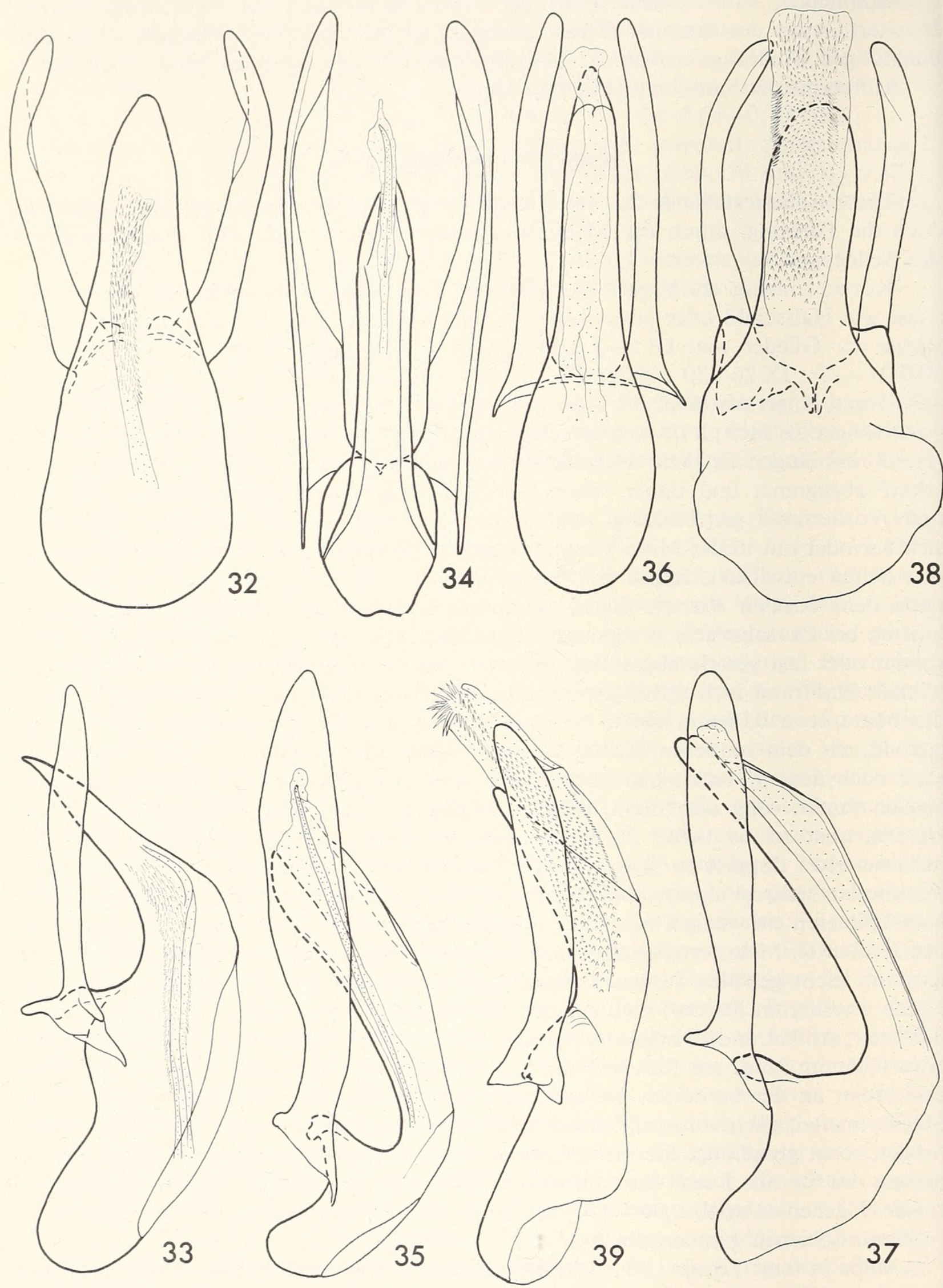

Авв. 32 bis 39 .

Aedoeagi von Scaphisoma bei Dorsal- und Lateralansicht.

32 und 33. papuanum sp. n., Holotypus; 34 und 35. sulcatum sp. n., Holotypus; 36 und 37. budemuense sp. n., Holotypus; 38 und 39. festivum sp. n., Holotypus. 
Holotypus ô: Papua, Quelilag (Museum Genf).

Paratypus: Haus Copper Wau, Mt. Missim, 22.-24.IV.1965, 1 ๙ leg. J. Balogh und J. J. Szent-Ivány (Museum Budapest).

\section{Scaphisoma budemuense $\mathrm{sp} . \mathrm{n}$.}

Äusserlich der Art portevini Pic ähnlich, von dieser besonders durch die apikalwärts viel stärker verjüngten Flügeldecken und durch die schlankeren Fühlerglieder IV bis XI abweichend.

Körper stark gewölbt. Kopf und Halsschild schwarz. Flügeldecken leicht durchscheinend, ziemlich dunkel rötlichbraun, im apikalen Neuntel hellbraun. Fühler ab dem Glied VII abgeplattet; relative Länge der Glieder wie: III 7 : IV 16 : V 19 : VI 16 : VII 23 : VIII 19 : IX 24 : X 22 : XI 29; Glieder IV-VI fast gleich schlank, VI gut 5 mal länger als breit; VII etwas mehr als doppelt so breit wie VI, etwas mehr als 3,5 mal länger als breit; VIII etwa 4 mal länger als breit; XI so breit wie VII, ein wenig mehr als 4,5 mal länger als breit. Halsschild dicht und sehr fein, bei $\times 25$ Vergrösserung gut sichtbar punktiert; Seiten nach vorne relativ stark abgerundet verjüngt; Seitenkielchen bei Dorsalansicht kurz nach der Mitte schlecht bemerkbar, sonst nicht sichtbar; Vorderrand ausser an den Seiten gerade abgestutzt; Vorderrandstreifen nur an den Seiten entwickelt. Spitze des Scutellums freiliegend. Flügeldecken am breitesten knapp nach dem basalen Fünftel, von dort apikalwärts gleichmässig auffallend stark verjüngt; Seiten nach der breitesten Stelle nur sehr leicht abgerundet, Seitenrand fast geradlinig; Seitenkielchen bei Dorsalansicht vorne kaum bemerkbar und im apikalen Viertel nicht sichtbar, dazwischen deutlich; Apikalrand schmal, gerade abgestutzt; apikaler Innenwinkel liegt ein wenig hinter dem Niveau der Aussenwinkel; Nahtrand leicht erhaben; Nahtgegend flach, äusserst fein punktiert, in der Mitte etwa $0,05 \mathrm{~mm}$, vorne $0,07 \mathrm{~mm}$ breit; Nahtstreifen seicht, deutlich punktiert, verlaufen ab dem Apex leicht divergierend, biegen vorne entlang dem Halsschildlappen und kurz entlang dem Basalrand der Flügeldecken nach aussen, verlöschen in der Nähe der Mitte der Basalbreite der Flügeldecken; diskale Punktierung ziemlich spärlich und sehr fein, die einzelnen Punkte sind grösser aber schlechter sichtbar als jene des Halsschildes. Pygidium deutlich querrunzelig mikroskulptiert, sehr fein punktiert. Mes-Epimeren ein wenig kürzer als der Abstand zwischen ihnen und den Hüften II. Metasternum überall spärlich und sehr fein punktiert, zwischen den Hüften II und III runzelig mikroskulptiert; sein mittlerer Teil gewölbt, zwischen den Hüften III verflacht, mit ziemlich tiefen, länglichen mediodistalen Eindrücken; Apikalrand zwischen den Hüften gerade. Flächen hinter den Coxalkavitäten II gross, fast abgerundet dreieckig, 0,08 mm lang, am Rande deutlich, dicht punktiert. Met-Episterna flach, hinten $0,12 \mathrm{~mm}$ breit, nach vorne kaum verjüngt; Innenrand ausser an den abgerundeten Winkeln geradlinig. Sternite querrunzelig mikroskulptiert. Sternit I wie Metasternum sehr fein und spärlich punktiert; postcoxale Flächen schmal, im äusseren 2/3 gleichmässig etwa $0,03 \mathrm{~mm}$ lang, am Rande ein wenig deutlicher punktiert. Schienen schlank, gerade.

Maße in mm; Länge 1,5; Basalbreite des Halsschildes 0,91; Flügeldecken an der Naht 0,88 lang, an den Seiten 1,0 lang, zusammen 0,98 breit; Schienen III 0,55 lang; Fühlerglieder III-XI 0,83 lang.

Männchen. Tarsenglieder I-III der Vorderbeine ziemlich stark erweitert. Aedoeagus (Abb. 36 und 37) 0,26 mm lang, mässig stark sklerotisiert.

Holotypus ô: Madang Dist., Finisterre Mts. Budemu c. 4000 ft. (Stn. No 51), 15.-24.X.1964, leg. M. E. Bacchus (British Museum, London). 


\section{Scaphisoma festivum sp. n.}

Diese Art steht isoliert. Sie ist durch die Färbung und durch die Form des Halsschildes recht auffällig und gut gekennzeichnet.

Körper ziemlich stark gewölbt. Kopf dunkelbraun, Halsschild gelbbraun. Flügeldecken gelbbraun, durchscheinend, mit je einem dunkelbraunen Band an der Basis und einem grossen, irregulär rundlichen Fleck vor dem Apex; das basale Band ist in der äusseren Hälfte etwa 0,13 mm lang. in der Innenhälfte gegen die Nahtstreifen verlängert und etwa 0,23 mm lang. Fühler ab dem Glied VII abgeplattet; relative Länge der Glieder wie: III 5: IV 10: V 18: VI 17: VII 26: VIII 17: IX 27: X 27: XI 32; Glieder IV-VI fast gleich schlank, V und VI kaum so breit wie IV, V 6 mal länger als breit; VII etwa 5 mal länger als breit; VIII 4 mal länger als breit; XI etwa 6 mal länger als breit. Halsschild nach vorne relativ sehr leicht verjüngt, am Vorderrand auffällig breit; Seitenrand überwiegend geradlinig; Seitenkielchen bei Dorsalansicht der ganzen Länge nach sichtbar; Vorderrand gleichmässig abgerundet; Vorderrandstreifen nur an den Seiten entwickelt; Punktierung ziemlich spärlich und fein, bei $\times 12$ Vergrösserung kaum bemerkbar. Spitze des Scutellums freiliegend. Flügeldecken am breitesten knapp vor dem mittleren Drittel der Seitenlänge, von dort distalwärts ziemlich stark verjüngt; Seiten fast gleichmässig abgerundet; Seitenkielchen bei Dorsalansicht im basalen Drittel sichtbar; Apikalrand abgerundet; apikaler Innenwinkel liegt etwas vor dem Niveau der Aussenwinkel; Nahtrand erhaben; Nahtgegend vorne gegen den Nahtrand erhaben, sonst flach, mit einer Reihe feiner Punkte, in der Mitte nicht ganz 0,05 mm breit; Nahtstreifen ziemlich tief, hinten divergierend, sonst lang parallel miteinander verlaufend, biegen vorne nur kurz schräg nach aussen und verlöschen ziemlich plötzlich hinter dem Halsschildlappen; diskale Punktierung dicht und grob, die Punktradien sind meistens deutlich grösser als die Punktzwischenräume. Pygidium querrunzelig mikroskulptiert, sehr fein und ziemlich spärlich punktiert. Mes-Epimeren nicht ganz doppelt so lang wie der Abstand zwischen ihnen und den Hüften II. Metasternum, abgesehen von der Fläche seitlich der Hüften II, sehr fein querrunzelig mikroskulptiert; Punktierung in den sehr seichten mediodistalen Eindrücken und in je einer Querlinie vor den Hüften III relativ kräftig, sonst überall sehr fein und spärlich; Apikalrand zwischen den Hüften konkav. Flächen hinten den Coxalkavitäten II sehr schmal, kaum 0,02 mm lang, am Rande sehr fein punktiert. Met-Episterna kaum gewölbt, hinten etwas konvex erweitert und 0,07 mm breit, im mittleren Teil parallelseitig, vorne abgerundet verjüngt. Sternit I querrunzelig mikroskulptiert, dicht und sehr fein punktiert; postcoxale Flächen fast gleichmässig abgerundet und fast $0,05 \mathrm{~mm}$ lang, am Rande sehr fein punktiert. Schienen schlank, gerade.

Maße in mm: Länge 1,05; Basalbreite des Halsschildes 0,62; Flügeldecken an der Naht 0,67 lang, an den Seiten 0,75 lang, zusammen 0,70 breit; Schienen III 0,42 lang; Fühlerglieder III-XI 0,84 lang.

Männchen. Tarsenglieder I-III der Vorderbeine und I und II der Mittelbeine deutlich erweitert. Aedoeagus (Abb. 38 und 39) 0,24 mm lang, schwach sklerotisiert (Basalkapsel des einziges Männchens deformiert).

Holotypus $\mathrm{o}^{\mathrm{t}}$ : Schering Halbinsel, Umgebung von Friedrich-Wilhems-Hafen (Museum Genf).

\section{Scaphisoma triste sp. n.}

Nach dem Aedoeagus scheint diese Art nahe der S. peterseni Löbl zu stehen, äusserlich ist sie aber eher der japanischen castaneipenne Reitter ähnlich. Von der 
letzteren durch viel feinere Punktierung der Flügeldecken und durch sehr abweichend ausgebildete Fühler und Nahtstreifen der Flügeldecken verschieden.

Körper stark gewölbt, einfarbig, tief dunkelbraun mit rötlichem Ton. Schenkel und Schienen viel heller und deutlich rötlich. Tarsen und Fühler gelbbraun. Fühler ab dem Glied VII abgeplattet; relative Länge der Glieder wie: III 10: IV 20: V 25: VI 28: VII 32: VIII 26: IX 31: X 30: XI 38; Glieder IV-VI fast gleich schlank; VII gut doppelt so breit wie VI, 3,5 mal länger als breit; VIII etwas mehr als 4 mal länger als breit; XI so breit wie VII, gut 4 mal länger als breit. Halsschild dicht und sehr fein, bei $\times 12$ Vergrösserung jedoch schon bemerkbar punktiert, da die winzigen Punkte scharf abgegrenzt sind; Seitenkielchen bei Dorsalansicht nicht sichtbar; Vorderrand an den Seiten abgerundet, sonst fast gerade abgestutzt; Vorderrandstreifen vollständig, im äusseren Fünftel ziemlich tief, dazwischen äusserst fein und kaum bemerkbar. Spitze des Scutellums freiliegend. Flügeldecken am breitesten kurz nach dem basalen Viertel, von dort gegen das apikale Drittel abgerundet und leicht verjüngt, im apikalen Drittel stärker und fast geradlinig verjüngt; Seitenkielchen bei Dorsalansicht nicht sichtbar; Apikalrand abgerundet, im inneren Drittel verzahnt; apikaler Innenwinkel liegt im Niveau der Aussenwinkel; Nahtrand nicht erhaben; Nahtgegend flach, irregulär, dicht und sehr fein punktiert, in der Mitte fast $0,07 \mathrm{~mm}$ breit; Nahtstreifen mässig tief, verlaufen ab dem Apex proximalwärts parallel miteinander, biegen vorne entlang dem Halsschildlappen und der Flügeldeckenbasis nach aussen, verlöschen kurz ausserhalb des inneren Drittels der Basalbreite der Flügeldecken; diskale Punktierung spärlicher und ein wenig kräftiger als jene des Halsschildes, sehr fein, die Punktzwischenräume sind meistens 6-9 mal grösser als die Punktradien. Propygidium und Pygidium ähnlich fein punktiert wie der Halsschild und mit punktierter, Propygidium gegen die Basis mit runzeliger Mikroskulptur versehen. Mes-Epimeren kurz, so lang wie die Hälfte des Abstandes zwischen ihnen und den Hüften II. Metasternum überall sehr fein, auf den Seiten spärlicher, auf dem gewölbten mittleren Teil dichter punktiert; mediodistale Eindrücke deutlich, nach vorne divergierend, hinten durch eine Verflachung verbunden; Apikalrand zwischen den Hüften konkav. Flächen hinter den Coxalkavitäten II gut entwickelt, 0,05 mm lang, am Rande sehr fein punktiert. Met-Episterna flach, gross, an der breitesten Stelle, hinten, etwa $0,16 \mathrm{~mm}$ breit, nach vorne stark verjüngt, ihr innerer Apikalwinkel verlängert; Innenrand hinten leicht konkav, sonst geradlinig. Sternit I ohne Mikroskulptur, Punktierung besonders gegen die Mitte deutlicher als auf dem Metasternum, auf den Seiten spärlicher als im mittleren Teil; postcoxale Flächen ziemlich gross, etwa 0,10 mm lang, nach aussen geradlinig verjüngt, hinter das innere Drittel der Met-Epimeren reichend, am Rande fein punktiert. Schienen gerade, ziemlich kräftig.

Maße in mm: Länge 2,15; Basalbreite des Halsschildes 1,32; Flügeldecken an der Naht 1,32 lang, an den Seiten 1,47 lang, zusammen 1,51 breit; Schienen III 0,79 lang; Fühlerglieder III-XI 1,08 lang.

Männchen. Tarsenglieder I-III der Vorderbeine deutlich erweitert. Aedoeagus (Abb. 40 und 41) 0,60 mm lang, ziemlich stark, Flagellum sehr stark sklerotisiert.

Holotypus ô : Huon Golf, Umgebung von Sattelberg (Museum Genf).

\section{Scaphisoma loriai sp. n.}

Äusserlich sehr ähnlich der Art triste, von dieser durch die dichtere Punktierung der Oberseite, durch die sekundären Geschlechtsmerkmale des Männchens und durch die Form des Aedoeagus deutlich verschieden.

Körper wie bei triste gewölbt und gefärbt. Fühler ähnlich wie bei triste ausgebildet, relative Länge der Glieder wie: III 7,5-8: IV 20-21; V 27-29: VI 25: VII 31-32: 

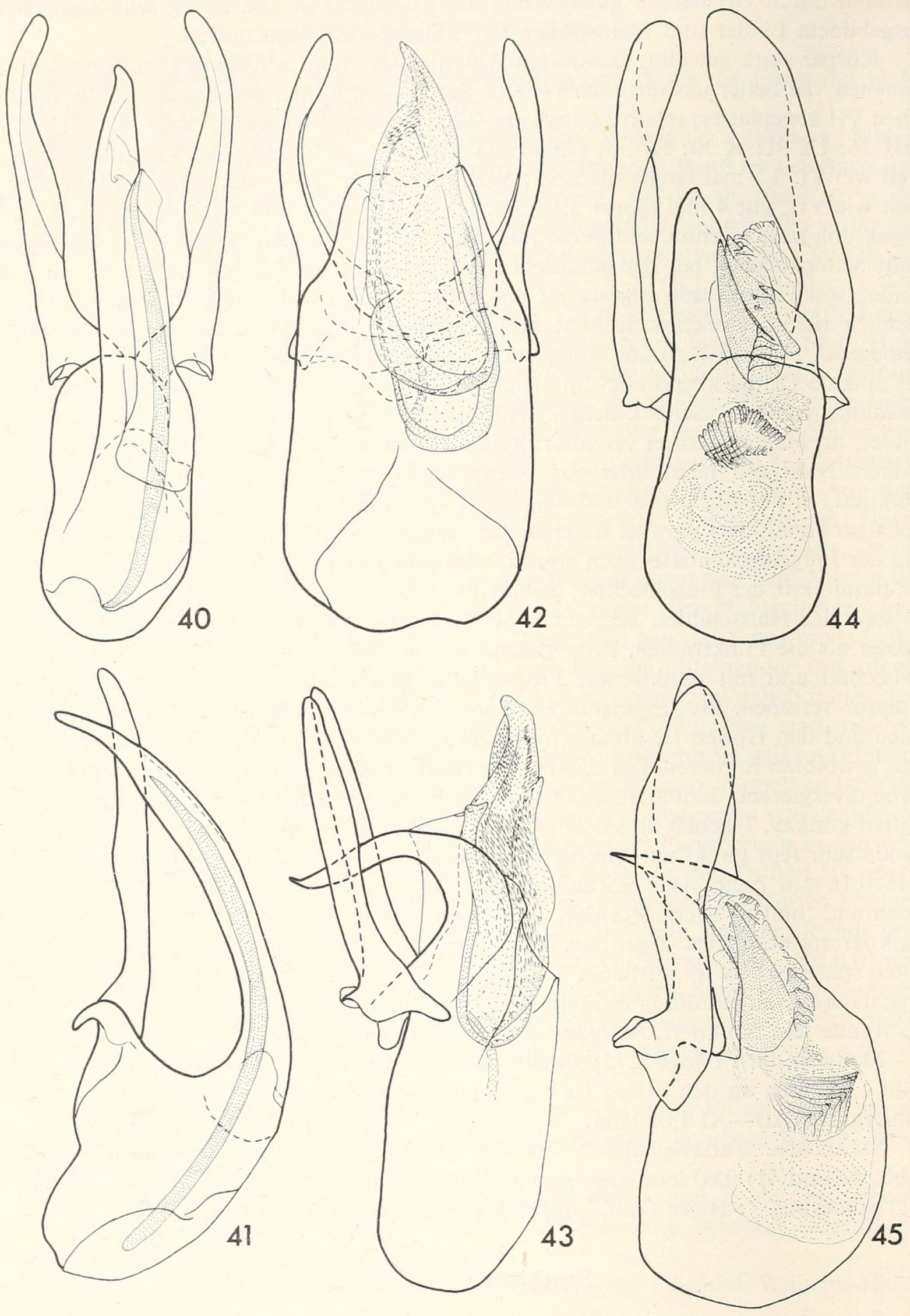

Авв. 40 bis 45 .

Aedoeagi von Scaphisoma bei Dorsal- und Lateralansicht.

40 und 41. triste sp. n., Holotypus; 42 und 43. loriai sp. n., Paratypus von Bujako; 44 und 45. bacchusi sp. n., Paratypus von Budemu. 
VIII 24-25: IX 32-35: X 28-30: XI 37-40; Glied VII etwa 4,5 mal länger als breit; VIII 5 mal länger als breit; XI etwa 5 mal länger als breit. Halsschild etwas kräftiger und deutlich dichter punktiert als bei triste; Seitenkielchen bei Dorsalansicht nicht oder nur kurz vor der Mitte sichtbar; Vorderrand gleichmässig abgerundet; Vorderrandstreifen nur an den Seiten ausgebildet. Spitze des Scutellums freiliegend. Flügeldecken an den Seiten gleichmässig abgerundet; Seitenkielchen bei Dorsalansicht nicht sichtbar oder nur im basalen Drittel bemerkbar; Nahtstreifen verlaufen vorne weiter lateralwärts entlang dem Basalrand als bei triste, enden kurz ausserhalb der Mitte der Basalbreite der Flügeldecken; diskale Punktierung ähnlich wie auf dem Halsschild oder etwas kräftiger und ein wenig spärlicher, ein wenig kräftiger und viel dichter als bei triste, die Punktzwischenräume sind meistens 2-3 mal grösser als die Punktradien. Propygidium und Pygidium querrunzelig mikroskulptiert, ein wenig spärlicher punktiert als der Halsschild. Mes-Epimeren länger als bei triste, deutlich kürzer als der Abstand zwischen ihnen und den Hüften II. Metasternum gleichmässig dicht punktiert; mediodistale Eindrücke breiter, kürzer und weiter voneinander liegend als bei triste. Met-Episterna an der breitesten Stelle etwa $0,14 \mathrm{~mm}$ breit, nach vorne geradlinig verjüngt, innerer Apikalwinkel nur etwas verlängert. Sternite sehr deutlich querrunzelig mikroskulptiert. Sternit I etwas spärlicher und etwas feiner punktiert als das Metasternum; postcoxale Flächen etwa $0,06 \mathrm{~mm}$ lang.

Maße in mm. Länge 1,9-2,0; Basalbreite des Halsschildes 1,17-1,25; Flügeldecken an der Naht 1,19-1,22 lang, an den Seiten 1,30-1,37 lang, zusammen 1,34 1,45 breit; Schienen III 0,75-0,78 lang; Fühlerglieder III-XI 1,10-1,16 lang.

Männchen. Tarsenglieder I-III der Vorderbeine sehr stark, I und II der Mittelbeine deutlich erweitert. Sternit V mit einem Höckerchen in der Mitte, dessen halbrunde Vorderseite steil dekliniert, Hinterseite ab Vorderrand schräg gegen den Apikalrand des Segments dekliniert; in der Nähe des Apikalrandes ist das Höckerchen etwa $0,18 \mathrm{~mm}$ breit. Apex des Sternits VI einfach dreieckig verlängert. Aedoeagus (Abb. 42 und 43) $0,84 \mathrm{~mm}$ lang, stark sklerotisiert.

Holotypus $\widehat{\jmath}$ : Bujako, VIII.1890, leg. L. Loria (Museum Genua).

Paratypen: wie Holotypus 2 oิ ô und 1 क (Museum Genua und Genf).

\section{Scaphisoma bacchusi sp. $n$.}

Habituell der Art viduum Löbl ziemlich ähnlich, von dieser durch den nach vorne weniger stark verjüngten und nicht mikroskulptierten Halsschild verschieden. Nach der Form des Aedoeagus scheint sie nahe loriai zu stehen.

Körper stark gewölbt, einfarbig schwarz, seltener braunschwarz. Fühler ab dem Glied VII abgeplattet; relative Länge der Glieder wie: III 3-4: IV 14-16: V 17-20: VI 17-20: VII 22-23: VIII 16-18: IX 22-25: X 22-25: XI 24-27; Glieder IV-VI sehr schlank, V und VI nur etwas breiter als IV und etwa 6 mal länger als breit; VII etwa 4,5 mal länger als breit; VIII etwa 5 bis fast 6 mal länger als breit; XI etwa 4 mal länger als breit. Halsschild spärlich und sehr fein, bei $\times 25$ Vergrösserung schlecht oder kaum sichtbar punktiert; Seiten gleichmässig abgerundet; Seitenkielchen bei Dorsalansicht mindestens in der basalen Hälfte, öfter der ganzen oder fast der ganzen Länge nach deutlich; Vorderrand im breiten mittleren Teil nur leicht abgerundet oder fast gerade; Vorderrandstreifen nur an den Seiten entwickelt. Spitze des Scutellums freiliegend. Flügeldecken am breitesten nach dem basalen Viertel, danach apikalwärts leicht verjüngt; Seitenrand nach der breitesten Stelle leicht abgerundet oder geradlinig und erst hinten abgerundet; Seitenkielchen kräftig, bei Dorsalansicht meistens der ganzen Länge nach 
sichtbar; Apikalrand breit, gerade abgestutzt; apikaler Innenwinkel liegt hinter dem Niveau der Aussenwinkel; Nahtrand nicht erhaben; Nahtgegend flach, mit einer Reihe sehr feiner Punkte, in der Mitte etwa $0,05 \mathrm{~mm}$ breit; Nahtstreifen seicht, hinten divergierend, sonst nach vorne parallel mit der Naht verlaufend, biegen vorne entlang dem Halsschildlappen nach aussen und verlöschen noch in dessen Nähe; diskale Punktierung überall spärlich und sehr fein, nur ein wenig deutlicher als auf dem Halsschild, die Punktzwischenräume sind meistens 5-8 mal grösser als die Punktradien. Pygidium mässig dicht und fein punktiert, mit einer kaum wahrnehmbaren punktierten Mikroskulptur versehen. Mes-Epimeren deutlich länger als der Abstand zwischen ihnen und den Hüften II. Metasternum überall sehr fein, an den Seiten spärlich, im kaum gewölbten mittleren Teil dichter punktiert; ohne mediodistale Eindrücke, dagegen hinten flach eingedrückt; Apikalrand zwischen den Hüften gerade. Flächen hinter den Coxalkavitäten II höchstens 0,04 mm lang, am Rande sehr dicht und tief punktiert. Met-Episterna leicht gewölbt oder fast flach, an der breitesten Stelle, hinten, 0,09-0,12 $\mathrm{mm}$ breit, nach vorne mässig verjüngt, mit fast geradlinigem Innenrand. Sternit I ohne bemerkbare Mikroskulptur $(\times 100)$, folgende Sternite mit kaum wahrnehmbarer punktierter Mikroskulptur. Sternit I spärlich und sehr fein punktiert; postcoxale Flächen höchstens 0,03 mm lang, nach aussen allmählich verjüngt, am Rande sehr dicht und tief punktiert. Schienen schlank, gerade.

Maße in mm: Länge 1,35-1,5; Basalbreite des Halsschildes 0,80-0,93; Flügeldecken an der Naht 0,82 - 0,95 lang, an den Seiten 0,85-0,99 lang, zusammen 0,93-1,05 breit; Schienen III 0,42-0,50 lang; Fühlerglieder III-XI 0,72-0,79 lang.

Männchen. Tarsenglieder I-III der Vorderbeine und I und II der Mittelbeine stark, III der Mittelbeine leichter erweitert. Apikallappen des Sternits VI 0,08-0,10 mm lang, Einbuchtungen des Apikalrandes 0,02-0,04 mm tief. Aedoeagus (Abb. 44 und 45) 0,69-0,74 mm lang, stark sklerotisiert.

Holotypus ô: Madang Dist., Finisterre Mts. Budemu c. 4000 ft., 15-24.X.1964 (Stn. No. 66), leg. M. E. Bacchus (British Museum, London).

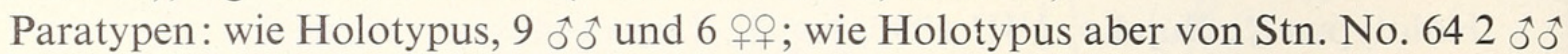
und von Stn. No. 511 ô und 2 우 (British Museum, London und Museum, Genf); E. Highland Dist., Mt. Michael, 18.XII.1964, 1 ô leg. R. H. Hornabrook (British Museum, London); Wau, Mc.Adam park, 18-21.IV.1965, 1 ô leg. J. Balogh und J. J. Szent-Ivány (Museum Budapest).

\section{Scaphisoma ornatipenne sp. $\mathrm{n}$.}

Diese isoliert stehende Art ist durch die Färbung der Flügeldecken und durch die Form des Aedoeagus sehr gut charakterisiert.

Körper ziemlich stark gewölbt, hell braun (das einzige vorliegende Exemplar ist nicht ganz ausgefärbt, normalweise dürfte die Färbung wahrscheinlich dunkelbraun sein). Flügeldecken an der Basis, an der Nahtgegend, an einem queren Band knapp vor den Apizes, im mittleren Teil und an den Pseudoepipleuren wie der Halsschild braun oder ein wenig heller, sonst gelb (Abb. 46). Fühler ab dem Glied VI abgeplattet; relative Länge der Glieder wie: III 6 : IV 20 : V 25 : VI 28 : VII 31 : VIII 30 : IX 33 : X 30 : XI 30; Glieder IV und V 5 mal länger als breit, VI, VII und XI je etwa 4 mal länger als breit. Halsschild dicht und fein, bei $\times 25$ Vergrösserung ziemlich gut sichtbar punktiert; Seitenrand und Vorderrand gleichmässig abgerundet; Seitenkielchen bei Dorsalansicht der ganzen Länge nach deutlich; Vorderrandstreifen nur an den Seiten entwickelt, jedoch relativ weit nach innen verlaufend. Spitze des Scutellums freiliegend. 
Flügeldecken im basalen Sechstel erweitert, von der breitesten Stelle etwa gegen die Mitte der Seitenlänge fast geradlinig und sehr leicht verjüngt, nach der Mitte deutlicher abgerundet verjüngt; Seitenkielchen kräftig, abgesehen von dem apikalen Sechstel, der ganzen Länge nach deutlich; Apikalrand gerade abgestutzt; apikaler Innenwinkel liegt etwa im Niveau der Aussenwinkel; Nahtrand nach dem basalen Drittel leicht erhaben; Nahtgegend flach, sehr dicht und irregulär punktiert, in der Mitte gut 0,05 mm breit; Nahtstreifen mässig tief, hinten leicht divergierend, überwiegend parallel miteinander verlaufend, biegen vorne entlang dem Halsschildlappen nach aussen, verlöschen knapp hinter dem Basalrande der Flügeldecken neben dem Halsschildlappen; diskale Punktierung dicht, kräftiger als auf dem Halsschild, aber seicht und fein, nur hinten ziemlich grob, die Punktzwischenräume sind meist 1,5-2 mal grösser, hinten etwa so gross oder kleiner als die Punktradien. Pygidium querrunzelig mikroskulptiert, äusserst fein punktiert. Mes-Epimeren so lang wie der Abstand zwischen ihnen und den Hüften II.

Авв. 46 und 47.

46. Scaphisoma ornatipennes p. n., Flügeldecke;

47. Scaphisoma blandum sp. n., Flügeldecke.
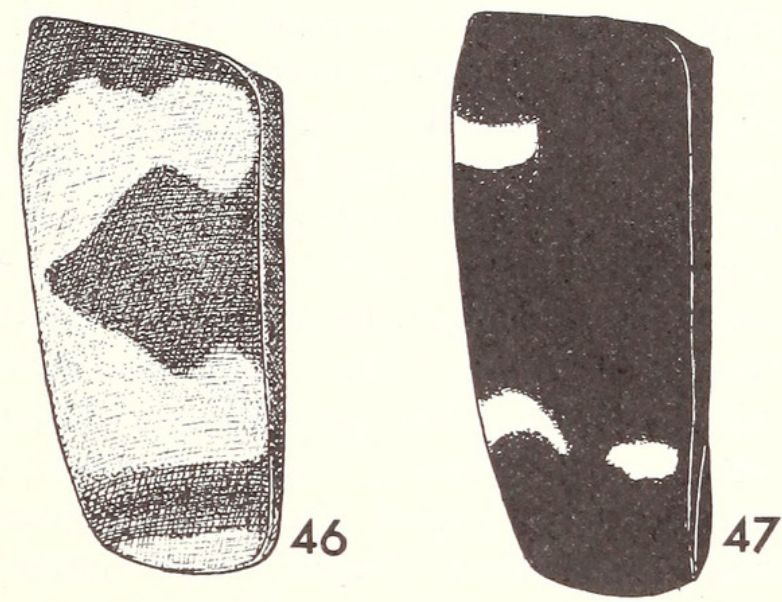

Metasternum überall querrunzelig mikroskulptiert, sehr fein und ziemlich spärlich punktiert, im mittleren Teil fast flach, mit nur angedeuteten mediodistalen Eindrücken; Apikalrand zwischen den Hüften gerade. Flächen hinter den Coxalkavitäten II etwa $0,04 \mathrm{~mm}$ lang. Met-Episterna flach, an der breitesten Stelle, hinten, 0,09 $\mathrm{mm}$ breit, nach vorne deutlich, zum inneren Apikalwinkel leicht verjüngt; Innenrand in den hinteren 3/5 und am Vorderwinkel konvex abgerundet, dazwischen gerade. Sternite querrunzelig mikroskulptiert und sehr fein punktiert. Postcoxale Flächen des Sternits I $0,06 \mathrm{~mm}$ lang, nach aussen geradlinig verjüngt, gegen die Spitze der Met-Epimeren reichend, am Rande dicht und kräftig punktiert. Schienen ziemlich dick, I und III leicht, II stärker gebogen.

Maße in mm: Länge 1,75; Basalbreite des Halsschildes 1,02; Flügeldecken an der Naht 1,04 lang, an den Seiten 1,19 lang, zusammen 1,19 breit; Schienen III 0,65 lang, Fühlerglieder III-XI 1,12 lang.

Männchen. Tarsenglieder I-III der Vorderbeine stark, der Mittelbeine mässig erweitert. Apex des Sternits VI einfach dreieckig verlängert. Aedoeagus (Abb. 48 und 49) 0,69 mm lang, ziemlich stark sklerotisiert.

Holotypus ô: Wau, Mc. Adam park, 18-21.IV.1965, leg. J. Balogh und J. J. SzentIvány (Museum Budapest).

Scaphisoma blandum sp. n.

In der Körperform an die Art sapitense Pic erinnernd, jedoch stärker gewölbt, ganz anders gefärbt und auch durch den abgerundeten, nicht spitzig verlängerten inneren 
Apikalwinkel der Flügeldecken deutlich abweichend. Durch die Form des Aedoeagus steht diese neue Art eher nahe den Arten der unicolor-Gruppe.

Körper stark gewölbt. Kopf und Halsschild schwarz. Flügeldecken braunschwarz, mit je einem kleinen queren gelben subhumeralen Band, das in der äusseren Hälfte des Diskus liegt, aber den Seitenstreifen nicht berührt, und mit je zwei gelben subapikalen Flecken, wovon der äussere quer, grösser und nach innen verjüngt, der innere kleiner und leicht quer ist (Abb. 47). Fühler ab dem Glied VII abgeplattet; relative Länge der Glieder wie: III 10 : IV 22 : V 28 : VI 26 : VII 31 : VIII 28 : IX 32 : X 30 : XI 31; Glied III sehr auffällig, an der Basis normal schlank, nach der Basis plötzlich nach innen stark erweitert, in der Mitte etwa so breit wie V oder VI, danach apikalwärts leicht verjüngt; V deutlich breiter als IV jedoch sehr schlank und etwa 7 mal länger als breit; VI etwas breiter als V und etwa 5 mal länger als breit; VII ein wenig mehr als 3 mal länger als breit, fast doppelt so breit wie VI; VIII breiter als VI, fast 5 mal länger als breit; XI so breit wie VII. Halsschild ziemlich dicht und sehr fein, bei $\times 25$ Vergrösserung schlecht sichtbar punktiert; Seiten gleichmässig abgerundet; Seitenkielchen bei Dorsalansicht nicht bemerkbar; Vorderrand, ausser in der Nähe der Winkel, gerade abgestutzt; Vorderrandstreifen nur an den Seiten kurz entwickelt. Spitze des Scutellums freiliegend. Flügeldecken am breitesten knapp nach dem basalen Viertel, von dort gegen das apikale Drittel leicht abgerundet, im apikalen Drittel geradlinig verjüngt; Seitenkielchen bei Dorsalansicht nur im basalen Viertel bemerkbar; Diskus im apikalen Viertel leicht verflacht; Apikalrand fast gerade abgestutzt; innerer Apikalwinkel liegt hinter dem Niveau der Aussenwinkel; Nahtrand leicht erhaben; Nahtgegend flach, sehr fein punktiert, in der Mitte fast 0,06 mm breit, hinten stark verjüngt, dagegen der untere Nahtrand relativ stark erweitert; Nahtstreifen sehr seicht, nicht punktiert, ab dem Apex fast bis zum mittleren Drittel abgerundet konvergierend, danach nach vorne parallel miteinander verlaufend, biegen vorne knapp entlang dem Halsschildlappen nach aussen und verlöschen in seiner Nähe; diskale Punktierung überwiegend spärlich und sehr fein, nicht viel deutlicher als jene des Halsschildes, hinten viel kräftiger und dichter, die Punktzwischenräume dort etwa 2-3 mal grösser, sonst meist 6-9 mal grösser als die Punktradien. Pygidium mit punktierter Mikroskulptur, normale Punktierung fein bis sehr fein. Mes-Epimeren etwa so lang wie der Abstand zwischen ihnen und den Hüften II. Metasternum ohne Mikroskulptur, überall sehr fein, an den Seiten spärlich, am schmalen, gewölbten mittleren Teil dichter punktiert; ohne mediodistale Eindrücke; Apikalrand zwischen den Hüften gerade. Flächen hinter den Coxalkavitäten II kaum 0,04 mm lang. Met-Episterna fast flach, im vorderen Drittel etwa 0,08 $\mathrm{mm}$ breit, nach der Mitte erweitert, an der breitesten Stelle 0,13 mm breit; innerer Apikalwinkel entlang dem Met-Epimerum stark verlängert, Innenrand konkav abgerundet. Sternite mit deutlicher, punktierter Mikroskulptur. Sternit I dichter und ein wenig kräftiger punktiert als das Metasternum; postcoxale Flächen gleichmässig schmal, etwa $0,03 \mathrm{~mm}$ lang, nach aussen bis zum Seitenrand des Segments reichend, am Rande fein punktiert. Hüften auffällig nahe aneinander liegend, der kleinste Abstand zwischen den Hüften II, sowie zwischen den Hüften III, nur $0,15 \mathrm{~mm}$ gross. Schienen gerade, ziemlich kräftig.

Maße in mm: Länge 2,25; Basalbreite des Halsschildes 1,33; Flügeldecken an der Naht 1,54 lang, an den Seiten 1,58 lang, zusammen 1,46 breit; Schienen III 0,83 lang; Fühlerglieder III-XI 1,12 lang.

Männchen. Tarsenglieder I-III der Vorderbeine leicht erweitert. Sternit VI mit breitem und kurzem Apikallappen, sein Apikalrand ohne Einbuchtungen. Aedoeagus (Abb. 50 und 51) 0,84 mm lang, ziemlich stark sklerotisiert.

Holotypus ô: Mt. Kaindi, 2400 m, 15-16.IV.1965, leg. J. Balogh und J. J. SzentIvány (Museum Budapest). 

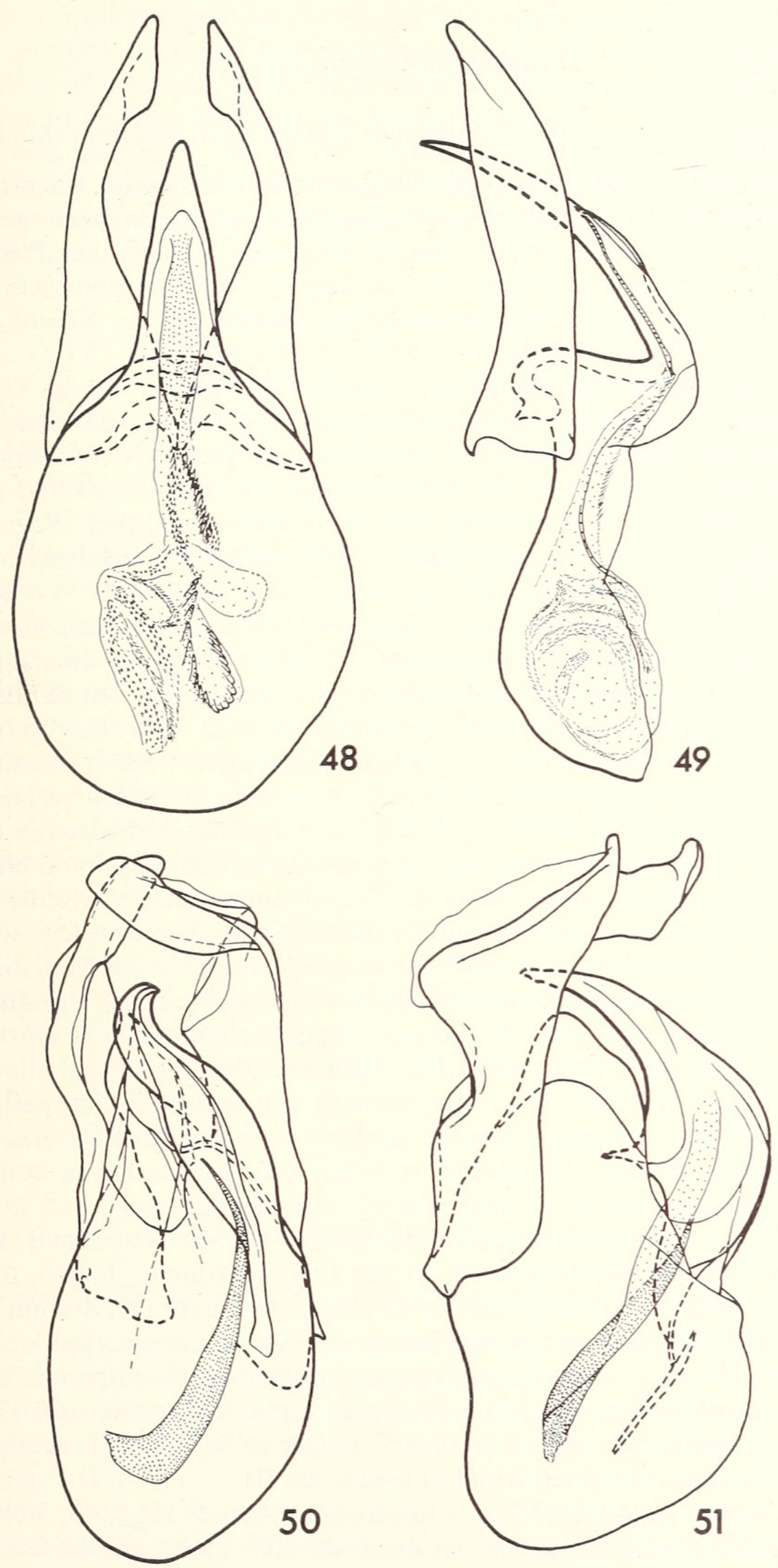

Авв. 48 bis 51.

Aedoeagi von Scaphisoma bei Dorsal- und Lateralansicht.

48 und 49. ornatipenne sp. n., Holotypus; 50 und 51. blandum sp. n., Holotypus. 


\section{Scaphisoma unifasciatum Pic}

Scaphosoma unifasciatum PIC, 1956: 72; Holotypus + : Huon Golf, Sattelberg (Museum Budapest)

Körper robust, ziemlich stark gewölbt, dunkel rötlichbraun bis rötlich schwarzbraun. Flügeldecken mit je einem grossen, queren, scharf abgegrenzten gelbbraunen bis fast gelben und mehr oder weniger durchscheinenden subapikalen Fleck. Dieser ist etwa doppelt so breit wie lang und etwa so lang wie der Abstand zwischen ihm und dem Apex der Flügeldecken. Fühler sehr lang, Glieder IV bis XI auffällig schlank; relative Länge der Glieder wie: III 6-8 : IV 22-30 : V 27-35 : VI 23-32 : VII 3237 : VIII 24-30 : IX 35-43 : X 32-37 : XI 33-42; Glieder V und VI etwas breiter als IV; VII und VIII am Ende stark verjüngt und dort etwa so breit wie IV, VII etwa 4,5 mal länger als breit, VIII 4,5-5,5 mal länger als breit; IX-XI ähnlich breit wie VII, XI besonders variabel gross, 4-5,5 mal länger als breit. Halsschild ziemlich dicht und sehr fein, bei $\times 25$ Vergrösserung schlecht sichtbar punktiert; Seiten nach vorne stark abgerundet verjüngt; Seitenkielchen kräftig und bei Dorsalansicht der ganzen Länge nach deutlich; Vorderrand gleichmässig konvex abgerundet; Vorderrandstreifen nur an den Seiten, aber ziemlich lang entwickelt. Distalteil des Scutellums freiliegend. Flügeldecken am breitesten nach dem basalen Drittel; Seiten gleichmässig abgerundet, nach hinten mässig verjüngt; Seitenkielchen sehr kräftig, bei Dorsalansicht bis zum oder fast bis zum Apex sichtbar; Apikalrand gerade oder fast gerade; apikaler Innenwinkel liegt etwas vor oder im Niveau der Aussenwinkel; Nahtrand deutlich erhaben; Nahtgegend in der Mitte 0,09-0,10 $\mathrm{mm}$ breit, entlang dem Nahtrand eingedrückt, mit einer spärlichen Reihe ziemlich feiner Punkte; Nahtstreifen tief, verlaufen parallel mit der Naht, biegen vorne nach aussen entlang dem Basalrand bis zu der Mitte der Basalbreite der Flügeldecken; Seitenstreifen mit einer spärlichen Reihe tiefer Punkte; diskale Punktierung ausgesprochen fein in der Nähe der Nahtstreifen, sonst irregulär, überwiegend grob und dicht, auch bei $\times 10$ Vergrösserung sehr deutlich, die Punktradien sind meist kleiner als die Punktzwischenräume. Propygidium und Pygidium mit punktierter Mikroskulptur versehen, die normale Punktierung ziemlich spärlich und fein, deutlicher als jene des Halsschildes. Mes-Epimeren deutlich länger als der Abstand zwischen ihnen und den Hüften II. Metasternum sehr fein und sehr spärlich punktiert; sein Medianteil vorne gewölbt, mit einer Medianfurche, die hinten in den tiefen mediodistalen Eindruck mündet; Distalrand zwischen den Hüften etwas konkav. Flächen hinter den Coxalkavitäten II schmal, am kantigen Rande dicht und grob punktiert, diese Punkte gehen bis zur mes-epimeren Spitze. Met-Episterna und Met-Epimeren gross und gewölbt, die Met-Episterna an der breitesten Stelle, hinten, 0,17-0,20 mm breit, von dort nach vorne fast geradlinig verjüngt; Innennaht tief, nur am Vorderwinkel abgerundet. Met-Epimeren ein wenig breiter als die Episterna, ihr kleiner Innenteil flach, vom gewölbten Aussenteil durch einen Längseindruck getrennt. Sternit I kaum bemerkbar mikroskulptiert, spärlich und sehr fein punktiert; postcoxale Flächen gleichmässig schmal, am Rande gröber punktiert. Folgende Sternite mit deutlicherer, punktierter Mikroskulptur. Schienen I und II dicker ais III.

Maße in mm: Länge 1,8-2,3 (mit Kopf und Abdomen bis 2,95); Halsschild an der Basis 1,13-1,40 breit; Flügeldecken an der Naht 1,06-1,40, an den Seiten 1,24-1,60 lang, zusammen 1,29-1,62 breit; Schienen III 0,68-0,98 lang; Fühlerglieder III-XI $1,05-1,31$ lang.

Männchen. Körper durchschnittlich robuster. Tarsenglieder I-III der Vorder- und Mittelbeine ziemlich stark erweitert. Schienen III etwas gebogen. Apikalrand des Pro- 
pygidiums gewellt. Apikallappen des Sternits VI 0,18 - 0,20 mm lang, die Einbuchtungen des Apikairandes 0,09-0,10 mm tief. Aedoeagus (Abb. 52-54) 1,41-1,52 mm lang, stark sklerotisiert, asymmetrisch, mit ungewöhnlich grosser Basalkapsel, mit Öffnung rechts vom schräg gestellten Distalteil des Medianlobus.

Weibchen. Tarsenglieder I-III der Vorder- und Mittelbeine leicht erweitert. Schienen III gerade. Apikalrand des Propygidiums einfach abgerundet oder gewellt.

Untersuchtes Material: Huon Golf, Sattelberg, 15 Ex. leg. L. Biró (Museum Budapest, Paris und Genf).

\section{Scaphisoma unimaculatum sp. $\mathrm{n}$.}

Nahe verwandt und sehr ähnlich der Art unifasciatum, in folgenden äusserlichen Merkmalen abweichend: Körper etwas stärker gewölbt, dunkler braunschwarz bis schwarz, die rötlichbraunen Flecken auf den Flügeldecken kleiner, irregulär rundlich; relative Länge der Fühlerglieder bei + wie: III 6 : IV 25 : V 35 : VI 30 : VII 35 : VIII 26 : IX 32 : X 31 : XI 35, bei ô wie: III 6 : IV 24 : V 36 : VI 34 : VII 38, danach Fühler abgebrochen; Flügeldecken gleichmässiger, spärlicher und viel feiner punktiert, die Punktzwischenräume sind meist 3-5 mal grösser als die Punktradien; Seitenkielchen der Flügeldecken bei Dorsalansicht hinten nicht sichtbar, Nahtrand nicht erhaben; Mes-Epimeren so lang wie der Abstand zwischen ihnen und den Hüften II; Met-Episterna leichter gewölbt, an der breitesten Stelle $0,18 \mathrm{~mm}$ breit, ihr Innenrand nach der Mitte kaum konkav, am apikalen Innenwinkel konvex abgerundet, vorne geradlinig; Schienen III in beiden Geschlechtern etwas gebogen.

$\mathrm{Maße}$ in $\mathrm{mm}$ : Länge 2,2-2,35; Basalbreite des Halsschildes 1,37-1,49; Flügeldecken an der Naht 1,37-1,49 lang. an den Seiten 1,48-1,60 lang, zusammen 1,521,75 breit; Schienen III 0,84 - 0,98 lang; Fühlerglieder III-XI bei $q$ 1,13 lang (bei ô wahrscheinlich länger).

Männchen. Sekundäre Geschlechtsmerkmale wie bei unifasciatum. Aedoeagus (Abb. 55-57) 1,67 mm lang, stark sklerotisiert, durch die Form des Medianlobus und der Parameren sowie durch die kräftigen Zähnchen des Innensackes deutlich von dem der Art unifasciatum verschieden.

Holotypus ơ: „,Papua: Kokoda. 1,200 ft. VIII.1933. L. E. Cheesman. B. M. 1933577.“ (British Museum, London).

Paratypen: wie Holotypus, 2 우 (British Museum, London und Museum Genf).

\section{Scaphisoma quadripunctatum (Pic), comb. nov.}

Amalocera quadripunctata PIC, 1956: 72; Holotypus ỗ : Astrolabe Bai, Erima (Museum Budapest)

In der Form des Körpers der Arten unifasciatum und unimaculatum ähnlich, besonders mit unifasciatum in vielen Merkmalen übereinstimmend.

Durchschnittlich kleiner als unifasciatum. Flügeldecken mit je zwei hellen, durchscheinenden, queren Flecken, sonst Färbung wie bei unifasciatum. Relative Länge der Fühlerglieder wie: III 5 : IV 20 : V 28-29 : VI 27-28 : VII 28-31 : VIII 21-22 : IX 28-29 : X 25-27 : XI 26-28. Seitenkielchen des Halsschildes vorne nicht sichtbar, sonst Halsschild sehr ähnlich wie bei unifasciatum. Flügeldecken ähnlich punktiert wie bei unimaculatum, die diskale Punktierung nut etwas kräftiger als jene des Halsschildes; Nahtrand nicht erhaben; Nahtstreifen verlaufen vorne entlang dem Basalrand bis an die Seiten und sind mit den Seitenstreifen verbunden; Seitenstreifen nicht punktiert; innerer Apikalwinkel liegt im oder etwas hinter dem Niveau der Aussen- 

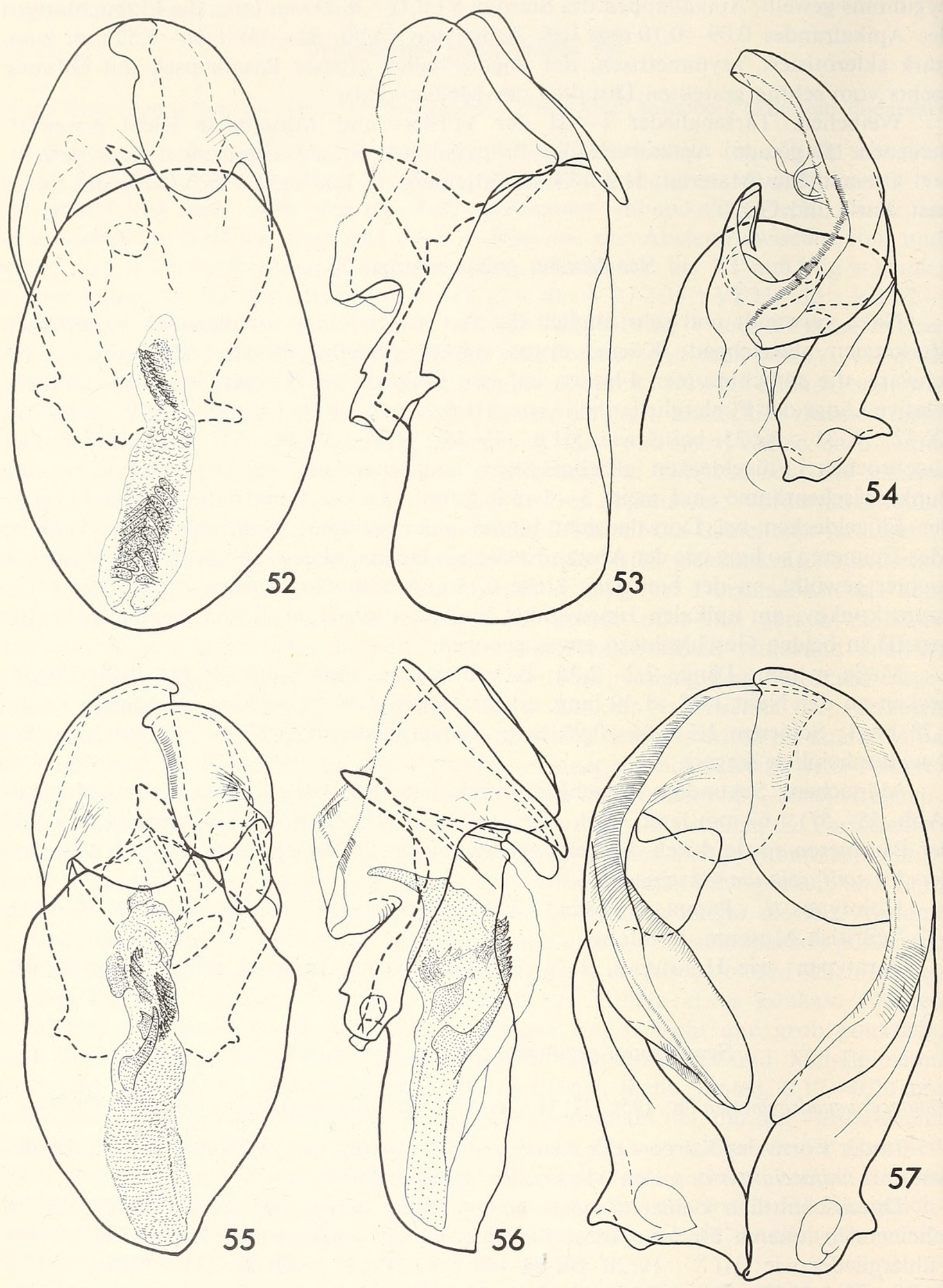

Авв. 52 bis 57.

Aedoeagi von Scaphisoma.

52 bis 54. unifasciatum Pic., Paratypus von Sattelberg; 52. Dorsalansicht; 53. Lateralansicht; 54. Medianlobus ohne proximalen Teil, mit der rechten Paramere, Ventralansicht; 55 bis 57. unimaculatum sp. n., Holotypus; 55. Dorsalansicht; 56. Lateralansicht; 57. Parameren bei Ventralansicht, doppelte Vergrösserung. 
winkel. Mes-Epimeren kürzer als der Abstand zwischen ihnen und den Hüften II. Der flach eingedrückte mediodistale Teil des Metasternums durch drei Grübchen abgegrenzt, davon ist das mittlere grösser, liegt vor dem Niveau der seitlichen und ist mit einer feinen Medianfurche verbunden. Met-Episterna kleiner als bei unifasciatum, an der breitesten Stelle $0,13 \mathrm{~mm}$ breit. Schienen III schlanker als I oder II und gerade.

$\mathrm{Maße}$ in mm: Länge 1,85-1,95; Basalbreite des Halsschildes 1,15-1,22; Flügeldecken an der Naht 1,13-1,20 lang, an den Seiten 1,24-1,32 lang, zusammen 1,281,36 breit; Schienen III 0,67-0,72 lang; Fühlerglieder III-XI 0,94-0,98 lang.

Männchen. Tarsenglieder I und II der Vorder- und Mittelbeine sehr stark, III leichter erweitert; I etwa so breit wie die Schiene. Sternit VI kleiner als bei unifasciatum, sein Medianlappen etwa 0,13 mm lang, die Einbuchtungen des Apikalrandes 0,06 mm tief. Aedoeagus (Abb. 58 und 59) 0,92-1,05 mm lang, stark sklerotisiert.

Untersuchtes Material: Astrolabe Bai, Erima, 3 Ex; Astrolabe Bai, FriedrichWilhems-Hafen, 2 Ex.; Huon Golf, Sattelberg, 2 Ex. Alles leg. L. Biró (Museum Budapest, Paris und Genf).

\section{Scaphisoma audax sp. n.}

Unter den Paratypen von quadripunctatum fielen einige kleinere und etwas heller gefärbte Exemplare auf. Eine nähere Untersuchung zeigte, dass sie eine distinkte Art repräsentieren.

Nahe verwandt mit quadripunctatum und dieser täuschend ähnlich. Abgesehen von der Körpergrösse und Färbung unterscheidet sich diese Art in den ektoskelettalen Merkmalen von quadripunctatum noch durch feinere Punktierung der Oberseite, besonders der Flügeldecken, durch die Ausbildung der Fühler, durch kleinere Mes-Epimeren, die viel kürzer sind als der Abstand zwischen ihnen und den Hüften II (Index 13:32), durch das Fehlen der metasternalen Medianfurche, durch weiter lateralwärts reichende Reihe grober Punkte am Vorderrand des Metasternums und durch den Sternit I ohne bemerkbarer Mikroskulptur.

Relative Länge der Fühlerglieder wie: III 5 : IV 15-17 : V 24-26 : VI 21-26 : VII 25-27 : VIII 16-22 : IX 23-27:X 23-25: XI 22-27.

Maße in mm: Länge 1,55-1,75; Basalbreite des Halsschildes 1,0-1,10; Flügeldecken an der Naht 0,97-1,10 lang, an den Seiten 1,06-1,19 lang, zusammen 1,10-1,23 breit; Schienen III 0,56-0,64 lang; Fühlerglieder III-XI 0,78-0,92 lang.

Männchen. Tarsenglieder I-III der Vorder-und Mittelbeine deutlich schmaler als bei quadripunctatum, jedoch ausgesprochen breit. Apikallappen des Sternits VI 0,08$0,09 \mathrm{~mm}$ lang, die Einbuchtungen des Apikalrandes etwa 0,04 mm tief. Aedoeagus (Abb. 60 und 61) 0,60-0,66 mm lang, stark sklerotisiert.

Holotypus ô: Huon Golf, Simbang, leg. L. Biró (Museum Budapest).

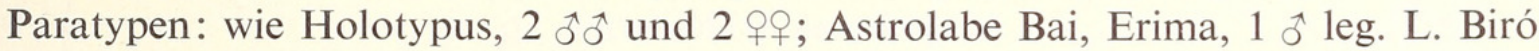
(Museum Budapest, Paris und Genf).

\section{Scaphisoma beccarii $\mathrm{sp}$. $\mathrm{n}$.}

Gehört in die Gruppe haemorrhoidale, habituell ähnlich der Art modiglianii Pic, aber schlanker, heller gefärbt und durch die Form der Nahtstreifen und Nahtgegend der Flügeldecken auffallend abweichend.

Körper mässig gewölbt, einfarbig braun oder dunkelbraun, Flügeldecken etwas durchscheinend. Fühler ab dem Glied VI abgeplattet; relative Länge der Glieder wie: 
III 6-7 : IV 14-15: V 23-25 : VI 20-21 : VII 25-26 : VIII 19-20 : IX 25-27 X 24-26 : XI 37-41; Glied V deutlich breiter als IV, gut 5 mal länger als breit; VI 4 mal länger als breit; VII etwa 3,5 mal länger als breit; VIII breiter als VI, 3 mal länger als breit; XI etwa 5 mal länger als breit. Halsschild dicht, relativ seicht und fein, bei $\times 12$ Vergrösserung schon bemerkbar punktiert; Seiten leicht abgerundet; Seitenkielchen bei Dorsalansicht der ganzen Länge nach oder fast der ganzen Länge nach, ausser in der Nähe der Basalwinkel, sichtbar; Vorderrand gleichmässig leicht konvex; Vorderrandstreifen nur an den Seiten entwickelt. Distalteil oder nur die Spitze des Scutellums freiliegend. Flügeldecken am breitesten knapp nach dem basalen Drittel; Seiten fast gleichmässig abgerundet; Seitenkielchen bei Dorsalansicht der ganzen Länge nach sichtbar; Apikalrand abgerundet; apikaler Innenwinkel liegt im Niveau der Aussenwinkel; Nahtrand erhaben; Nahtgegend flach, mit einer dichten Punktreihe, in der Mitte 0,06-0,07 $\mathrm{mm}$ breit; Nahtstreifen ziemlich seicht, verlaufen nach vorne kaum divergierend, biegen vorne etwas nach aussen, verlöschen noch hinter dem Halsschildlappen; diskale Punktierung dicht, viel kräftiger als auf dem Halsschild, die Punktzwischenräume sind meistens so gross bis doppelt so gross wie die Punktradien. Propygidium und Pygidium querrunzelig mikroskulptiert und äusserst fein punktiert. Metasternum und Sternite querrunzelig mikroskulptiert. Metasternum im mittleren Teil deutlich gewölbt, hinten, besonders in den sehr seichten mediodistalen Eindrücken, sehr dicht und ziemlich kräftig punktiert, einige gröbere Punkte sind noch auf der Fläche zwischen den Hüften II und III; Apikalrand zwischen den Hüften gerade. Metasternalseiten mit je einer sehr dichten Punktreihe vor den Hüften III, sonst ziemlich spärlich und sehr fein punktiert. Flächen hinter den Coxalkavitäten II fast 0,05 mm lang, am Rande spärlich und tief punktiert. Met-Episterna gross, an der breitesten Stelle, hinten, etwa 0,14 mm breit, nach vorne geradlinig verjüngt, Innenrand nur an den Winkeln abgerundet. Sternit I sehr fein punktiert; postcoxale Flächen gut 0,06 mm lang, am Rande spärlich und tief punktiert. Schienen gerade und schlank.

Maße in mm: Länge 1,5-1,65; Basalbreite des Halsschildes 0,89-0,95; Flügeldecken an der Naht 0,93-1,02 lang, an den Seiten 1,02-1,11 lang, zusammen 1,011,10 breit; Schienen III 0,54 - 0,57 lang; Fühlerglieder III-XI 0,88-0,94 lang.

Männchen. Tarsenglieder I-III der Vorderbeine ziemlich stark, die der Mittelbeine deutlich erweitert. Apex des Sternits V in der Mitte verlängert und mit drei winzigen Zähnchen versehen. Apikallappen des Sternits VI dreieckig, 0,05-0,06 mm lang, die Einbuchtungen des Apikalrandes etwa 0,02 mm tief. Aedoeagus (Abb. 62 und 63) $0,40-0,42 \mathrm{~mm}$ lang, ziemlich stark sklerotisiert.

Holotypus đ̊: Hatam, VII.1875, leg. O. Beccari (Museum Genua).

Paratypen: wie Holotypus, 1 ô und 2 우 (Museum Genua und Genf).

\section{Scaphisoma tridentatum sp. $\mathrm{n}$.}

Offenbar nahe verwandt der Art beccarii, aber viel kleiner, anders gefärbt und durch die Ausbildung der Fühler stark abweichend.

Körper mässig gewölbt, hellbraun oder gelbiaun, Kopf manchmal ein wenig verdunkelt. Flügeldecken an der Basis dunkelbraun, ein dunkelbrauner irregulär rundlicher Fleck noch kurz vor dem Apex (es liegen auch einfärbig gelbraune Exemplare vor, diese sind aber nicht ausgefärbt). Das dunkle Basalband ist in der äusseren Hälfte der Flügeldecken sehr schmal, gegen die Naht verlängert, an der Naht bis zu 0,2 mm lang. Fühler ab dem Glied VI abgeplattet; relative Länge der Glieder wie: III 6 : IV 11 : V 16-17 : VI 17-18 : VII 22-23: VIII 17-19: IX 22-24:X 21-23:XI 26-28; Glied V 

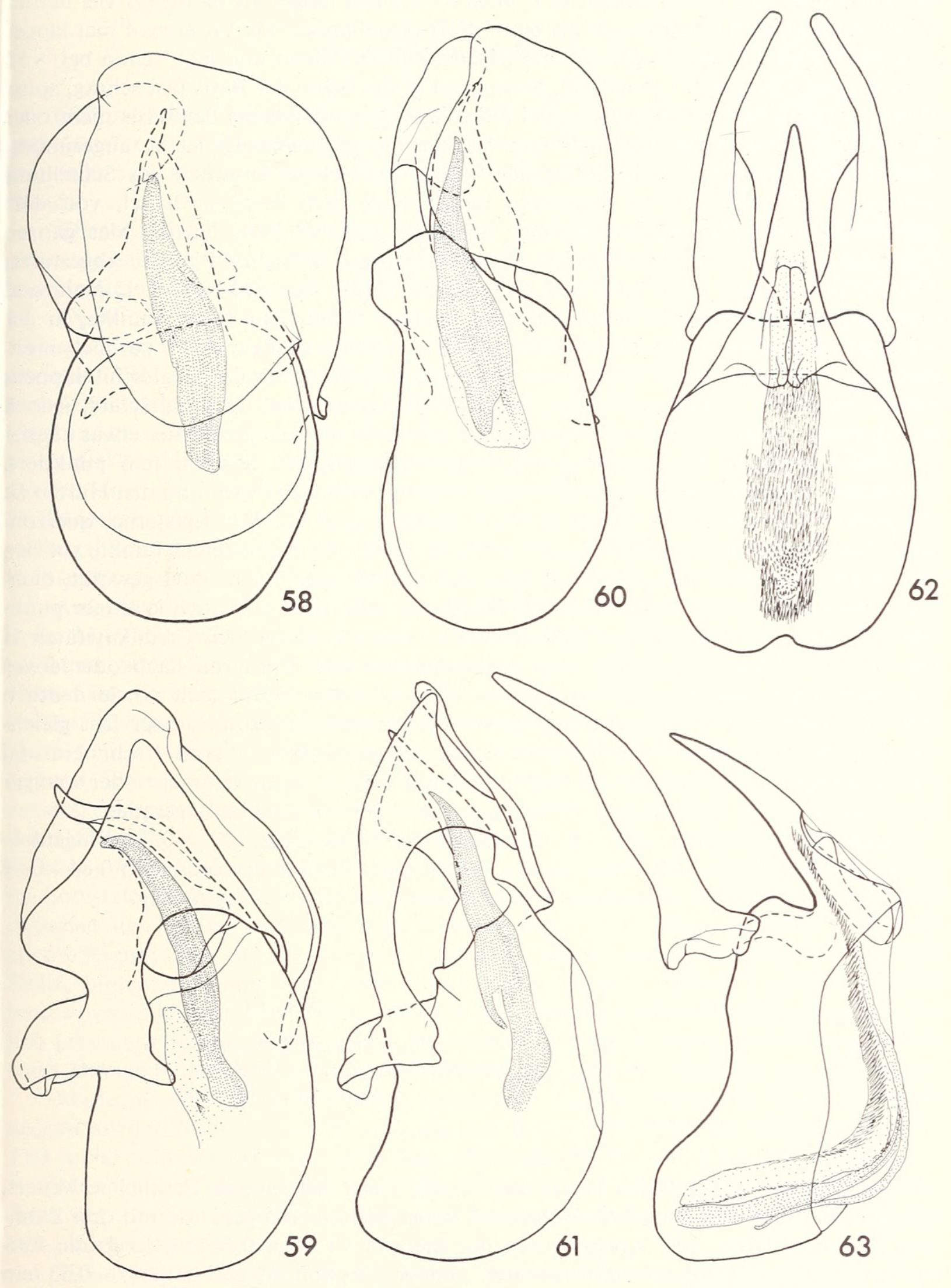

Авв. 58 bis 63.

Aedoeagi von Scaphisoma bei Dorsal- und Lateralansicht.

58 und 59. quadripunctatum (Pic), Paratypus von Erima; 60 und 61. audax sp. n., Holotypus; 62 und 63. beccarii sp. n., Paratypus von Hatam. 
deutlich breiter als IV; VI breiter als V, etwa 4 -4,5 mal länger als breit; VII viel breiter als VI, nicht ganz 3,5 mal länger als breit; VIII etwas breiter als VI, etwa 4 mal länger als breit; XI etwa 4 mal länger als breit. Halsschild sehr dicht und fein, schon bei $\times 12$ Vergrösserung bemerkbar punktiert; Seitenrand in der Nähe der Basis fast schräg, sonst deutlich abgerundet; Seitenkielchen bei Dorsalansicht in der Nähe der Basis nicht oder kaum bemerkbar, sonst gut sichtbar; Vorderrand gleichmässig leicht abgerundet; Vorderrandstreifen nur in der Nähe der Winkel entwickelt. Distalteil des Scutellums freiliegend. Flügeldecken am breitesten knapp nach dem basalen Drittel, von dort apikalwärts leicht abgerundet verjüngt; Seitenkielchen bei Dorsalansicht der ganzen Länge nach oder fast der ganzen Länge nach sichtbar; Apikalrand gerade abgestutzt; apikaler Innenwinkel liegt ein wenig hinter dem Niveau der Aussenwinkel; Nahtrand nicht erhaben; Nahtgegend flach, mit einer dichten Reihe sehr feiner Punkte, in der Mitte etwa 0,04 $\mathrm{mm}$ breit; Nahtstreifen seicht, verlaufen ab dem Apex parallel miteinander, biegen vorne etwas nach aussen, verlöschen noch hinter dem Halsschildlappen; diskale Punktierung dicht und seicht, deutlich kräftiger als auf dem Halsschild, jedoch ausgesprochen fein, die Punktzwischenräume sind meist etwa so gross oder etwas kleiner als die Punktradien. Pygidium querrunzelig mikroskulptiert, äusserst fein punktiert. Mes-Epimeren etwa doppelt so lang wie der Abstand zwischen ihnen und den Hüften II. Metasternum, ausser in der Nähe der Mes-Epimeren und der Met-Episterna, querrunzelig mikroskulptiert; Metasternalseiten mit je einer dichten Reihe feiner Punkte vor den Hüften III, sonst sehr fein punktiert. Mittelteil des Metasternums leicht gewölbt, dichter, in den sehr seichten mediodistalen Eindrücken sehr dicht und auch kräftiger punktiert; Apikalrand zwischen den Hüften gerade. Flächen hinter den Coxalkavitäten II kaum 0,03 mm lang, am Rande sehr fein punktiert. Met-Episterna flach oder etwas gewölbt, an der breitesten Stelle, hinten, 0,09-0,11 $\mathrm{mm}$ breit, nach vorne deutlich verjüngt; Innenrand vorne geradlinig und hinten konvex abgerundet oder fast gleichmässig leicht abgerundet. Sternite querrunzelig mikroskulptiert. Sternit I sehr fein und dicht punktiert; postcoxale Flächen etwa 0,05 mm lang, nach aussen mehr oder weniger geradlinig verjüngt, am Rande sehr fein punktiert. Schienen schlank, gerade.

Maße in mm: Länge 1,2-1,3; Basalbreite des Halsschildes, 073-0,75; Flügeldekken an der Naht 0,77-0,80 lang, an den Seiten 0,82-0,84 lang, zusammen 0,84 0,86 breit; Schienen III 0,46-0,48 lang; Fühlerglieder III-XI 0,72-0,76 lang.

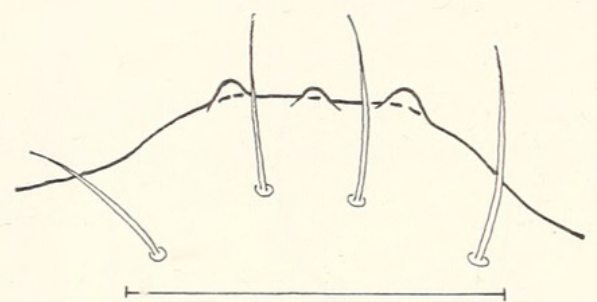

Авв. 64.

Scaphisoma tridentatum $\mathrm{sp} . \mathrm{n}$., Apex des Sternits V (Mittelteil), Männchen. Massstab $=0,1 \mathrm{~mm}$.

Männchen. Tarsenglieder I-III der Vorder- und Mittelbeine deutlich erweitert. Apex des Sternits V ähnlich wie bei beccarii in der Mitte verlängert und mit drei Zähnchen versehen. (Abb. 64). Apikallappen des Steinits VI etwa 0,04 mm lang, die Einbuchtungen des Apikalrandes 0,02 mm tief. Aedoeagus (Abb. 65 und 66) 0,37-0,53 mm lang, ziemlich stark sklerotisiert.

Holotypus ô: Astrolabe Bai, Friedrich-Wilhems-Hafen, leg. L. Biró (Museum Budapest).

Paratypen: wie Holotypus, 3 ô ô und 2 우; Insel Deslacs, 1 q leg. L. Biró (Museum Budapest, Genf und Paris). 


\section{Scaphisoma inornatum sp. $\mathrm{n}$.}

Gehört in die Gruppe haemorrhoidale und steht nahe den Arten mindanaosum Pic und dansalanense Löbl, von diesen aber durch die Form der Nahtstreifen der Flügeldecken sehr verschieden, von dansalanense ausserdem durch die Färbung auffällig abweichend.

Körper mässig stark gewölbt. Kopf und Halsschild schwarzbraum, Flügeldecken ein wenig heller und etwas rötlich, im apikalen Zehntel hellbraun. Fühler ab dem Glied V abgeplattet; relative Länge der Glieder wie: III 5 : IV 10 : V 17 : VI 17 : VII 22 : VIII 16 : IX 20 : X 20 : XI 25; Glied V gut 4 mal länger als breit, deutlich breiter als IV; VI etwa 3,5 mal länger als breit und ein wenig breiter als V; VII nicht ganz 4 mal länger als breit; VIII gut 3 mal länger als breit, so breit wie VI; XI etwa 3,5 mal länger als breit. Halsschild dicht und fein, bei $\times 20$ Vergrösserung gut sichtbar punktiert; Seiten abgerundet; Seitenkielchen bei Dorsalansicht der ganzen Länge nach, ausser in der Nähe der Vorderwinkel, sichtbar; Vorderrand gleichmässig leicht konvex; Vorderrandstreifen kurz, nur in der Nähe der Winkel ausgebildet. Spitze des Scutellums freiliegend. Flügeldecken am breitesten knapp nach dem basalen Viertel, danach fast geradlinig verjüngt; Seitenkielchen bei Dorsalansicht der ganzen Länge nach gut sichtbar; Apikalrand leicht abgerundet; apikaler Innenwinkel liegt im Niveau oder etwas vor dem Niveau der Aussenwinkel; Nahtrand in der Apikalhälfte etwas erhaben; Nahtgegend flach, in der Mitte 0,05 $\mathrm{mm}$ breit, im Niveau der Scutellumspitze 0,07 $\mathrm{mm}$ breit, vorne irregulär punktiert, sonst mit einer dichten Punktreihe; Nahtstreifen seicht, verlaufen ab dem Apex nach vorne geradlinig divergierend, sind vorne nicht nach aussen gebogen, verlöschen knapp hinter dem Rande des Halsschildlappens; diskale Punktierung ziemlich dicht, fein, ein wenig kräftiger als auf dem Halsschild, die Punktzwischenräume sind meist 4-7 mal grösser als die Punktradien. Pygidium querrunzelig mikroskulptiert, äusserst fein punktiert. Mes-Epimeren etwas länger als der Abstand zwischen ihnen und den Hüften II. Metasternum überall sehr fein, auf den Seiten spärlich, gegen die Mitte dicht punktiert; Mittelteil leicht gewölbt, zwischen den Hüften III verflacht, ohne mediodistale Eindrücke, in der Apikalhälfte querrunzelig mikroskulptiert; Apikalrand zwischen den Hüften etwas konkav. Flächen hinter den Coxalkavitäten II rundlich, etwa 0,03 mm lang, am Rande nicht punktiert. Met-Episterna flach, an der breitesten Stelle, hinten, $0,12 \mathrm{~mm}$ breit, nach vorne ziemlich stark verjüngt; Innenrand vorne breit abgerundet, sonst geradlinig. Sternite querrunzelig mikroskulptiert. Sternit I ähnlich punktiert wie das Metasternum; postcoxale Flächen im äusseren Teil sehr schmal, sonst gross, 0,09 mm lang, am Rande dicht und fein punktiert. Schienen schlank, gerade.

Maße in mm: Länge 1,3-1,45; Basalbreite des Halsschildes 0,79-0,93; Flügeldecken an der Naht 0,75-0,90 lang, an den Seiten 0,84-1,0 lang, zusammen 0,931,03 breit; Schienen III 0,44 - 0,49 lang; Fühlerglieder III-XI 0,68-0,72 lang.

Männchen. Tarsenglieder I-III der Vorder- und Mittelbeine deutlich erweitert. Apex des Sternits VI dreieckig verlängert. Aedoeagus (Abb. 67 und 68) 0,60-0,66 mm lang, stark sklerotisiert.

Holotypus ô: Hatam, VI.1875, leg. O. Beccari (Museum, Genua).

Paratypen: Ramoi, II.1875, 1 ô leg. O. Beccari; Ighibirei, VII-VIII. 1890, 1 oै leg. L. Loria; Rapakapa, V-VI.1891, 1 ô leg. L. Loria (Museum Genua und Genf). 

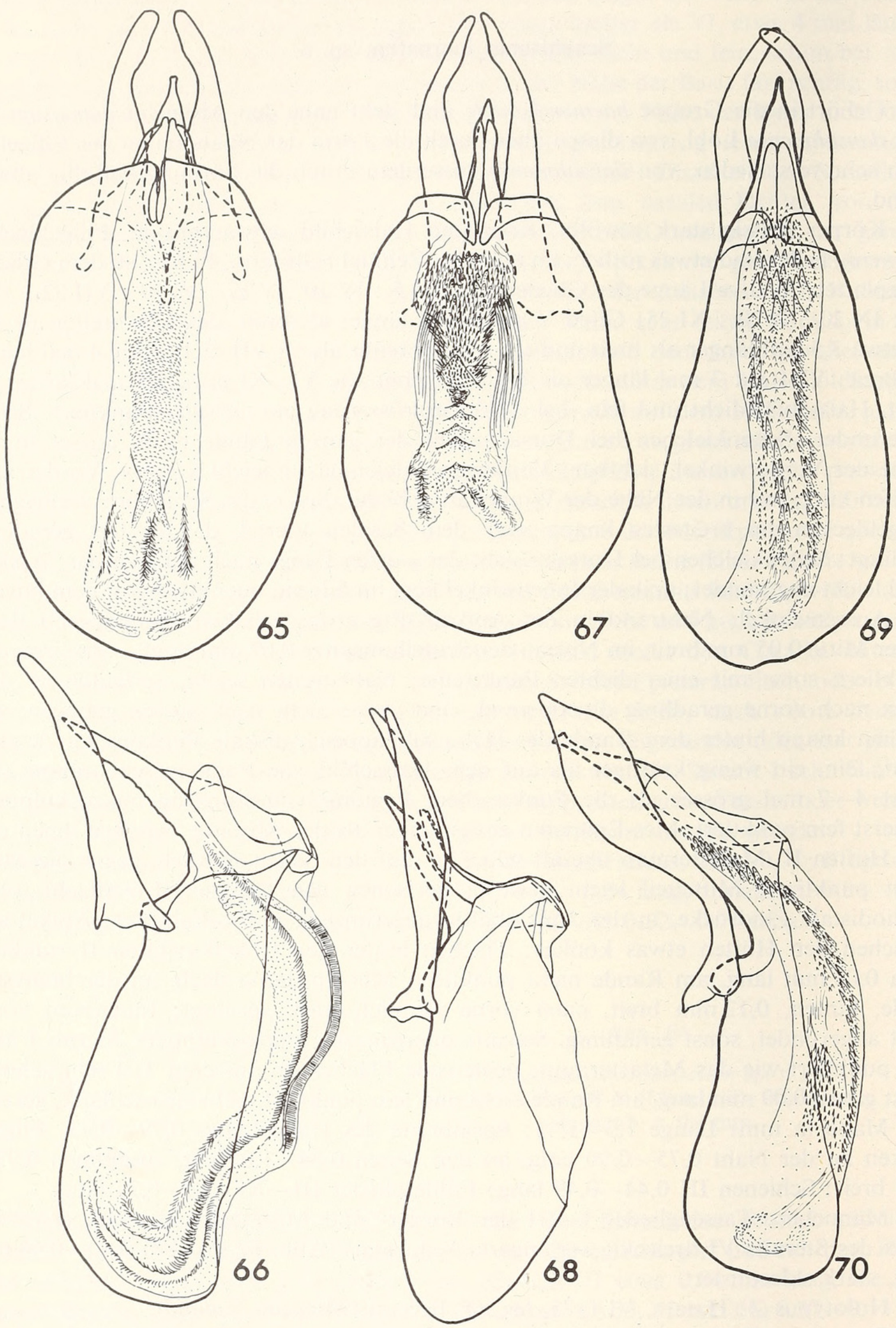

Авв. 65 bis 70 .

Aedoeagi von Scaphisoma bei Dorsal- und Lateralansicht.

65 und 66. tridentatum sp. n., Paratypus von Friedrich-Wilhems-Hafen; 67 und 68. inornatum sp. n., Paratypus von Ramoi; 69 und 70. baloghi sp. n., Holotypus. 


\section{Scaphisoma baloghi sp. n.}

Gehört in die Gruppe haemorrhoidale und ist besonders der Art anderssoni Löbl ähnlich, jedoch durch die Färbung der Flügeldecken und besonders durch die Form des Aedoeagus gut gekennzeichnet.

Körper mässig gewölbt, hellbraun. Flügeldecken mit je einem grossen durchscheinenden gelben Fleck, der fast die basale $2 / 5$ des Diskus einnimt, auf einer schmalen Zone an der Basis, in der Nähe der Nahtgegend und hinter diesem Fleck wie der Halsschild oder Kopf braun, im apikalen Viertel wieder ein wenig heller. Fühler ab dem Glied VII abgeplattet; relative Länge der Glieder wie: III 6 : IV 13 : V 17 : VI 17 : VII 23 : VIII 19 : IX 25 : X 22 : XI 26; Glieder V und VI gleich gross, ein wenig breiter als IV, gut 4 mal länger als breit; VII und VIII fast 4 mal länger als breit, VII etwa um 1/3 breiter, VIII ein wenig breiter als VI; XI nicht ganz 4 mal länger als breit. Halsschild ziemlich dicht und fein, bei $\times 20$ Vergrösserung gut sichtbar punktiert; Seiten leicht abgerundet; Seitenkielchen bei Dorsalansicht der ganzen Länge nach sichtbar; Vorderrand gleichmässig konvex; Vorderrandstreifen nur an den Seiten kurz entwickelt. Distalteil des Scutellums freiliegend. Flügeldecken am breitesten nach dem basalen Drittel, von dort apikalwärts mässig verjüngt; Seiten gleichmässig leicht abgerundet; Seitenkielchen bei Dorsalansicht von der Basis bis zum apikalen Viertel sichtbar; Apikalrand abgerundet; apikaler Innenwinkel liegt hinter dem Niveau der Aussenwinkel; Nahtrand nicht erhaben; Nahtgegend flach, mit einer spärlichen, sehr feinen Punktreihe, in der Mitte $0,04 \mathrm{~mm}$ breit; Nahtstreifen seicht, verlaufen nach vorne fast parallel miteinander, biegen vorne entlang dem Halsschildlappen nach aussen, enden noch in dessen Nähe; diskale Punktierung ziemlich dicht, deutlich kräftiger als jene des Halsschildes, jedoch ausgesprochen fein, die Punktzwischenräume sind meist 2-4 mal grösser als die Punktradien. Pygidium querrunzelig mikroskulptiert, äusserst fein punktiert. Mes-Epimeren sehr schlank, doppelt so lang wie der Abstand zwischen ihnen und den Hüften II. Metasternum überall querrunzelig mikroskulptiert, mit je einer dichten Reihe kräftigerer Punkte vor den Hüften III, sonst sehr fein, auf den Seiten spärlich, auf dem leicht gewölbten mittleren Teil dichter punktiert; mediodistale Eindrücke klein und sehr seicht; Apikalrand zwischen den Hüften gerade. Flächen hinter den Coxalkavitäten II kaum $0,03 \mathrm{~mm}$ lang, am Rande ein wenig tiefer punktiert. Met-Episterna deutlich gewölbt, an der breitesten Stelle, hinten, $0,10 \mathrm{~mm}$ breit, von dort nach vorne allmählich verjüngt; Innenrand nur gegen die Winkel abgerundet. Sternite querrunzelig mikroskulptiert. Sternit I ähnlich punktiert wie das Metasternum; postcoxale Flächen relativ gross, etwa 0,06 mm lang, am Rande spärlich und ziemlich tief punktiert. Schienen schlank, Mittelschienen nach dem basalen Drittel gebogen.

Maße in mm: Länge 1,15; Basalbreite des Halsschildes 0,65; Flügeldecken an der Naht 0,71 lang, an den Seiten 0,74 lang, zusammen 0,75 breit; Schienen III 0,40 lang; Fühlerglieder III-XI 0,78 lang.

Männchen. Tarsenglieder I-III der Vorder- und Mittelbeine stark erweitert. Sternit VI mit 0,09 mm langem dreieckigem Apikallappen, Apikalrand ohne Einbuchtungen. Aedoeagus (Abb. 69 und 70) 0,61 mm lang, ziemlich stark sklerotisiert.

Holotypus ô: Brown riv., $40 \mathrm{~km} \mathrm{~N}$ of Port Moresby, 4-8.IV.1965, leg. J. Balogh und J. J. Szent-Ivány (Museum Budapest). 


\section{Scaphobaeocera Csiki}

Drei von den vier nun bekannten neuguineischen Arten dieser Gattung sind mit den ostasiatischen japonica (Reitter) und minutissima (Löbl) und den ceylonischen delicatula Löbl, stipes Löbl und mussardi Löbl nahe verwandt. Die vierte Art, ptiliformis sp. n., durch breite Parameren und einfachen Innensack des Aedoeagus gekennzeichnet, steht ganz isoliert.

1 Fühlerglied XI etwa um 1/4 bis um 1/3 länger als $\mathrm{X}$, deutlich kürzer als IX und $\mathrm{X}$ zusammen

- Fühlerglied XI fast doppelt so lang wie X, etwa so lang wie IX und X zusammen. Körper einfarbig dunkel rötlichbraun. Mikroskulptur der Metasternalseiten viel feiner als jene der Sternite. Länge $1 \mathrm{~mm}$

antennalis sp. $\mathrm{n}$.

2 Flügeldecken ohne bemerkbare Mikroskulptur bei $\times 100$ Vergrösserung

- Flügeldecken mehr ode weniger deutlich querrunzelig mikroskulptiert, hellbraun, am Seitenrande leicht verdunkelt, kaum opalisierend. Fühlerglied VIII doppelt so lang wie breit. Länge etwa $1 \mathrm{~mm}$. . . . . . P papuana Csiki

3 Flügeldecken gelbbraun, verdunkelt an der Basis, am Apex, am Seitenrande und an der Naht. Schienen III kürzer als die zugehörigen Tarsen. MetEpisterna schmal, in der Mitte kaum 0,03 mm breit, schmaler als die MetEpimeren. Länge $1 \mathrm{~mm}$

ornata $(\mathrm{Pic})$

- Flügeldecken einfarbig hellbraun. Schienen III so lang wie die zugehörigen Tarsen. Met-Episterna 0,05 mm breit, so breit wie die Met-Epimeren. Länge $0,8 \mathrm{~mm}$

ptiliformis sp. $\mathrm{n}$.

\section{Scaphobaeocera papuana Csiki}

Scaphobaeocera papuana Csiki, 1909: 342; Holotypus ô: Astrolabe Bai, Friedrich-WilhemsHafen (Museum Budapest).

Körper glänzend hellbraun, Kopf, Vorderrand des Halsschildes und Metasternum deutlich dunkler, Basis des Halsschildes und Seitenränder der Flügeldecken etwas dunkler. Relative Länge der Fühlerglieder wie: III 6 : IV 9 : V 11 : VI 10 : VII 12 : VIII 8 : IX 14 : X 14 : XI 18; Glieder III-V gleich schlank, VI ein wenig breiter, VII bedeutend breiter, etwa 3,5 mal länger als breit; VIII etwas breiter als VII, doppelt so lang wie breit; XI etwa 2,5 mal länger als breit. Halsschild spärlich, äusserst fein, bei $\times 50$ Vergrösserung kaum sichtbar punktiert. Spitze des Scutellums freiliegend. Flügeldecken sehr fein querrunzelig mikroskulptiert, kaum opalisierend, ähnlich wie der Halsschild spärlich und äussert fein punktiert; Nahtstreifen seicht, verlöschen vorne seitlich des Halsschildlappens; Nahtgegend flach; parasuturale Streifen nur angedeutet, im basalen Drittel und apikalen Viertel der Flügeldeckenlänge nicht bemerkbar, von den Nahtstreifen fast $0,05 \mathrm{~mm}$ entfernt. Metasternum im mittleren Teil flach, kurz behaart. Metasternalseiten und Sternit I querrunzelig mikroskulptiert, spärlich und ähnlich fein wie die Flügeldecken punktiert. Met-Episterna an der breitesten Stelle, vorne, fast $0,05 \mathrm{~mm}$ breit, nach hinten kaum verjüngt, hinten ein wenig schmaler als die Met-Epimeren. 


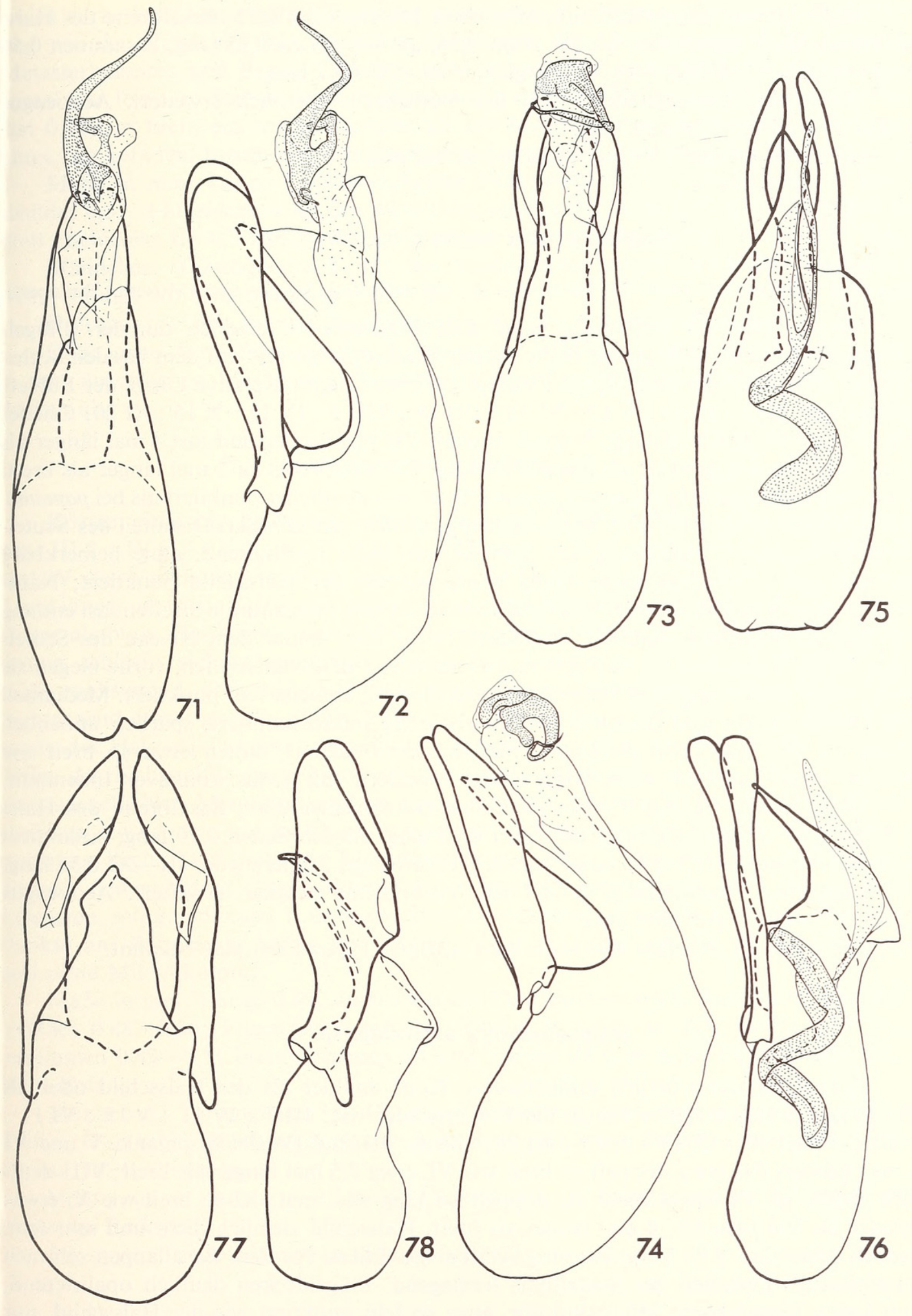

Авв. 71 bis 78 .

Aedoeagi von Scaphobaeocera bei Dorsal- und Lateralansicht.

71 und 72. papuana Csiki, Holotypus; 73 und 74. ornata (Pic), Holotypus; 75 und 76. antennalis sp. n., Holotypus; ptiliformis sp. n., Holotypus. 
Maße in mm: Länge 0,95; dorsoventraler Durchmesser 0,53; Basalbreite des Halsschildes 0,48; Flügeldecken an der Naht 0,58, an den Seiten 0,65 lang, zusammen 0,50 breit; Schienen III 0,33 lang; Fühlerglieder III-XI 0,47 lang.

Männchen. Tarsenglieder I-III der Vorderbeine deutlich erweitert. Aedoeagus (Abb. 71 und 72) 0,26 mm lang.

Diese Art ist nur nach dem Holotypus bekannt.

Scaphobaeocera ornata (Pic), comb. nov.

Toxidium ornatum PIC, 1956: 73; Holotypus ỗ: Astrolabe Bai, Stephansort (Museum Budapest).

Körper glänzend gelbbraun, Kopf und Metasternum deutlich dunkler, Flügeldecken leicht verdunkelt an der Naht, an den Seitenrändern und auf dem basalen Sechstel, vor dem Apex auf dem distalen Viertel stark verdunkelt. Relative Länge der Fühlerglieder wie: III 8 : IV 11 : V 13 : VI 11 : VII 15 : VIII 9 : IX 15 : X 15 : XI 20; Glieder III, IV und VI gleich schlank, V etwas breiter, VII viel breiter und fast 4 mal länger als breit, VIII ein wenig mehr als doppelt so lang wie breit, XI etwa 3 mal länger als breit. Halsschild sehr leicht opalisierend, etwas dichter und deutlicher punktiert als bei papuana, die einzelnen Punkte bei $\times 50$ Vergrösserung ziemlich gut sichtbar. Distalteil des Scutellums freiliegend. Flügeldecken auf dem Diskus leicht opalisierend, ohne bemerkbare Mikroskulptur, ziemlich dicht, kaum deutlicher als der Halsschild punktiert; Nahtstreifen fein, enden vorne seitlich des Halsschildlappens; parasuturale Streifen fast entlang der ganzen Nahtlänge deutlich, verlöschen vorne kurz hinter dem Niveau des Scutellums, in der Mitte sind sie fast 0,05 mm entfernt von den Nahtstreifen, vorne biegen sie etwas nach innen. Pygidium runzelig mikroskulptiert, äusserst fein punktiert. Medianteil des Metasternums und Sternit I fein querrunzelig mikroskulptiert, spärlich und noch feiner als der Halsschild punktiert. Met-Episterna schmal, hinten etwa so breit wie 2/3 der Met-Epimeren, nach vorne etwas erweitert, mit etwas konkaver Innennaht.

$\mathrm{Ma}$ e in $\mathrm{mm}$ : Länge 1; dorsoventraler Durchmesser 0,61; Basalbreite des Halsschildes 0,48; Flügeldecken an der Naht 0,62 lang, an den Seiten 0,70 lang, zusammen 0,54 breit; Schienen III 0,37 lang; Tarsen III 0,46 lang; Fühlerglieder III-XI 0,56 lang.

Männchen. Tarsenglieder I-III der Vorderbeine deutlich erweitert. Aedoeagus (Abb. 73 und 74) 0,29 mm lang.

Diese Art ist ebenfalls nur nach dem einzigen Typus-Exemplar bekannt.

\section{Scaphobaeocera antennalis sp. n.}

Körper glänzend rötlich dunkelbraun, Kopf dunkler als der Halsschild oder als die Flügeldecken. Relative Länge der Fühlerglieder wie: III 7 : IV 11 : V 15 : VI 11 : VII 15 : VIII 10 : IX 14 : X 15 : XI 28; Glieder III und IV gleich schlank, V und VI etwas breiter; VII etwa doppelt so breit wie VI, etwa 2,5 mal länger als breit; VIII deutlich breiter als VI, etwas mehr als doppelt so lang wie breit; XI so breit wie X, etwas breiter als VII oder IX, 4 mal länger als breit. Halsschild ziemlich dicht und sehr fein, jedoch schon bei $\times 25$ Vergrösserung sichtbar punktiert, vor dem Basallappen schwach opalisierend. Distalteil des Scutellums freiliegend. Flügeldecken deutlich opalisierend, mit kaum bemerkbarer Mikroskulptur, etwa so fein punktiert wie der Halsschild, nur am Apex die Punktierung etwas deutlicher; Nahtgegend flach; Nahtstreifen sehr seicht, verlöschen vorne seitlich des Halsschildlappens; parasuturale Streifen gut sichtbar, verlaufen parallel mit den Nahtstreifen und sind von ihnen etwa $0,04 \mathrm{~mm}$ entfernt, 
enden vorne kurz hinter dem Niveau des Scutellums. Pygidium runzelig mikroskulptiert und wie der Halsschild fein punktiert. Medianteil des Metasternums leicht gewölbt. Metasternalseiten und Sternit I ähnlich punktiert wie der Halsschild, die Metasternalseiten sehr fein, der Sternit deutlich querrunzelig mikroskulptiert. Met-Episterna hinten fast $0,05 \mathrm{~mm}$ breit, ein wenig schmaler als die Met-Epimeren, nach vorne leicht verjüngt, mit geradem Innenrand. Flächen hinter den Coxalkavitäten II fast 0,03 mm lang.

Maße in mm: Länge 1; dorsoventraler Durchmesser 0,58; Basalbreite des Halsschildes 0,51; Flügeldecken an der Naht 0,60, an den Seiten 0,68 lang, zusammen 0,54 breit; Schienen III 0,37 lang; Tarsen III 0,41 lang; Fühlerglieder III-XI 0,57 lang.

Männchen. Tarsenglieder I-III der Vorderbeine deutlich erweitert. Aedoeagus (Abb. 75 und 76) 0,38 mm lang.

Holotypus ỗ: Huon Golf, Sattelberg, leg. L. Biró (Museum Budapest).

Diese neue Art steht nahe der $S$. delicatula Löbl und minutissima (Löbl), weicht in den äusserlichen Merkmalen besonders durch die deutlich opalisierenden Flügeldecken ab.

\section{Scaphobaeocera ptiliformis sp. $\mathrm{n}$.}

Körper einfarbig hellbraun, mässig glänzend. Relative Länge der Fühlerglieder wie: III 5 : IV 6,5 : V 9 : VI 7 : VII 13 : VIII 6,5 : IX 11 : X 13 : XI 18; Glieder III und IV gleich schlank, V und VI etwas breiter, VII um $1 / 3$ breiter als V oder VI, etwa 3 mal länger als breit, VIII kaum breiter als VI, fast doppelt so lang wie breit, XI 3,5 mal länger als breit. Halsschild ohne Mikroskulptur, dicht und sehr fein, bei $\times 50$ Vergrösserung schlecht sichtbar punktiert. Spitze des Scutellums freiliegend. Flügeldecken nicht opalisierend, ohne Mikroskulptur, etwas deutlicher punktiert als der Halsschild; Nahtgegend etwas gewölbt; Nahtstreifen ziemlich seicht, verlöschen vorne am Seitenrande des Halsschildlappens; parasuturale Streifen sehr fein, nur seitlich des mittleren Teiles der Nahstreifen bemerkbar, von diesen etwa 0,03 $\mathrm{mm}$ entfernt (bei dem nicht ganz ausgefärbten Männchen sind sie kaum sichtbar). Pygidium ohne sichtbare Mikroskulptur, etwa so fein wie die Flügeldecken, aber dichter punktiert. Medianteil des Metasternums flach, kurz behaart. Metasternalseiten ohne Mikroskulptur, spärlich und äusserst fein punktiert. Met-Episterna gross, gewölbt, gleichmässig breit wie die MetEpimeren, mit geradliniger Innennaht. Sternit I mit einer Querreihe kräftiger, länglicher Punkte am Basalrande hinter den Hüften, sonst punktiert wie die Metasternalseiten und ohne Mikroskulptur.

Maße in mm: Länge 0,80; dorsoventraler Durchmesser 0,45; Basalbreite des Halsschildes 0,48-0,50; Flügeldecken an der Naht 0,51 lang, an den Seiten 0,58 lang, zusammen 0,49-0,51 breit; Schienen III und Tarsen III 0,24 lang; Fühlerglieder IIIXI 0,40 lang.

Männchen. Tarsenglieder I-III der Vorderbeine sehr stark erweitert, Glied I breiter, II so breit, III schmaler als der Apex der zugehörigen Schiene. Aedoeagus (Abb. 77 und 78) $0,42 \mathrm{~mm}$ lang.

Holotypus đ̊: Bussu riv., Lae. 13.IV.1965, leg. J. Balogh und J. J. Szent-Ivány (Museum Budapest).

Paratypus 9 : wie Holotypus (Museum Genf).

\section{Toxidium LeConte}

Nur eine Art dieser Gattung ist aus Neuguinea bekannt geworden.

Rev. Suisse De Zool., T. 82, 1975 


\section{Toxidium biroi Pic}

Toxidium biroi PIC, 1956: 73; Holotypus $\odot$ : Huon Golf, Sattelberg (Museum Budapest).

Körper einfarbig rötlichbraun. Punktierung der Oberseite sehr fein, bei $\times 50$ Vergrösserung schlecht sichtbar. Relative Länge der Fühlerglieder wie: III 9 : IV 8 : V 11 : VI 9 : VII 12 : VIII 8 : IX 12 : X 13 : XI 21; Glieder III-V etwa gleich schlank, VI ein wenig breiter; VII etwa um 1/3 breiter als VI, nicht ganz 3 mal länger als breit; VIII nur etwas schlanker als VII, doppelt so lang wie breit; XI gut 4 mal länger als breit. Endglieder der Kiefertaster ein wenig länger und viel schlanker als das vorhergehende Glied. Scutellum völlig verdeckt. Flügeldecken mit seichten, aber deutlichen Nahtstreifen, die etwa $0,1 \mathrm{~mm}$ hinter dem Niveau des Halsschildlappens enden; Nahtgegend in der Mitte nicht ganz $0,04 \mathrm{~mm}$ breit, in der apikalen Hälfte etwas erhaben, vorne flach. Metasternum glatt, in der Mitte eingedrückt. Flächen hinter den Coxalkavitäten II gross, fast 0,05 mm lang. Met-Episterna etwas gewölbt, vorne etwa 0,04 $\mathrm{mm}$ breit, fast parallelseitig, die Innennaht ist vorne relativ tief und breit, apikalwärts wird sie allmählich seichter und schmaler, verlöscht schliesslich $0,06 \mathrm{~mm}$ vor dem Rande der sehr kleinen MetEpimeren. Sternit I sehr spärlich und äusserst fein punktiert.

Maße in mm: Länge 1,1; dorsoventraler Durchmesser 0,62; Basalbreite des Halsschildes 0,55; Flügeldecken an der Naht 0,79 lang, maximal 0,82 lang, zusammen an der breitesten Stelle 0,58 breit, am Apex 0,28 breit; Schienen III 0,26 lang; Tarsen III 0,34 lang; Fühlerglieder III-XI 0,48 lang.

Ausser dem Holotypus liegt kein weiteres Exemplar vor.

\section{Bironium Csiki}

Die einzigen Belege dieser Gattung stammen aus den Biró-Ausbeuten. Sie gehören zwei gut charakterisierten Arten an.

1 Körper rötlichbraun, Flügeldecken leicht durchscheinend. Punktierung der Flügeldecken, abgesehen von deren Apikalteil, und des Halsschildes äusserst fein, bei $\times 100$ Vergrösserung kaum bemerkbar. Seitenstreifen der Flügeldecken nicht punktiert. Innennaht der Met-Episterna tief und vollständig, hinten entlang dem Rand der Met-Epimeren verlaufend . . . basicolle (Pic)

- Körper sehr dunkelbraun, etwas rötlich, nicht beleuchtet schwarz scheinend. Flügeldecken nicht durchscheinend. Punktierung der Flügeldecken und des Halsschildes sehr fein und spärlich, jedoch bei $\times 50$ Vergrösserung deutlich. Seitenstreifen der Flügeldecken ausgesprochen grob punktiert. Innennaht der Met-Episterna sehr tief, furchenartig, verlöscht aber plötzlich hinten, sodass die Met-Episterna vor den Met-Epimeren mit dem Metasternum verwachsen sind

biroi (Pic)

\section{Bironium basicolle (Pic)}

Bironium longipes CsıKI, 1909: 341; Holotypus ỗ: Huon Golf, Sattelberg (Museum Budapest) - nec longipes Reitter, 1880.

Heteroscapha basicolle Pic, 1956: 72; Holotypus ㅇ: Huon Golf, Sattelberg (Museum Budapest).

Obwohl das weiblich Typus-Exemplar von basicolle beschädigt ist (Fühler und Mundteile fehlen), konnte dessen Identität mit dem Typus von longipes Csiki einwandfrei festgestellt werden. 
Der Name longipes Csiki ist aber wegen Scaphicoma longipes Reitter, 1880 nicht verwendbar. Diese letztere Art wurde schon von ACHARD (1924) in die mit Bironium synonyme Gattung Heteroscapha Achard gestellt. Ich selber hatte keine Gelegenheit, den Typus von longipes Reitter zu untersuchen, doch besitze ich ein Exemplar der Gattung Bironium von „Mysol“ (Insel Misool, typische Lokalität der Art longipes Reitter), das mit der Reitter'schen Originalbeschreibung ziemlich gut übereinstimmt (nur die Tarsen sind nicht so lang wie Reitter angibt).

Untersuchtes Material: die zwei Holotypen und ein Paratypus von longipes Csiki, alle von Sattelberg, 1899, leg. L. Biró.
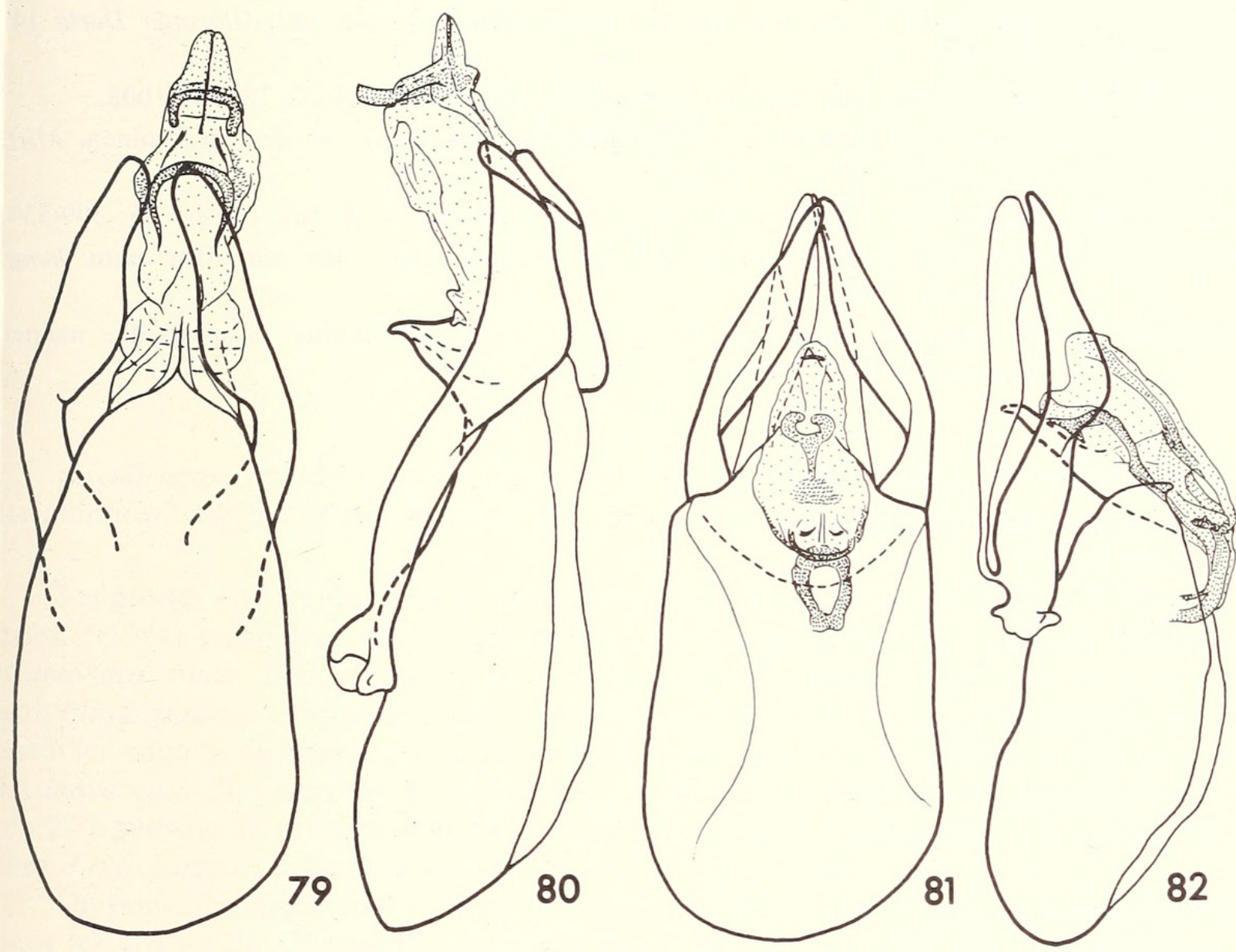

Авв. 79 bis 82 .

Aedoeagi von Bironium bei Dorsal- und Lateralansicht.

79 und 80. basicolle (Pic), Holotypus von longipes Csiki; 81 und 82. biroi (Pic), Holotypus.

\section{Bironium biroi (Pic)}

Heteroscapha biroi Pic, 1956: 71; Holotypus ô: Astrolabe Bai, Stephansort (Museum Budapest).

Diese Art ist besonders durch die gespaltenen Parameren des Aedoeagus gut gekennzeichnet.

Untersuchtes Material: Holotypus und ein Paratypus (ㅇ), beide von L. Biró 1898 in Stephansort gesammelt. 


\section{LITERATUR}

Achard, J. 1920. Notes sur les Scaphidiidae de la faune indo-malaise. Annls. Soc. ent. Belg. 60: 123-136.

Achard, J. 1924. Essai d'une subdivision nouvelle de la famille des Scaphidiidae. Annls. Soc. ent. Belg. 65: 25-31.

Csiki, E. 1909. Coleoptera nova in Museo nationali hungarico. Annls. hist.-nat. Mus. nath. hung. 7: $340-343$.

Gestro, R. 1879. Descrizioni di nuove specie di Coleotteri raccolte nella regione Austro-Malese dal signor L. M. D’Albertis. Annali Mus. civ. Stor. nat. Giacomo Doria 14: 552-565.

LöBL, I. 1971. Scaphidiidae von Ceylon (Coleoptera). Revue suisse Zool. 78: 937-1006.

LöBL, I. 1972. Beitrag zur Kenntnis der Scaphidiidae (Coleoptera) von den Philippinen. Mitt. schweiz. ent. Ges. 45: 79-109.

Löвl, I. 1973. Scaphidiidae (Coleoptera) von Neu Kaledonien. Archs Sci. Genève 25: 309-334.

PIC, M. 1956. Nouveaux Coléoptères de diverses familles. Annls. hist.-nat. Mus. natn. hung. (N.S.) 7: 71-92.

Reitter, E. 1880. Die Gattungen und Arten der Coleopteren-Familie: Scaphidiidae meiner Sammlung. Verh. naturf. Ver. Brünn 18: 35-49.

Adresse de l'auteur:

Muséum d'Histoire naturelle

Case postale 284

CH-1211 Genève 6

Suisse 


\section{$2 \mathrm{BHL}$ Biodiversity Heritage Library}

Loll, I. 1975. "Beitrag zur Kenntnis der Scaphidiidae (Coleoptera) von

Neuguinea." Revue suisse de zoologie 82, 369-420.

https://doi.org/10.5962/bhl.part.78265.

View This Item Online: https://www.biodiversitylibrary.org/item/127363

DOI: https://doi.org/10.5962/bhl.part.78265

Permalink: https://www.biodiversitylibrary.org/partpdf/78265

\section{Holding Institution}

Smithsonian Libraries

\section{Sponsored by}

Biodiversity Heritage Library

\section{Copyright \& Reuse}

Copyright Status: In Copyright. Digitized with the permission of the rights holder.

Rights Holder: Muséum d'histoire naturelle - Ville de Genève License: http://creativecommons.org/licenses/by-nc-sa/3.0/

Rights: https://www.biodiversitylibrary.org/permissions/

This document was created from content at the Biodiversity Heritage Library, the world's largest open access digital library for biodiversity literature and archives. Visit BHL at https://www.biodiversitylibrary.org. 